\title{
1 North and Equatorial Pacific Ocean Circulation in the CORE-II Hindcast 2 Simulations
}

3

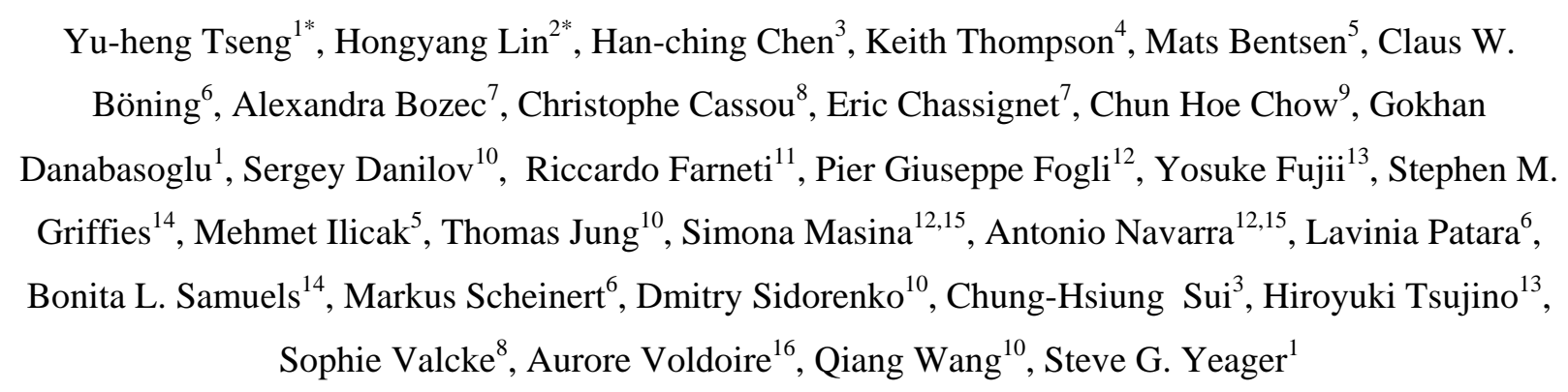

* Corresponding author: Dr. Yu-heng Tseng, Climate and Global Dynamics Laboratory, National Center for Atmospheric Research, P.O. Box 3000, Boulder, CO80305, USA Email: ytseng@ucar.edu; Dr. Hongyang Lin, State Key Laboratory of Marine Environmental Science, College of Ocean and Earth Sciences, Xiamen University, Xiamen361102, China, Email: hylin@xmu.edu.cn 
Abstract:

31 We evaluate the mean circulation patterns, water mass distributions, and tropical dynamics of the North

32 and Equatorial Pacific Ocean based on a suite of global ocean-sea ice simulations driven by the CORE-II

33 atmospheric forcing from 1963-2007. The first three moments (mean, standard deviation and skewness)

34 of sea surface height and surface temperature variability are assessed against observations. Large

35 discrepancies are found in the variance and skewness of sea surface height and in the skewness of sea

36 surface temperature. Comparing with the observation, most models underestimate the Kuroshio transport

37 in the Asian Marginal seas due to the missing influence of the unresolved western boundary current and

38 meso-scale eddies. In terms of the Mixed Layer Depths (MLDs) in the North Pacific, the two observed

39 maxima associated with Subtropical Mode Water and Central Mode Water formation coalesce into a large

40 pool of deep MLDs in all participating models, but another local maximum associated with the formation

41 of Eastern Subtropical Mode Water can be found in all models with different magnitudes. The main model

42 bias of deep MLDs results from excessive Subtropical Mode Water formation due to inaccurate

43 representation of the Kuroshio separation and of the associated excessively warm and salty Kuroshio

44 water. Further water mass analysis shows that the North Pacific Intermediate Water can penetrate

45 southward in most models, but its distribution greatly varies among models depending not only on grid

46 resolution and vertical coordinate but also on the model dynamics. All simulations show overall similar

47 large scale tropical current system, but with differences in the structures of the Equatorial Undercurrent.

48 We also confirm the key role of the meridional gradient of the wind stress curl in driving the equatorial

49 transport, leading to a generally weak North Equatorial Counter Current in all models due to inaccurate

50 CORE-II equatorial wind fields. Most models show a larger interior transport of Pacific subtropical cells

51 than the observation due to the overestimated transport in the Northern Hemisphere likely resulting from

52 the deep pycnocline.

53

54

55

56

57

58 Keywords: CORE global ocean-ice simulations, Kuroshio, Mode Water, Subtropical Cell, North Pacific 59 simulations

60 


\section{Introduction}

\subsection{Background}

The dynamics of the Pacific Ocean affect not only the regional climate system but also global climate variability, e.g., El Niño Southern Oscillation (ENSO). The Kuroshio, the major western boundary current of the North Pacific, is of particular importance because it transports an enormous amount of mass, geochemical material, and heat from low to mid-latitudes (Imawaki et al., 2013). It also has a significant impact on ocean-atmosphere interactions in the North Pacific Ocean (Kwon et al., 2010). Many previous studies have reported that basin-wide variations of wind stress curl (WSC) have important effects on transport and large scale changes of the Kuroshio and its extension region (e.g., Deser et al 1999; Sugimoto et al., 2010). These

72 WSC variations are likely related to variations of Aleutian Low activity and the Pacific Decadal

73 Oscillation at the interanual to decadal scales (Soeyanto et al., 2014). However, the mechanisms

74 responsible for the Kuroshio transport and its variability dynamics, remain unclear.

The formation of water masses in the North and tropical Pacific, and their transport pathways, are driven mainly by the WSC in contrast with the thermohaline circulation of the North Atlantic, and as a result the WSC can significantly affect the oceanic uptake of passive tracers such as carbon dioxide. Excluding the deep bottom water (addressed in the Southern Ocean companion paper by Downes et al., 2015), the most important water masses in the North Pacific are the Antarctic Intermediate Water (AAIW), North Pacific Intermediate Water (NPIW) and three mode waters: Central Mode Water (CMW), Eastern Subtropical Mode Water (ESMW) and Subtropical Mode Water (STMW). A list of all acronyms used in this paper is provided in Appendix A and a schematic of the major North and equatorial Pacific surface wind-driven currents and water mass distributions is shown in Fig. 1. Many issues related to water mass formation and transport in the Pacific remain unresolved. For example, the pathway of NPIW from the mixed water region (MWR, Talley et al., 1995), between the Kuroshio and Oyashio, to the western part of the subtropical gyre remains controversial. It is well known that NPIW plays an important role in the uptake of anthropogenic gases in the North Pacific. Talley (1993) assumed NPIW is carried southward into the subtropical gyre by the recirculation of the

91 Extension at the southern edges of the Kuroshio Extension troughs. Some researchers have 
92 explored the possibility that NPIW may enter at the westernmost climatological trough due to the 93 existence of cross-frontal flow across the Kursoshio Extension (Joyce et al., 2001). However, a 94 significant amount of NPIW is assumed to be transported eastward past $150^{\circ} \mathrm{E}$ (Masujima et al., 95 2003). Based on an inverse model analysis, Nishina (1997) suggested that part of the NPIW turns 96 southwestward around $160^{\circ} \mathrm{E}$ and reaches the northwestern part of the subtropical gyre south of 97 Japan. This route roughly corresponds to the shortcut pathway proposed in Nakano et al. (2007) 98 and recently verified by Fujii et al. (2013). On the other hand, You (2003, 2010) has suggested 99 that NPIW is generated in the broad area between the subtropical and subarctic gyres and 100 transported eastward to $140^{\circ} \mathrm{W}$ where the Kuroshio Extension does not reach before entering the subtropical gyre. This coincides with the pathway proposed in Nakano et al. (2007), however, its 102 existence is not completely validated due to the paucity of observations.

The shallow meridional overturning circulation (also known as the subtropical cells, STCs), controls the subsurface transfer of mass, heat and salt between the subtropical and equatorial Pacific (Capotondi et al., 2005). The interior STC transport is compensated by the low-latitude western boundary transport in both hemispheres climatologically. But at interannual scales, the compensation does not exactly hold in the Northern Hemisphere (Chen et al., 2015). The lack of compensation in the Northern Hemisphere is caused by the 7-month phase lag between the interior STC transport and western boundary transport according to Ishida et al. (2008). Recent studies indicate that the STCs have an important effect not only on the

112 shown that strengthening of the STCs over the last decade is directly related to strengthening of 113 the trade winds, thus resulting in the recent slow-down (up to 2014) in global surface 114 temperatures. In the equatorial Pacific, the STCs involve subtropical water, subducted in eastern 115 areas of the Pacific ocean, that flows westward and equatorward in the upper pycnocline layers. 116 The STCs feed the Equatorial Undercurrent (EUC), and upwelling in eastern equatorial regions, 117 before returning to the subtropics as part of the surface Ekman flow (McCreary and Lu, 1994). 118 Given the STCs are much shallower and narrower than the Atlantic meridional overturning 119 circulation, their time scale is shorter, ranging from interannual to multi-decadal, and cannot be 120 ignored in decadal prediction of Pacific climate (Solomon et al, 2011). Farneti et al. (2013) 121 recently suggested a potential mechanism linking the STCs with changes in atmospheric 122 circulation in order to explain tropical-extratropical atmosphere-ocean interactions on multi- 
123 decadal time scales. Unfortunately our understanding of the STCs, and their variability in 124 relation to the WSC, remains limited due to the lacks of observational data and well-validated 125 model simulations.

In the present study, we shed light on some of the above uncertainties through a detailed examination and intercomparison of a suite of global ocean models integrated from 1948 to 2007 under the Coordinated Ocean-ice Reference Experiments (CORE-II) protocol. The CORE-II was designed to evaluate the performance of ocean and sea-ice models, and to quantify and understand variability on time scales of seasons to decades (Griffies et al., 2009). These hindcast experiments provide a common framework to assess the differences and similarities among models compared with the observation. Several accompanying papers have assessed aspects of sea level variability (Griffies et al., 2014), North Atlantic-mean state (Danabasoglu et al., 2014) and interannual to decadal variability (Danabasoglu et al., 2016), Southern ocean circulation (Downes et al, 2015) and others. In this study, our aim is to assess how well these models can represent the dominant dynamical processes that are unique to the Pacific Ocean if the atmospheric state for recent decades is prescribed? The specific questions are:

- Can we quantify the overall performance of the surface variability which is the first order evaluation of the ocean models?

- How well the western boundary current system is represented in these models, particularly the amount of transport which is the key to move energy to high latitude?

- How are the water masses and their origins represented in such models? Can they help to clarify the unclear pathway of NPIW?

- Can the models adequately simulate the equatorial dynamics, particularly the STCs circulation? What is the role of a better representation of ocean mesoscale eddies?

In this paper, we focus only on the evaluation and discussion of the mean statistical properties and features of the CORE-II simulations over the period of 1963-2007 and leave the study of interannual to decadal variability for future studies. We hope the current 
154 evaluation of the mean statistical properties may provide useful guidelines for future 155 variability studies of CORE-II simulations and comparisons of coupled climate simulations 156 in the Pacific.

\subsection{Contents of this paper}

After a brief description of the 15 participating models and the observational data in section 2, section 3 provides a statistical summary of the surface variability, which gives us an overall performance of the participating models in the focused region. Section 4 investigates the performance of the models in terms of transport by the Kuroshio Current System (KCS) in the North Pacific. Section 5 and 6 further address the interior pathway and origin of the North Pacific water mass transport by analyzing the mixed layer depth (MLD) and water mass properties. Section 7 addresses the key tropical dynamics linking closely to the interannual and decadal variability. We conclude with a brief summary and suggestions for future research in section 8.

2. Models and Observations

Fifteen model simulations are evaluated in the present study (Table 1). The most extensive descriptions of the models participating in the CORE-II protocol are given in Danabasoglu et al. (2014) except the updated version of FSU model used in this study (which is 175 the FSU2 described in Danabasoglu et al., 2016) and the recent contribution from the 176 Consortium for Climate Change Study (CCLICS) at Academia Sinica, Taiwan (See Appendix B 177 for a brief description of this system). CCLICS uses the Community Earth System Model 178 framework but replaces the ocean component with the Taiwan Multi-scale Community Ocean 179 Model (Tseng and Chien, 2011; Young et al., 2012). All participating models have a nominal $1^{\circ}$ 180 horizontal resolution except for the ICTP and two KIEL models which have nominal resolutions 181 of $2^{\circ}$ and $0.25^{\circ} / 0.5^{\circ}$, respectively. Most models have a finer grid spacing in the tropics. The number of vertical levels, or layers, ranges from 30 to 63. All models use z-levels except BERGEN and GFDL-GOLD which use isopycnal coordinates, and FSU which uses a hybrid coordinate system. One of the models, MRI-ASSIM, is a global ocean data assimilation system. 
The configurations of all the models are summarized in Table 1.

The atmospheric state and river freshwater input are based on the interannually varying CORE-II forcing (Large and Yeager, 2009) from 1948 to 2007. Surface fluxes of heat, salt, and momentum are calculated using the bulk formulae of Large and Yeager (2009). Even though all of the models use the same CORE-II atmospheric state, their performances in the Pacific are quite different due to differences in model grids, numerics, physics and the sea-ice models. All models except MRI-ASSIM were run for 300 years (5 repeated cycles of the CORE-II forcing) to ensure they approached a statistical steady state. Further discussion regarding to the CORE-II protocol can be found in Griffies et al. (2012) and Danabasoglu et al. (2014). Note that for all ensemble mean diagnostics, the assimilated results from MRI-ASSIM are not included as part of the mean. Unless stated otherwise, only the last 45 years of monthly mean data are used in the present study, corresponding to the period 1963 to 2007.

\subsection{Observations}

The observed sea surface temperatures (SSTs) are in the form of monthly means defined on a $1^{\circ} \times 1^{\circ}$ grid retrieved from the HadISST dataset (Rayner et al., 2006). The $0.25^{\circ}$ dynamic sea level was obtained from the gridded satellite altimeter product of AVISO (Archiving, Validation, and Interpolation of Satellite Oceanographic) from 1993 to 2007 (Rio et al., 2011). The $0.25^{\circ}$ wind stress data from the Scatterometer Climatology of Ocean Winds is also used (Risien and Chelton, 2008). In order to facilitate direct comparison with observations, all model results are regridded onto the observation grids except the AVISO data.

Transport observations from three North Pacific sections are used to evaluate the model simulations of the Kuroshio current system: PCM-1 (east of Taiwan), PN (East China Sea, ECS) and P09 (a meridional section along $137^{\circ} \mathrm{E}$ ) (See Fig. 1 for the locations of these sections). The PCM-1 section is located over the Ilan Ridge, northeast of Taiwan at about $24.5^{\circ} \mathrm{N}$, and has a maximum depth of $1000 \mathrm{~m}$ (Tseng et al., 2012). This section is ideal for monitoring transport and the variability of the Kuroshio main axis located between the deep Okinawa Trough and the western Philippine Sea (Johns et al., 2001). Current velocity observations were made by a moored current meter array along the section at the entrance to the ECS, between September 1994 and May 1996 as a part of the World Ocean Circulation Experiment (see Johns et al. (2001) for details). The PN (Pollution Nagasaki) section is located in the central ECS and has a 
216 northwest-southeast orientation. Long-term hydrographic observations have been conducted

217 along the PN section by the Nagasaki Marine Observatory of the Japan Meteorological Agency

218 since 1972 (Ichikawa and Beardsley, 2002). Before 1972, only two or three cruises were

219 performed each year (Zhang et al., 2012; Wei et al., 2013). This section has proved useful in

220 monitoring transport and variability of the Kuroshio in the central ECS, e.g., Kawabe (1988),

221 Oka and Kawabe (2003), Andres et al. (2008), Zhang et al. (2012), Wei et al. (2013). The P09

$222\left(137^{\circ} \mathrm{E}\right)$ line is located south of Japan and crosses the western part of the subtropical gyre of the

223 North Pacific. Long-term, repeated hydrographic observations have been collected along P09,

224 and also P13 (165 $\left.{ }^{\circ} \mathrm{E}\right)$, as part of the biannual hydrographic surveys by the Japan Meteorological

225 Agency since 1972 (Sugimoto et al., 2010). Some hydrographic lines along P09 and P13 are used

226 to compare the models with the World Ocean Atlas 2009 (WOA09).

\section{Statistical Summary of SSH and SST Variability}

229

In order to get the overall performance of the participating ocean models, the statistical properties of two ocean variables of practical and scientific interest, SSH and SST, are first summarized here. Griffies et al. (2014) have already evaluated the mean SSH fields of the CORE-II simulations and so we only discuss them briefly in this paper. We also do not discuss in detail the mean SST because, as will be shown later, the modeled mean SST distribution is very close to the mean of the observation. Instead, we focus primarily on two statistics that describe the temporal variability of SSH and SST about their seasonal mean state: standard deviation and skewness. Both of these statistics provide complementary information on the variability of the upper ocean and the general circulation (Thompson and Demirov, 2006). Taylor diagrams (Taylor, 2001) are used below to quantify the similarity of all model-based maps, for a given variable and statistical moment, with the corresponding map calculated from observations (see

242 first in order to remove variabilities with a spatial scale less than $200 \mathbf{~ k m}$, and thus to better 243 compare with these non-eddy resolving models without eddy variances in the Taylor diagram. 
The mean, standard deviation and skewness of SSH are quantified first. The Taylor diagram (Fig. 2a) for the mean SSH shows the spatial correlations between the mean SSH (i.e., mean dynamic topography) of Rio et al. (2011) and the simulated mean fields exceed 0.94 for all 15 models. The high correlation indicates that all models successfully reproduce the large scale features of the mean sea surface topography which are mainly due to the forcing by the large scale WSC (Griffies et al., 2014). The normalized root-mean-square difference (RMSD) is also < 0.4 (given by the radial distance of each point on the Taylor diagram from the point $x=1, y=0$ ).

256 Griffies et al. (2014) showed that the RMSD in the Pacific is larger than the global difference.

257 Overall the standard deviation of the grid point values of simulated mean SSH is within $15 \%$ of 258 the observed standard deviation (given by the radial distance of each point from the origin).

Spatial maps of standard deviation and skewness are also generated using the observations and CORE-II simulations for the 1993-2007 period (Figs. 3 and 4 discussed in details next). This period is chosen because of the availability of altimeter observations. The annual and six month cycles ( $\mathrm{p}=1$, Appendix $\mathrm{C})$ were removed from each grid point time series before calculating the standard deviation and skewness.

Standard deviation: All models have smaller standard deviations of SSH than the observations (Fig. 3) in the major current systems and so the ensemble mean has a smaller magnitude than the observations. This is confirmed by the corresponding Taylor diagram (Fig. 2c) which clearly shows all models underestimate the SSH variability (points are closer to the origin). The maps for all models except FSU, KIEL-R025 and MRI-ASSIM are weakly correlated with the observed map (correlations between 0.19 to 0.52). The relatively high correlation for MRIASSIM (0.88) is not surprising because this model assimilates temperature and salinity and this

272 is expected to improve the accuracy of the sea level fields. All ensemble means discussed 273 subsequently are based only on the free running models in order to omit the effect of data 274 assimilation.

275 It is not surprising that the $1^{\circ}$ and $2^{\circ}$ (even the $0.5^{\circ}$ KIEL-R050) resolution models 276 underestimate SSH variability in the KCS. KIEL-R025 has a nominal $0.25^{\circ}$ resolution and so it 277 better represents eddy activity than the others. The standard deviation is enhanced when the 
model resolution is increased (compare KIEL-R025 and KIEL-R050). In all $1^{\circ}$ or coarser CORE-

279 II simulations, the Kuroshio and Oyashio form a broad eastward extension in mid-latitudes after their confluence east of Japan (not shown here) in contrast with several distinct jets and fronts seen in nature. This is due to the low horizontal resolution of these models. We will call this eastward current the Kuroshio/Oyashio extension (KOE). The FSU model has higher standard deviations in the KOE than the other models possibly due to its refined resolution at this latitude, close (but still weaker) in magnitude to the observed values. In the tropics, all models capture the overall pattern of SSH variability, although the standard deviations are still weaker than observed in general. The high SSH variability associated with subtropical Counter Current eddies (Qiu and Chen, 2010) is missing from all models except MRI-ASSIM, which have modelled standard deviations that are closer to the observed standard deviations. Note that nearly all models have elevated SSH variability along the path of the North Equatorial Counter Current (NECC).

Skewness: This statistic is a non-dimensional measure of the asymmetry of a histogram or probability density function (see Appendix C for details). Skewness of grid point time series of SSH has been used previously to identify regions dominated by eddies with a preferred sense of rotation, and the line of zero skewness has also been shown (e.g., Thompson and Demirov, 2006) to delineate the mean path of unstable, mid-ocean jets with positive (negative) skewness occurring in regions with low (high) mean SSH. In the present study, we explore the changes of mean path and direction of unstable jets (e.g., KOE) resulting from the reduced level of mesoscale variability of the CORE-II simulations due to their relatively coarse resolution.

The Taylor diagram (Fig. 2e) for the SSH skewness fields (Fig. 4) shows that, the magnitudes are between 0.75 and 1.15 and the correlations are between 0.62 and 0.88 for all models. In the tropical Pacific, all models show positive anomalies in the eastern Pacific and negative anomalies in the western Pacific. Positive ENSO events are characterized by a deeper thermocline (positive SSH) in the east, and shallower thermocline (negative SSH) in the west, a zonal dipole pattern similar to the observed SSH skewness pattern (Fig. 4). This result indicates that El Niño events are stronger than La Niña events. However, during the relatively short time period considered for this analysis, interannual variations are dominated by the large 1997-98 El Niño, and may not be representative of ENSO behavior over a longer period. Indeed, the skewness is significantly reduced in all models if the 
analysis period is extended to 1963-2007 (not shown). There are two reasons for this reduction.

310 One is that the variability is no longer dominated by the large 1997-1998 El Niño event. The

311 other reason is that SSH variability on decadal and longer time scales becomes more important.

312 The histogram of this lower frequency variability is approximately symmetric (e.g., positive and

313 negative anomalies are equally likely) and this reduces the skewness of the extended time series.

314 Outside of the tropics, large-scale positive and negative patches of SSH skewness are

315 evident in all model fields but they vary amongst models and do not agree well with the observed

316 field (bottom left panel, Fig. 4). The discrepancies are most pronounced in the KOE region

317 where, unlike the models, the line of zero skewness in the observations clearly traces out the 318 mean path of this unstable, mid-ocean jet. The zero skewness lines for the models in this region 319 are not very clear but consistent with the modeled mean SSH fields (compare Fig. 4 with Fig. 15 320 of Griffies et al., 2014). Note the MRI-ASSIM does not generate realistic values of skewness. 321 This could be possibly due to the broad Kuroshio in the nominal $1^{\circ}$ MRI-ASSIM even though 322 temperature and salinity are assimilated. These results indicate that local WSC is not the only 323 factor determining the models' standard deviation and skewness; mesoscale eddies and their 324 feedbacks cannot be ignored when considering variability (Penduff et al., 2010). Even if the 325 model is eddy-permitting (e.g., KIEL-R025), it may not generate the eddies at about the same 326 locations as observations in terms of the large-scale pattern, leading to a relatively low 327 agreement as shown by the Taylor diagram. It can also be seen that the models do not reproduce 328 the observed band of high skewness along the Kuril-Kamchtka and Aleutian Trenches, 329 presumably because they do not generate anti-cyclonic eddies in these regions.

\subsection{Sea surface temperature (SST)}

The Taylor diagram (Fig. 2b) for mean SST indicates close agreement between the modeled and observed mean SST (e.g., correlation greater than 0.99). This is perhaps not surprising because the model mean SST reflects the CORE-II surface heat flux which is partly based on observed SST and is similar for all models.

Maps of the standard deviation and skewness of SST were generated using the HadISST observations and CORE-II simulations for the period 1963-2007. The mean seasonal cycle is removed using the same procedure of SSH analysis. 
341 Standard deviation: The Taylor diagram (Fig. 2d) for SST standard deviation (Fig. 5) shows the 342 model fields are realistic with normalized standard deviation between 1.07 and 1.47 and most 343 correlations between 0.82 and 0.92 . All models have relatively high standard deviations in the 344 vicinity of the KOE and in the eastern tropical Pacific (Fig. 5). The patterns are consistent with 345 the HadISST observations which indicate high variability in these regions. However, the maxima 346 of the standard deviations are generally higher than in the HadISST observations and vary 347 greatly amongst models (see the ensemble mean). AWI, CERFACS, CNRM, GFDL-GOLD, 348 MRI-ASSIM have high standard deviations along the equator while ICTP, MRI-FREE, NCAR 349 have low standard deviations.

350 The different standard deviations may indicate how the models respond to heat flux in 351 their configurations. For example, the large difference of CMCC from CERFACS and CNRM 352 may be due to the different NEMO versions (NEMO3.3 in CMCC versus NEMO3.2 in 353 CERFACS and CNRM). The higher standard deviation of MRI-ASSIM compared to MRI-FREE, 354 which is also higher than the standard deviation of HadISST, is likely due to the assimilation of 355 vertical temperature profiles using a 3-dimensional variational (3DVAR) scheme (Fujii and 356 Kamachi, 2003). In the eastern equatorial Pacific, the 3DVAR scheme generally applies 357 corrections to the model temperature fields that reflect large misfits with observations in the 358 thermocline. The corrections can become excessive at the surface through the inaccurate vertical 359 correlations of background errors used by the scheme, leading to spurious SST variations (Fujii 360 and Kamachi, 2003). More generally we should not always expect the data assimilation models 361 to perform better than the free running dynamical models because inaccuracies in the statistical 362 and dynamical information utilized by assimilation schemes can increase errors in some model 363 variables. As for the differences in SST standard deviation for the other models, it is not trivial to 364 isolate the causes because their configurations all differ (resolution, parameters, vertical level 365 and coupling framework etc.).

367 Skewness: The Taylor diagram (Fig. 2f) for SST skewness (Fig. 6) indicate some differences 368 between the simulations and the observations although the large scale patterns look similar; 369 correlations for all models cluster between 0.46 and 0.71. Similar to SSH, all models and the 370 observations show the influence of ENSO emerging from the coast of America in the tropics (Fig. 
371 6). The large-scale tropical pattern reflects the SST asymmetry of El Niño and La Niña in 372 the central and eastern Pacific, perhaps resulting from the nonlinear zonal and meridional 373 temperature advection in these regions (Su et al., 2010) in associated with different strength 374 and timing characteristics of El Niño and La Niña. High positive values of skewness 375 offshore of the U.S. west coast can be seen from all models and the observation, related to 376 the skewed surface heat flux forcing associated with the Seasonal Footprinting Mechanism, 377 which can lead to the El Niño development (Vimont et al., 2001, Vimont et al., 2003; Ding et 378 al., 2015).

The transport of the KCS modulates the climate of this region (e.g., Hirose et al., 2009). It is also affected directly by the regional climate variability (Shen et al., 2014). Here, we assess the realism of the mean KCS transport simulated by the CORE-II simulations based on three representative sections although accurate simulation is rather challenging for most of them due to their low resolution.

This line is located east of Taiwan in the vicinity of a sill and a choke point for the Kuroshio as it flows into the ECS (Fig. 1). The Kuroshio generally exhibits much stronger variability on interannual compared to seasonal time scales (Shen et al., 2014; Soeyanto et al., 394 in Kuroshio transport and in the location of the Kuroshio axis. The reason for this is that the 395 Kuroshio axis east of Taiwan migrates seasonally (controlled by the monsoonal winds and local 396 topography): seaward in summer and shoreward in boreal winter (Tang et al., 2000; Shen et al., 397 2011). During times of strong (weak) transport, the axis of the Kuroshio migrates seaward 398 (shoreward), and less (more) Kuroshio Surface Water intrudes onto the continental shelf of the 399 southern ECS (Tang et al., 2000). 
We have estimated the upper $1000 \mathrm{~m}$ mean volume transport and its seasonal variability 402 across PCM-1 $\left(123.2^{\circ} \mathrm{E}\right.$ westward to the coast) for all of the models from 1963 to 2007. Given 403 the grid resolution varies amongst models, we extended the PCM-1 section approximately $1^{\circ}$ 404 eastward to $124.5^{\circ} \mathrm{E}$ or even more eastward for some models to allow at least two grid points to 405 calculate mean volume transport (e.g., $126^{\circ} \mathrm{E}$ for ICTP because of its $2^{\circ}$ resolution). The 406 observed mean volume transport is approximately $21.2 \mathrm{~Sv}$ (Tseng et al., 2012; red solid line 407 shown in their Fig. 6b), consistent with the earlier estimate of $22.6 \mathrm{~Sv}$ based on repeated 408 CTD/ADCP sections (Liu et al., 1998), and an estimate of $23.3 \mathrm{~Sv}$, with a standard deviation of $4092.0 \mathrm{~Sv}$, based on current meter measurements made during September 1994 and May 1996. The 410 estimated mean volume transports from all of the participating models are listed in Table 2. The 411 ensemble mean for all 14 free running models (i.e., omitting MRI-ASSIM) is 16.4 Sv with 412 standard deviation of 7.5 Sv. It can be seen that most models underestimate the mean transport; 413 only six models have mean transports larger than 20 Sv (AWI, FSU, the two KIEL models and 414 the two MRI models). Except for high resolution KIEL-R025, these models have comparable 415 mean transport with the observations in the range of $20.9 \mathrm{~Sv}$ to $26.1 \mathrm{~Sv}$. KIEL-R025 416 overestimates the transport by about $10 \mathrm{~Sv}$. Note the AWI, FSU and two KIEL models all have 417 much higher resolution than $1^{\circ}$ in this region. The weak transport in other models is mainly due 418 to inadequate resolution of the western boundary currents, resulting in an offshore shift of the 419 Kuroshio axis. Extending the section to $128^{\circ} \mathrm{E}$ leads to a significant increase in the transports of 420 all other low-resolution models (values in parentheses of Table 2), suggesting a broad western 421 boundary current with larger Kuroshio transport offshore.

422 Because the seasonal variation of Kuroshio transport is an important characteristic of 423 variability in the vicinity of PCM-1, we show in Fig. 7a the modeled mean seasonal cycle of the 424 transport for the 1963-2007 period. Most models simulate an intensification in transport in the 425 middle of the year as is found in the observations. reflecting a common direct response to the 426 large-scale summer/winter monsoon forcing provided by the CORE-II data (Tang et al., 2000), 427 However, the range of seasonal variation is usually too small. Note that CERFACS and CNRM 428 have almost identical seasonal variations, indicating that they may share similar transport 429 characteristics due to similar model configurations. Although the FSU model has a mean 430 transport similar to that of the observations (Table 2), its seasonal variation is out of phase 431 compared with the observed transport, possibly resulting from the model's subsurface transport 
432 dynamics (only the top 4 sigma levels have a good correspondence with the CORE-II surface 433 monsoonal wind forcing but not the levels below). It can also be seen that the transport maxima 434 in GFDL-MOM, ICTP and KIEL-R050 occur in spring rather than summer.

\subsection{The PN line}

This line gives a representative section of the Kuroshio in the central ECS (Fig. 1). The underlying bottom topography includes a continental shelf and steep slope with a maximum depth of $1000 \mathrm{~m}$. Time series of annual mean volume transports across this line, from 1963 to 2007, are shown in Fig. 7b. All models exhibit much lower volume transport than the long-term observed transport (black dashed line on Fig. 7b, the mean transport is $24.1 \mathrm{~Sv}$ for the 1963-2003 period). They are also lower than then geostrophic estimate of 25.4-25.8 Sv referred to $700 \mathrm{db}$ depth from 1973-1993 (Hinata, 1996) and 1973-2000 (Ichikawa and Beardsley, 2002). The ensemble mean for all free running models is 7.2 Sv with standard deviation of $3.7 \mathrm{~Sv}$ for the same observed 1963-2003 period (Table 2). Recently, Wei et al. (2013) reported a new estimate of Kuroshio transport of 22.48 \pm 2.78 Sv based on an inverse calculation for the period 1955-2010, which is slightly lower than the above geostrophic estimate due to a counter-current at the offshore side of the PN section. This new estimate is however still much larger than the models' ensemble mean. The low transports estimated by the models are likely due to unresolved mesoscale eddies, which contribute significantly to Kuroshio transport in the western North

452 Pacific (Shen et al., 2014; Soeyanto et al., 2014) and the bottom drag caused by the Ryukyu Islands in the low-resolution models because the transports in all models are consistently weaker

454 than their corresponding transports along the PCM-1, contrast to the observation. Extending the 455 section from $129^{\circ} \mathrm{E}$ to $132^{\circ} \mathrm{E}$ also leads to an increase in some modeled transports (particularly 456 CCLICS), suggesting an offshore shifting and broadening of the main core of the Kuroshio in 457 these models (values in parentheses of Table 2).

Normally, the transport across the PN line is a few Sv stronger than that observed at PCM-1 because of the rejoining flow of the recirculation gyres and mesoscale eddies near the 461 central ECS. Our comparisons highlight the impact of mesoscale eddies on the Kuroshio 462 transport in the Western Pacific (Tseng et al., 2012; Shen et al., 2014). The largest model 
transport is given by the eddy-permitting, nominal $0.25^{\circ}$ resolution KIEL-R025 model (13.9 Sv),

464 suggesting that increasing model resolution may help to improve the realism of the model 465 simulations. The weak interannual variation of the Kuroshio in all models compared to 466 observations also suggests the lack of westward propagating mesoscale eddy activity which 467 has strong interannual variability (Fig. 7b).

We note that the observed Kuroshio transport shows a clear decadal increasing trend over the last 60 years in Fig. 7. Zhang et al. (2012) attributes the increasing trend to the increasing southerly winds above the Southern China Sea and Kuroshio region which are missing in the CORE-II winds (not shown). This will be further addressed in the follow-

This meridional line runs along $137^{\circ} \mathrm{E}$ (Fig. 1). The main core of Kuroshio passes through this section before entering the Kuroshio/Oyashio MWR. Table 2 shows the net 477 Kuroshio transport integrated northward from $25^{\circ} \mathrm{N}$ along the section. In order to minimize the latitude dependency of the Kuroshio path due to the meridional shift of Kuroshio and recirculation gyres in the observations (Sugimoto et al., 2010), we also calculate the Kuroshio eastward transport by taking only the eastward transport (positive zonal velocity) along P09 line (given in parentheses in Table 2). This does not consider the contribution of westward flow associated with the Kuroshio Counter Current and cold-core eddies north of the Kuroshio. The Kuroshio eastward transport is always larger than the net Kuroshio transport along P09 line due to the significant contribution of the Kuroshio Counter Current. The observed net Kuroshio transport and Kuroshio eastward transport from 1972-2007 are 33.0 Sv and 49.4 Sv (Table 2, Sugimoto et al., 2010), respectively. The transport is systematically underestimated in all models with a mean transport of 24.6 $\pm 3.3 \mathrm{~Sv}$ versus $33 \mathrm{~Sv}$ in the observations (Table 2). The model transports vary ranging from 18.0 to $29.5 \mathrm{~Sv}$, compared to the observation-based estimates over the same 1972-2007. These underestimated transports are expected due to the low current velocity in the coarse resolution models. When the impact of westward flow associated with the Kuroshio Counter Current is removed, the Kuroshio eastward transport in most models (the ensemble mean is $33.7 \pm 9.4 \mathrm{~Sv}$ ) is much larger than the net Kuroshio transport but still weaker 
than the observed transport of 49.4 Sv. Further analysis of the transport variability, and its causes, 494 will be investigated in a follow-on paper.

5. Mixed Layer Depth

The following two sections highlight the water masses transport and their origins in the North Pacific by considering the distribution of MLDs and water masses at several sections. MLDs generally reach their seasonal extrema in March and September. Following Danabasoglu et al. (2014), we use a density-based approach to calculate the March MLDs offline, defining the MLD as the depth at which the potential density (referenced to the surface) changes by $0.125 \mathrm{~kg} \mathrm{~m}^{-3}$ from its surface value. Long term monthly mean density profiles at each individual location are used to calculate mean March MLDs for the 1963-2007 period in all models. The same offline method is also used to calculate the observational MLD from the WOA09. MLDs for the South Pacific have been discussed by Downes et al. (2015) so the following discussion focuses entirely on the North Pacific.

The MLDs for March, calculated for the models, are compared with the corresponding

510 (about $50 \mathrm{~m}$ or less) between the equator to the subtropical gyre, but deepen toward higher

511 latitudes. The MLD gradients via lateral induction (Cushman-Roisin, 1987; Marshall et al., 1993)

512 across the base of a sloping mixed layer are responsible for creating regions of maximum

513 subduction (Ladd and Thompson, 2001). In contrast to the MLDs shown by Downes et al. (2015),

514 the subduction of mode waters in the North Pacific is mainly driven by surface wind forcing (e.g.,

515 mid latitude winter storms) in the upper layer and is strongly influenced by lateral exchanges in

516 the mixed layer (Suga et al., 2004). These mode and intermediate waters are normally formed at

517 shallower depths than those in the Southern Ocean because there is no deep water formation in 518 the North Pacific.

519 In the MWR east of Japan, between the Kuroshio Extension and Oyashio Front, the 520 March MLD is of the order $200 \mathrm{~m}$ and exceeds $250 \mathrm{~m}$ in some regions (Qu et al., 2002). Two 521 distinct zonal bands of deep MLD along $32^{\circ} \mathrm{N}$ and $42^{\circ} \mathrm{N}$ can be seen in the WOA09 (bottom 522 panel of Fig. 8), corresponding to different frontal regions. The northern band extends eastward 523 to $160^{\circ} \mathrm{W}$ and the southern band is located south of KOE and slants northeastward. The northern 
524 band is associated with the formation of CMW while the southern band is associated with the 525 formation of STMW (Suga et al., 2004).

526 It is not surprising that the three observed distinct MLD maxima shown in the WOA09

527 (bottom panel of Fig. 9) are not reproduced by any model except MRI-ASSIM, particularly the

528 band associated with the formation of CMW. The assimilation of in situ temperature and salinity 529 profiles by MRI-ASSIM leads to more accurate density stratification, and thus MLD, compared 530 to the other models. Rather, a large region of deep MLD east of Japan is simulated by all models, 531 reflecting the winter deepening of MLD. This winter deepening is critical for the formation of 532 STMW. However, its strength and distribution differ greatly among models. Contrast to the 533 observation, BERGEN is the only model which has the deep MLDs (deeper than $200 \mathrm{~m}$ ) 534 extending into eastern North Pacific, including the Gulf of Alaska.

Many models have MLDs that are much deeper than observed, particularly FSU and ICTP (depth greater than $400 \mathrm{~m}$ ). A few models with overly deep MLD in the KOE region also 537 overestimate MLD in the subarctic gyre in the northwest Pacific (e.g., FSU, GFDL-MOM, ICTP, MRI-FREE). This bias may relate to the origin of North Pacific Intermediate Water (NPIW) in these models, which will be discussed in detail in section 6 . We also note that even using the same MOM ocean model, but with different configurations, the ICTP and GFDL-MOM have 541 different MLDs due to differences in resolution and parameterization (e.g., the tidal mixing is turned off in ICTP). By way of contrast, all NEMO based models (see Table 1) have very similar

543 MLDs regardless resolutions and versions.

The March-mean MLDs for three different regions are listed in Table 3. Regions A to C correspond to the formation regions of CMW $\left(180^{\circ}-160^{\circ} \mathrm{W}, 37^{\circ}-42^{\circ} \mathrm{N}\right)$, STMW $\left(155^{\circ} \mathrm{E}-180^{\circ}\right.$, $\left.54629^{\circ}-34^{\circ} \mathrm{N}\right)$ and the gap region between them $\left(180^{\circ}-170^{\circ} \mathrm{W}, 32^{\circ}-35^{\circ} \mathrm{N}\right)$. The deepest March 547 MLDs are mostly found in region A and region B compared to region C, indicating the 548 deepening of MLDs associated with mode water formation by most models. A narrow transition 549 zone east of the deep MLD region off Japan can also be found in all models, similar to the 550 observed climatology. This region is called the MLD front (Xie et al., 2000). However, all 551 models except MRI-ASSIM show excessively strong MLD fronts (i.e., steep MLD gradients) 552 compared to WOA09 due to the commonly deeper MLDs. Moreover, the large region of deep 553 MLD indicates that the two observed MLD maxima associated with CMW and STMW 554 formation coalesce into one large pool in most models. This may result in an erroneous 
555 representation of the CMW formation process discussed in the next section, and possibly relates

556 to the inaccurate separation point of the western boundary current in the low-resolution models

557 (Ladd and Thompson, 2001). The northward shift of the Kuroshio separation causes the large

558 warm and salty biases of region B (bottom panel of Fig. 9) in all models except MRI-ASSIM and

559 NCAR (well known coarse resolution features so the patterns are not shown here). The bottom

560 panel of Figure 9 shows the relationships between the mean March MLD and the mean

561 hydrographical biases of March potential temperature and salinity for the region B over the upper

$562400 \mathrm{~m}$, in addition to the mean density biases. The corresponding linear regression lines along

563 with the correlation coefficients are shown for comparison. While both positive potential

564 temperature and positive salinity biases have a compensating impact on the density, the positive

565 potential temperature biases tend to dominate the changes in density, contributing to the negative

566 density biases in the upper-ocean, associated with deeper MLD (correlation $r=0.90$ for the

567 potential temperature biases and $r=-0.87$ for the density biases). This analysis confirms the

568 excess formation of STMW results in the deeper MLD in some models (e.g., FSU and ICTP-

569 MOM) due to the inaccurate Kuroshio separation associated with the excess warm and salty

570 Kuroshio water.

571 On the other hand, the biases associated with CMW cannot be easily explained. The top

572 panel of Figure 9 shows the same hydrographical biases for region A, indicating similar warm

573 and salty biases to those for region B (bottom panel of Fig. 9). The density and March MLD

574 relationship in region $\mathrm{A}$ is more scattered than region $\mathrm{B}$ and the linear regression coefficient is

575 also lower for both potential temperature and salinity. A very similar result is obtained when we

576 consider a broader area that includes a larger region (not shown). We cannot find a clear

577 potential temperature or salinity dominance in the models affecting the change of MLD. This

578 suggests the models deep water formation mechanism in region A may be similar to the

579 formation of STMW, but differs from the actual formation mechanism of CMW, supporting our

580 discussion above.

581 Another local maximum of MLD exists offshore of the west coast of North America

582 centered near $30^{\circ} \mathrm{N}$ (bottom left panel in Fig. 8). This region is partially responsible for the

583 formation of ESMW (Talley, 1988; Hosoda et al., 2001). The ESMW is a weak thermostad of

$58416^{\circ}-22^{\circ} \mathrm{C}$ lying in the upper permanent pycnocline and is formed primarily by weak cross- 
585 isopycnal flow (Ladd and Thompson, 2001; Suga et al., 2004). All models reproduce a maximum

586 in this region although the area of enhanced MLD is much larger than observed in most models.

\section{Upper-ocean Circulation of the North Pacific}

\section{We now further evaluate the water masses formed by the deepening of MLDs in the}

\section{North Pacific. In order to better understand the three-dimensional structures, we consider} two vertical sections first and then three isopycnal surfaces. We first discuss the salinity and potential density distributions along two meridional sections which can give us an overview of the modeled meridional water mass distribution. Then we further investigate the depth, salinity, potential temperature, and potential vorticity (PV) along selected density surfaces of the North Pacific. Mode water formation is commonly characterized by low PV. PV is thus a useful quantity and is defined here as follows:

$$
P V=(Z \mid f)_{\beta \partial z}^{1 g \beta}
$$

where $\zeta$ is the relative vorticity (vertical component of the curl of the velocity fields), $f$ is the Coriolis parameter (planetary vorticity), $\rho$ is the potential density referenced to the surface and $z$ is the vertical coordinate (positive upwards). Because no reliable estimation of the mean relative vorticity can be easily obtained from observations and it is an order of magnitude less than the planetary vorticity (not shown here), only the planetary vorticity is used here for the comparison.

\subsection{Vertical sections}

P09 (137 ${ }^{\circ}$ E): This vertical section cuts across the entire western North Pacific from the tropics to the south of Japan (Bingham et al., 2002). Figure 10 compares the simulated salinity 610 distributions along this section with the WOA09, focusing on the shallow and intermediate water 611 masses. In agreement with observations, all models except ICTP show an overall salinity 612 maximum exceeding 35.3 psu between $22 \sigma_{\theta}$ and $26 \sigma_{\theta}$ in the equatorial regions, indicating the 613 existence of the Tropical Waters discussed next. ICTP has a slightly weaker salinity maximum 614 (roughly 0.4 psu lower). The observations indicate a strong salinity front around $5^{\circ} \mathrm{N}$, with the 615 salinity maximum near $24 \sigma_{\theta}$ (Bingham et al., 2002). The high salinity maximum south of $5^{\circ} \mathrm{N}$ is 
616

617

618

619

620

621

622

623

624

625

626

627

628

629

630

631

632

633

634

635

636

637

638

639

640

641

642

643

644

645

646

associated with South Pacific Tropical Water, originating from the Southern Hemisphere. All models show such a feature but with different strengths, apparently related to the strength of the above mentioned salinity front.

The high salinity region between $10^{\circ} \mathrm{N}$ and $25^{\circ} \mathrm{N}$ (North Pacific Tropical Water, NPTW) lies mostly above $24 \sigma_{\theta}$. The NPTW is formed by midlatitude subduction, which is characterized as a subsurface salinity maximum in the North Equatorial Current and derived from the high surface salinity area of the central subtropical North Pacific (Suga et al., 2000). Suga et al. (2000) and Katsura et al. (2013) argue that the portions of NPTW north and south of $15^{\circ} \mathrm{N}$ originate from different formation regions, west and east of the dateline, respectively. All models except ICTP seem to have a well-defined local salinity maximum south of $15^{\circ} \mathrm{N}$, which is mainly controlled by the seasonal mixed layer variation in its eastern formation site (Katsura et al., 2013). However, the models exhibit large diversity in salinity north of $15^{\circ} \mathrm{N}$ in terms of the location of the maximum and thickness. The formation of NPTW north of $15^{\circ} \mathrm{N}$ results from large interannual variability rather than seasonal mixed layer variations due to local surface forcing (Katsura et al., 2013).

In the subtropical band between $20^{\circ} \mathrm{N}$ and $30^{\circ} \mathrm{N}$, and below the $25 \sigma_{\theta}$ surface, all of the models show diverse salinity distributions. The NPIW, characterized by the low salinity core less than 34.3 psu (approximately 34.0-34.3 psu) within a layer between $26.2 \sigma_{\theta}$ and $27.2 \sigma_{\theta}$, also extends southward to $15^{\circ} \mathrm{N}$ in some models with a comparable salinity minimum with the observation at depth (e.g., AWI, BERGEN, CERFACS, CMCC, CNRM, GFDL-MOM, KIELR025, KIEL-R050, MRI-ASSIM, MRI-FREE and NCAR). The other models have weak or no clear signature of a salinity minimum. Observational studies (e.g., Yasuda, 1997; You et al., 2000) indicate that the low salinity originates mainly from the Bering and Okhotsk Seas, which is also supported by a pathway analysis using an eddy-resolving ocean adjoint model (Fujii et al., 2013). The water is advected into the MWR by the Oyashio and enters the Kuroshio Extension (You, 2010; Fujii et al., 2013). But there may be several pathways for the NPIW observed along P09 line shown in Fig. 10. The subtropical gyre may be the most likely transport route (You, 2010). When the NPIW water enters the subtropical gyre, it recirculates within the wind-driven gyre and ages. The differences in the modeled NPIW distributions along P09 may be due to different recirculation patterns that transport the salinity minimum. We will further evaluate the associated pathways along the $26.8 \sigma_{\theta}$ isopycnal surface later. 
648 P13 (165 $\left.{ }^{\circ} \mathbf{E}\right):$ In general, the boundary between the Kuroshio Extension and Oyashio Front in the upper ocean is vague due to a large MWR. The P13 section cuts through these fronts and extends to the equatorial region. The salinity distribution of P13 is generally similar to that of the P09 651 section (compare Figs. 10 and 11), but the P13 salinity minimum (maximum) is roughly 0.1-0.2 652 lower (0.2-0.4 higher) in the subtropics. Similar to the observations, the lower salinity minimum 653 is likely caused by reduced mixing resulting from a narrower vertical extent of the salinity 654 minimum core (Qu et al., 2001; You et al., 2004). The higher salinity maximum for the P13 655 section, compared to P09, is because P13 is much closer to the subduction region of NPTW. 656 However, there is no significant change of buoyancy because potential temperature increases are 657 compensated by salinity increases (Qu et al., 2001). In general, the salinity is uniformly high 658 south of the $\mathrm{KOE}$ until $15^{\circ} \mathrm{N}$ on the shallow isopycnal surfaces in all models $\left(<26.2 \sigma_{\theta}\right.$, black 659 solid lines in Fig. 11 are $26.2 \sigma_{\theta}, 26.8 \sigma_{\theta}, 27.2 \sigma_{\theta}$, respectively).

660 In the observations (bottom left panel of Fig. 11), we can see the fishhook-like salinity 661 minimum intrusion extending from $40^{\circ} \mathrm{N}-50^{\circ} \mathrm{N}$ southward to $10^{\circ} \mathrm{N}-20^{\circ} \mathrm{N}$. The eastward flowing 662 KOE brings high salinity water from the west. The subduction of the salinity minimum occurs 663 near the boundary between the subtropical and subarctic water, sometimes called the subarctic 664 boundary (Favorite et al. 1976), located along the extension of the Kuroshio/Oyashio 665 (approximately $40^{\circ} \mathrm{N}$ ) where it forms an equatorward tongue. This latitude is roughly the 666 northern boundary of NPIW. The salinity minimum core (less than $34.2 \mathrm{psu}$ ) is centered at $30^{\circ} \mathrm{N}$ 667 but the salinity in the core increases to 34.5 psu north of $10^{\circ} \mathrm{N}$, separating the tropical high 668 salinity water from the subtropical low salinity water. The salinity minimum core intrusion into 669 the tropic can be seen in all models but the strengths differ (e.g., a large area of low salinity 670 below 26.2 $\sigma_{\theta}$ extending into the tropic in BERGEN and higher than 34.2 psu salinity minimum 671 core in GFDL-GOLD). This may be due to the different transport routes associated with different 672 North Pacific gyres simulated by these models (shown on isopycnal surfaces discussed in section $673 \quad 6.2)$.

674 From the observations, the NPIW (around the $26.8 \sigma_{\theta}$ surface) marks the bottom of recently 675 ventilated thermocline water of low salinity $(<34.1 \mathrm{psu})$. Below this depth, water properties are 676 conserved along isopycnals. The low salinity NPIW can be seen in all models but the locations 677 and extended depths differ. There is no direct evidence that the isopycnal models (BERGEN, 
678 GFDL-GOLD) catch these features better than models with other vertical coordinate systems. distribution of water properties along isopycnals. Three isopycnal surfaces (defined by $26.2 \sigma_{\theta}$, $26.8 \sigma_{\theta}$, and $27.2 \sigma_{\theta}$ shown in Figs. 10 and 11) are used in this section to describe the spatial distributions of isopycnal depth, PV, potential temperature and salinity. These surfaces are defined based on the mean density profiles in the individual models.

$\boldsymbol{\sigma}_{\boldsymbol{\theta}}=$ 26.2: We choose $26.2 \sigma_{\theta}$ because this is the maximum subduction density in the North Pacific and its sigma surface outcrops between $38^{\circ}-40^{\circ} \mathrm{N}$ (Qu et al., 2001) in winter. The $26.2 \sigma_{\theta}$ mean surface quickly deepens from the subpolar region $(<100 \mathrm{~m})$ to the subtropical gyre (center is deeper than $500 \mathrm{~m}$ ) south of the KOE in the observation (bottom left panel in Fig. 12). The significant increase of depth suggests that the KOE is characterized by strong horizontal density 693 gradients in the shallow waters. The $26.2 \sigma_{\theta}$ depth contours resemble the North Pacific recirculation contours for all models. According to the observations (bottom left panel of Fig. 12), the high PV occurs almost everywhere north of $35^{\circ} \mathrm{N}$ and with two maxima that correspond to 696 the maximum Ekman upwelling regions centered at $50^{\circ} \mathrm{N}, 165^{\circ} \mathrm{E}$ and $55^{\circ} \mathrm{N}, 145^{\circ} \mathrm{W}$, respectively 697 (Talley, 1988). The low PV in the recirculation gyres south of KOE is rather homogeneous 698 (approximately $3 \times 10^{-10} \mathrm{~m}^{-1} \mathrm{~s}^{-1}$ ) and represents the lower boundary of the STMW, which lies 699 mainly along the $25.2 \sigma_{\theta}$. The other region of low PV $\left(<3 \times 10^{-10} \mathrm{~m}^{-1} \mathrm{~s}^{-1}\right)$, near the international 700 dateline and in the subtropics, is likely due to the CMW, centered around $38^{\circ} \mathrm{N}, 160^{\circ} \mathrm{W}$ (Suga et 701 al., 1997). We can see a slightly elevated PV ridge separating these two local PV minima, 702 suggesting two different water formation processes for STMW and CMW (regions A and B in 703 Table 3). We note, however, that this gap is absent in all models or much higher than the upper 704 limit of STMW and CMW (Suga et al., 2004), including MRI-ASSIM. This seems to be a 705 common problem with the low-resolution models (even in the eddy-permitting KIEL-R025); 706 both STMW and CMW form south of the KOE, with STMW preconditioning the formation of 707 CMW (Ladd and Thompson, 2001). In most models, we can see low PV bands extending 708 continuously from south of the $\mathrm{KOE}$ northeastward to $160^{\circ} \mathrm{W}$, associated with formation due to 
709

710

711

712

713

714

715

716

717

718

719

720

721

722

723

724

725

726

727

728

729

730

731

732

733

734

735

736

737

738

739

the mixed layer front. In reality, CMW formation is primarily related to cross-isopycnal flow in the mixed layer (Suga et al., 2004).

Figure 13 shows the potential temperature and salinity distribution along $26.2 \sigma_{\theta}$, indicating relatively uniform potential temperature and salinity south of the KOE. The locations and the detailed distribution of STMW and CMW in different models vary consistently with the distribution of low PV in Fig. 12. North of the KOE, the potential temperature and salinity gradients are mostly sharp in the Oyashio Front for all models. There is no evidence that the isopycnal models can better capture these frontal features. The presence of a broad Kuroshio, and its extension, can be identified in all models with high potential temperature $\left(>11.5^{\circ} \mathrm{C}\right)$, high salinity (>34.4 psu), and low PV extending eastward from the coast of Japan.

$\boldsymbol{\sigma}_{\boldsymbol{\theta}}=\mathbf{2 6 . 8}$ : This surface was chosen because it lies in the range of NPIW, a known salinity minimum centered between $26.7 \sigma_{\theta}$ and $26.9 \sigma_{\theta}$ (Talley, 1993; Yasuda, 1997). Figure 14 shows the PV and depth distribution along $26.8 \sigma_{\theta}$. The observations indicate NPIW is formed in the western North Pacific and is spread over the entire basin by the large-scale circulation (Talley, 1993). A PV minimum ( $\left.<1 \times 10^{-10} \mathrm{~m}^{-1} \mathrm{~s}^{-1}\right)$ is observed (bottom left panel of Fig. 14) in the Okhotsk Sea and the PV maximum $\left(>4 \times 10^{-10} \mathrm{~m}^{-1} \mathrm{~s}^{-1}\right)$ is seen just to the east of this marginal sea, extending throughout the subarctic Pacific. No PV maximum or minimum is observed in the Kuroshio recirculation gyre east of Japan. These features are seen only in MRI-ASSIM. All free running models predict a variety of PV distributions in the Okhotsk Sea and the subarctic Pacific. In the Okhotsk Sea, a few models have very high PV (e.g., AWI, CCLICS, CERFACS, CMCC, CNRM, GFDL-GOLD, KIEL-R025) while other models (BERGEN, FSU, GFDL-MOM, ICTP, KIEL-R050, MRI-ASSIM, MRI-FREE and NCAR) have a low PV that is similar to observations. Nakamura et al. (2004) showed that the intense tidally-induced mixing along the Kuril Islands is one of the major reasons for the formation of low PV water, including the Okhotsk Sea. However, it is not clear (or easy to distinguish) if the tidal mixing affects the modeled PV distributions because all models except ICTP have enhanced tidal mixing parameterization (but different schemes). In most models with low PV in the Okhotsk Sea, we can see the low PV water along the coast of the Kuril Islands and Hokkaido extends southeastward and spreads over much of the subtropical region. Considering the “unventilated” theory of Rhines and Young (1982), this uniform PV is not surprising, and has been interpreted as evidence to support the idea that a 
convective (density driven) source of NPIW is unlikely in the open subtropical Pacific (Talley, 1993). Its connection with the PV minimum in the Okhotsk Sea supports the hypothesis that the origin of NPIW is the Okhotsk Sea mode water (Yasuda, 1997). Although GFDL-MOM and ICTP have low PV in the Okhotsk Sea, they also have high PV in the Kuroshio recirculation gyre. In the subpolar gyres east of the Kuril Islands, the modeled PV distributions diverge more than in the Okhotsk Sea. The observed high PV east of the Kuril Islands is associated with Ekman upwelling (Talley, 1988). Observations show two local PV maxima centered on the east and west sides of the dateline. Some models do not generate high PV in this region, e.g., BERGEN, CMCC, KIEL-R050, MRI-FREE and NCAR. It is possible that bathymetry plays an important role in generating these model differences, as supported by the differences between the two KIEL models (high PV in KIEL-R025 but low PV in KIEL-R050). Within the same coarse resolution NEMO family, the similarity in the Subarctic Pacific between CERFACS and CNRM, which is different from CMCC, indicates the additional impact of the different sea-ice model.

Overall it is encouraging to see that low potential temperature and fresh salinity extrema occur in the Okhotsk Sea in all models (Fig. 15) although the PV distributions differ greatly in Fig. 14. The Okhotsk Sea and the coast of the Kuril Islands are thought to be the formation source of NPIW as mentioned earlier. According to observations, these regions have the shallowest (approximately $200 \mathrm{~m}$ or less), coldest $\left(<2{ }^{\circ} \mathrm{C}\right)$ and freshest $(<33.6 \mathrm{psu})$ waters. The low salinity at the shallow depth in the Okhotsk Sea is responsible for the stable density stratification in the region that is associated with a broad, homogenous, low PV. These homogenous properties change dramatically southeastward in the MWR and they are then transported to most of the North Pacific by the North Pacific gyre circulation. The potential temperature and salinity distributions along $26.8 \sigma_{\theta}$ vary significantly among models. Only MRIASSIM and MRI-FREE simulate NPIW penetrating southward with relatively homogeneous, low salinity and low potential temperature at $26.8 \sigma_{\theta}$. The southward penetrating water in BERGEN is too cold and fresh. All other models have a southward penetration of NPIW that is either too warm or too salty. These features are also reflected in the P09 and P13 sections discussed above. Nevertheless, we confirm that the spreading of NPIW is strongly related to the large scale recirculation of the North Pacific in the individual models.

$\boldsymbol{\sigma}_{\boldsymbol{\theta}}=\mathbf{2 7 . 2}$ : This surface is where AAIW spreads over the North Pacific (Qu et al., 2001) and is 
771 useful in investigating the exchange of water between the subtropical and subpolar gyres at depth.

772 The circulation at this density surface is unventilated in the sense that these isopycnals do not

773 outcrop anywhere in the North Pacific. The depth of this density surface ranges from roughly

$774700 \mathrm{~m}$ at the equator to almost $1000 \mathrm{~m}$ in the subtropics south of Japan $(\mathrm{Qu}$ and Lindstrom,

775 2004). Most models capture this feature (contours in Fig. 16) except BERGEN. The BERGEN

776 model overestimates the depth by more than $300 \mathrm{~m}$ compared with observations (it is deeper than

777900 m over a significant portion of North Pacific). The PV is generally very low along $27.2 \sigma_{\theta}$

778 but higher than the PV along the $26.8 \sigma_{\theta}$ surface in the Okhotsk Sea, suggesting a low PV origin

779 of NPIW in the Okhotsk Sea. Another large bias can be found in the PV of GFDL-GOLD; it has

780 very high PV poleward of the subtropical North Pacific. The high PV may relate to the high

781 potential temperature and salinity gradients east of Japan (Fig. 17), resulting from the excessive

782 downward penetration of the Kuroshio Current associated with deeper MLDs in Fig. 8.

783 The patterns of potential temperature and salinity along $27.2 \sigma_{\theta}$ are compared in Fig. 17.

784 The lateral gradients of potential temperature and salinity are weak on this isopycnal surface 785 compared with those in the shallower waters along 26.2 and $26.8 \sigma_{\theta}$. The low salinity signal of 786 AAIW is lost by mixing with overlying and underlying waters at the midlatitudes of the North 787 Pacific. Some models even show relatively uniform water properties (4-6 ${ }^{\circ} \mathrm{C}, 34.4$ psu) 788 throughout the whole North Pacific (e.g., AWI, CERFACS, CMCC, CNRM, two KIEL models 789 and MRI-FREE). These models also miss the low salinity and low potential temperature 790 characteristics in the subartic. Further analysis on the isopycnal and diapycnal mixing 791 characteristics is required.

792

793 7. Mean Tropical Dynamics

794

795

796

797

798

799

Finally, we examine the mean tropical dynamics in the Pacific because of its importance in the global climate system (e.g., the impact of ENSO). We first compare the zonal mean current structure along the equator with observations (Johnson et al., 2002) for the 1986-2000 period (Fig. 18). Along the equator, the maximum speed of the EUC ranges from 79 $\mathrm{cm} \mathrm{s}^{-1}$ (MRI-FREE) to $114 \mathrm{~cm} \mathrm{~s}^{-1}$ (KIEL-R050) listed in Table 4 (MRI-ASSIM is excluded). The corresponding core depths (defined as the depth of the maximum eastward velocity) are also

800 listed for reference. The ensemble mean of the maximum speed for all free running models is 
$80194 \pm 11 \mathrm{~cm} \mathrm{~s}^{-1}$, weaker than the observations of Johnson et al. (2002) which indicated a maximum 802 of $110 \mathrm{~cm} \mathrm{~s}^{-1}$ at approximately $86 \mathrm{~m}, 130^{\circ} \mathrm{W}$; NCAR and the KIEL-R025 are the only models 803 having a comparable speed within $\pm 2 \%$ difference. The zonal tilt of the EUC is aligned with the 804 isopycnals for each model. The equatorial pycnocline in the eastern Pacific is relative weak in 805 most models in comparison with observations except in AWI and GFDL-GOLD. This results in a 806 deeper $26 \sigma_{\theta}$ in the model ensemble $(170 \mathrm{~m})$ while the observed $26 \sigma_{\theta}$ is approximately $100 \mathrm{~m}$. 807 The actual mechanism causing the deepened isopycnals is not clear.

808

809

810

811

812

813

814

815

816

817

818

819

820

821

822

823

824

825

826

827

828

829

830

The zonal currents at $140^{\circ} \mathrm{W}$ are also compared with the observation of Johnson et al. (2002) in Fig. 19 for the period of 1986-2000. The large scale structure of EUC and South Equatorial Currents (SEC) in all models are similar to the observations, however, there are differences in the details. The EUC in some models is too deep (e.g., AWI, CCLICS) and all are wider than the observations in the meridional direction to a certain extent so that the model ensemble (top right) has a wider EUC core than the observations. Nevertheless, all these models have a SEC flowing westward on the south side of EUC, consistent with the observations. However, their vertical and meridional extent on the north side is greatly influenced by the existence and strength of NECC and North Subsurface Countercurrent, an eastward surface current flowing against the prevailing winds, and a subsurface current, respectively. All models have a weak flow at latitudes normally associated with the NECC. MRI-ASSIM has the largest eastward velocity (of the order of $10-20 \mathrm{~cm} \mathrm{~s}^{-1}$ ), however, the speed is still weaker than the observed speed of about $40 \mathrm{~cm} \mathrm{~s}^{-1}$. The discrepancies in all free-running models may result from the interpolated low-resolution CORE-II wind field because the structure of the NECC depends heavily on two key factors: the strength of the near-equatorial zonal wind stress and the meridional gradient of the wind stress curl, i.e., (curl $\tau)_{y}$, in the Intertropical Convergence Zone (Yu et al., 2000).

This is supported by the mean wind stress curl shown in Fig. 20 and the Sverdrup transport U calculated using all models' wind stresses shown in Fig. 21 (Sverdrup, 1947; Kessler et al., 2003). Figures 20 and 21 compare the modeled wind stress curls and their associated Sverdrup transports with those calculated from the Scatterometer Climatology of Ocean Winds fields (Risien and Chelton, 2008) between $15^{\circ} \mathrm{S}$ and $15^{\circ} \mathrm{N}$. We can see dramatic differences between the models and observations, particularly the westward transport band between the 
831 equator and $5^{\circ} \mathrm{N}$ (compare the ensemble mean and the observation in the bottom panel of Fig.

832 21). We note that a strip of observed positive WSC (Fig. 20) just north of the equator around $150^{\circ} \mathrm{W}-100^{\circ} \mathrm{W}$ is missing in the CORE-II wind forcing, a robust feature seen in satellite winds but not in reanalysis or ship products (Kessler et al., 2003) and resulted from a tight coupling between the wind stress and SST (Chelton et al., 2001). This discrepancy in the CORE-II wind forcing causes a big difference in all models' Sverdrup transport comparing with the observations. Because the near-equatorial zonal wind stresses are all very similar among models, our results highlight the key role of the (curl $\tau)_{y}$ in the equatorial transport, greatly sensitive to the near equator positive WSC although it is weak (Kessler et al., 2003). Furthermore, the Sverdrup transport U values among the models also vary due to the different model grids which cause other differences in (curl $\tau)_{y}$ among models. transport caused by the inaccurate WSC from the CORE-II wind forcing may result in the NECC and SEC of all models being too weak. This is also supported by the Sverdrup transport of the NECC $\left(2^{\circ}-10^{\circ} \mathrm{N}\right)$ estimated using the wind stress on the model grids along $140^{\circ} \mathrm{W}$ (Table 5). The ensemble mean of $8.4 \mathrm{~Sv}$ is almost half of the Sverdrup transport (17.2 Sv) estimated from the Scatterometer Climatology of Ocean Winds fields (Kessler et al., 2003). The quality of CORE-II forcing requires a refinement near the equator.

Meridional transport also plays a key dynamical role in the tropics. Similar to Chen et al. (2015) and McPhaden and Zhang (2002), we further compare the modeled vertical sections of meridional velocity across $10^{\circ} \mathrm{S}$ and $10^{\circ} \mathrm{N}$ in order to estimate the mean meridional transport associated with STCs in the Pacific (Figs. 22 and 23). The latitude of $10^{\circ} \mathrm{N}$ is chosen because it approximates a choke point for the meridional geostrophic transport between the extratropics and tropics due to the existence of a PV ridge at $10^{\circ} \mathrm{N}$ (McPhaden and Zhang, 2002). The latitude of $10^{\circ} \mathrm{S}$ is chosen for hemispheric symmetry. Across both latitudes, the poleward surface Ekman transport of STCs is confined approximately to the upper $50 \mathrm{~m}$ in all models, consistent with the analysis shown in Chen et al. (2015). Therefore, the modeled Ekman transport is estimated as the

858 depth-integrated meridional velocity above $50 \mathrm{~m}$. Most models have similar magnitudes (see 859 Table 6 for the individual Ekman transport at $10^{\circ} \mathrm{N}$ and $10^{\circ} \mathrm{S}$ ) except BERGEN which has an 860 overall weaker Ekman transport along $10^{\circ} \mathrm{N}$. The ensemble mean Ekman transport is 19.4 \pm 2.7 
$861 \mathrm{~Sv}$ at $10^{\circ} \mathrm{N}$ and $-16.4 \pm 2.6 \mathrm{~Sv}$ at $10^{\circ} \mathrm{S}$. By comparing results for the two sections, it is clear that

862 the vertical extent of the Ekman layer is approximately symmetric across the equator.

The pycnocline transport of STCs is primarily above $26 \sigma_{\theta}$ in the observation (McPhaden 864 and Zhang, 2002). The isopycnal lines calculated using WOA09 data are superimposed as dashed 865 lines (22 $\sigma_{\theta}$ to $26 \sigma_{\theta}$ ). The $26 \sigma_{\theta}$ isopycnals are generally deeper in the models, regardless of the 866 vertical resolution and vertical coordinate system. This leads to a deeper extension of STC 867 transports in all models when comparing with McPhaden and Zhang (2004). The main core of 868 equatorward interior flow appears between approximately $150^{\circ} \mathrm{E}$ and $140^{\circ} \mathrm{W}$ in the observations 869 (Schott et al., 2004; Chen et al., 2015). This is the major contribution of the equatorward STCs at $87010^{\circ} \mathrm{N}$. However, all models show the interior equatorward flow can extend further eastward to 871 the surface Costa Rica Dome in the eastern tropical Pacific. It is clear that the pycnocline 872 features in the eastern tropical Pacific (dominated mainly by the thermoclines in this region, 873 Brown and Fedorov, 2010) are also not well represented in all models when compared with the 874 WOA09 data. The local unresolved, small-scale wind variations (strongly influenced by the 875 topography of the American continent), which is also missing in the CORE-II forcing, may be an 876 important cause of the discrepancy (Kessler, 2006).

At $10^{\circ} \mathrm{S}$, the pycnocline distribution of all models is similar to the WOA09 data (Fig. 23).

878 The $26 \sigma_{\theta}$ isopycnals vary between $250 \mathrm{~m}$ and $310 \mathrm{~m}$ in depth. The modeled equatorward interior 879 transports extend from $180^{\circ} \mathrm{W}$ to $90^{\circ} \mathrm{W}$. The largest interior transport at $10^{\circ} \mathrm{S}$ occurs between $880140^{\circ} \mathrm{W}$ to $100^{\circ} \mathrm{W}$ in all models, consistent with previous analysis (Chen et al., 2015). These 881 results suggest that the CORE-II forced models can simulate the Southern Hemisphere interior 882 transport, and its distribution, better than the Northern Hemisphere interior transport. 884 excluded) is also estimated by integrating the meridional velocity vertically from $50 \mathrm{~m}$ to the 885 depth of $26 \sigma_{\theta}$ (Ekman transport excluded) because it captures the density range of the majority 886 of interior pycnocline transport, and then integrating zonally from the eastern edge (roughly $887140^{\circ} \mathrm{E}$ at $10^{\circ} \mathrm{N}$ and $160^{\circ} \mathrm{E}$ at $10^{\circ} \mathrm{S}$ ) of the western boundary current to the eastern boundary. In 888 order to directly compare with the observations of McPhaden and Zhang (2004), the westernmost 889 longitudes of integration are chosen several hundred kilometers away from the western boundary, 
which avoids strong boundary currents and their local recirculation. The mean western boundary,

891 Ekman layer and interior STC transports from 1963-2007 for all models are tabulated in Table 6 892 for completeness (see Fig. 8 in Chen et al., 2015 for the geographical illustration).

McPhaden and Zhang (2004) indicated that the interior STC convergence (transport at $10^{\circ} \mathrm{S}$ minus transport at $10^{\circ} \mathrm{N}$ ) has a large temporal variability (e.g., $13.4 \pm 1.6 \mathrm{~Sv}$ from $07 / 1992$ to $06 / 1998$ and $24.1 \pm 1.8 \mathrm{~Sv}$ from 07/1998 to 06/2003, respectively). The ensemble mean of the interior STC convergence among models is $22.4 \pm 6.1 \mathrm{~Sv}$, which is within the range of McPhaden and Zhang (2004). The interannual variability of STC transports will be further addressed in the follow-on paper. Chen et al. (2015) further show that the mean interior transport at $10^{\circ} \mathrm{S}(13.6 \mathrm{~Sv})$ is more than twice that at $10^{\circ} \mathrm{N}(-5.9 \mathrm{~Sv})$ in general during $1960-2010$. The asymmetry of transport in Chen et al. (2015) (also MRI-ASSIM) indicates the dominant Southern Hemispheric role of STCs. However, most models have symmetric interior STC transport with larger values than Chen et al. (2015) at $10^{\circ} \mathrm{N}$, leading to the larger total interior STC convergence (Table 6). At $10^{\circ} \mathrm{S}$, the ensemble mean of the interior STC transport is $11.4 \pm$ 2.3 Sv, quite consistent with that estimated in Chen et al. (2015). This may not be surprising because all models have pycnocline distributions that are similar to the observations discussed above (Fig. 23). The interior STC transport will not deviate too much if the meridional velocity is also similar. BERGEN model has much weaker transport. The other weak interior transport at $10^{\circ} \mathrm{S}$ can be found in CCLICS (7.8 Sv) resulting from its shallowest depth of $26 \sigma_{\theta}$ among all of the models. However, at $10^{\circ} \mathrm{N}$, most models have larger equatorward pycnocline transport $(-10.9$ $\pm 4.0 \mathrm{~Sv}$ ) than that estimated in Chen et al. (2015). This is also consistent with the significantly

911 deeper pycnoclines in most models (Fig. 22). Both BERGEN and FSU have weaker transports 912 than the estimated -5.9 Sv in Chen et al. (2015). This is due not only to the weaker velocity but 913 also the deeper Ekman layers. Future assessment of the interannual to decadal variability of 914 interior STCs requires caution. The modeled interior STCs will in general be larger than 915 observed due to the overestimated transport at $10^{\circ} \mathrm{N}$. The overestimated transport may be linked 916 to the deep pycnocline in most models shown in Figs. 22 and the lack of high PV region in the 917 Northern Hemisphere in many models (not shown). The lack of high PV region in many 918 models potentially maintains a larger equatorward transport than the observation in the 919 central and eastern Pacific without rerouting more North Hemisphere water to the western 
boundary in the upper layer as seen in observation (Johnson and McPhaden, 1999).

921

922

8. Summary and future work

923

924

925

926

927

928

929

930

931

932

933

934

935

936

937

938

939

940

941

942

943

944

945

946

947

We have evaluated a suite of global ocean-sea ice models, driven by the CORE-II atmospheric forcing from 1963-2007, focusing on the North and equatorial Pacific. The key results are summarized as follows:

1. The overall model performance is clearly quantified by the Taylor diagrams of the first three moments of the surface variability. Our results clearly show that the mean standard deviation and skewness of SSH variability for the altimeter subperiod (19932007) deviate from the observations more than the mean SSH pattern in all models. In particular, comparison of spatial patterns of model standard deviation with a corresponding map based on altimeter observations clearly indicates the impact of missing meso-scale eddies for all models. Nevertheless, all models can simulate the contribution of the 1997 El Niño signature in the skewness of SSH (but not the specific skewness pattern in the vicinity of the Kuroshio and its extension due to the models' inability to reproduce the expected mesoscale variability). Similar features can also be found in the spatial maps of standard deviation and skewness of SST.

2. Several transports in the KCS are evaluated due to their important roles on the heat transport in the climate system. As expected, the discrepancy of the model mean western boundary current transports is mainly due to their poor model resolutions and lack of mesoscale eddies. We confirmed the modeled Kuroshio axis is further offshore than observed for most models (Table 2). However, many of them show seasonal variability as found in the observations along PCM-1 (Fig. 7). The modeled ensemble mean along PCM-1 is $16.4 \pm 7.5 \mathrm{~Sv}$ which is approximately $5 \mathrm{~Sv}$ lower than the observed value of 21.2 $\pm 2.4 \mathrm{~Sv}$. A larger model discrepancy is found along the PN line, where the modeled ensemble mean transport is $7.2 \pm 3.7 \mathrm{~Sv}$, significantly lower than the observed value of 24.1 $\pm 3.4 \mathrm{~Sv}$ (and the reported transports of 22.5-25.8 Sv for different time periods). The low ensemble mean is likely due to unresolved mesoscale eddies in the 
CORE-II simulations, which contribute significantly to Kuroshio transport in this region (Shen et al., 2014; Soeyanto et al., 2014) and the bottom drag caused by the Ryukyu Islands in the low-resolution models. The overall transports (ensemble mean is 24.6 $\pm 3.3 \mathrm{~Sv}$ ) across P09 for all models underestimate the observed value of $33.0 \mathrm{~Sv}$.

3. Water mass analysis shows that both the STMW and CMW in the North Pacific cannot be distinguished by all participating models. These models reproduce a local maximum of MLD in the ESMW region although the area of enhanced MLD is much larger than observed in most of them. It appears these models can simulate the water formation associated with the mixed layer front (e.g., STMW) but cannot simulate the water formation resulting from the cross-isopycnal flow in the mixed layer (e.g., CMW, Suga et al., 2004), an important contributor to interannual to decadal variability of the North Pacific. Our analysis confirms the excess formation of STMW results in the deeper MLD (e.g., FSU and ICTP-MOM) due to the inaccurate Kuroshio separation associated with the excess warm and salty Kuroshio water. In particular, potential temperature biases dominate the changes in density. However, the great diversity of model results complicates our interpretation of the model biases related to the formation of CMW due to compensating effects of potential temperature and salinity. Model resolution seems not to be critical because no significant differences can be found in the $0.25^{\circ}$ KIEL-R025 model.

All models confirm the NPIW origin in the high latitude of Western North Pacific, however, they do not agree well on the origin of NPIW from the Okhotsk Sea. Even with the same NEMO model (but different versions), the PV distribution in the Subarctic Pacific can differ greatly among CERFACS (or CNRM) and CMCC. The influence of the distribution of sea-ice may be a key contributor and further investigation of the Arctic and the subarctic North Pacific is required. The recently proposed origin of NPIW in the broad area between the subtropical and subarctic gyres (You, 2010) is also supported by some models. Nevertheless, the pathways of NPIW vary among these models, which are aligned with their own large-scale circulation routes. Note that the spreading of AAIW into the North Pacific is evident in all models. However, the meridional extent also varies significantly among models. 
4. Finally, the mean tropical dynamics are carefully assessed among the models. All CORE-II simulations generate similar, large scale tropical structures of EUC and SEC, but the EUC varies in terms of speed, depth, vertical and meridional extension. Interestingly, the ensemble mean of the maximum speed is $94 \pm 11 \mathrm{~cm} \mathrm{~s}^{-1}$, which is weaker than the observed $110 \mathrm{~cm} \mathrm{~s}^{-1}$ for the same period. Similar to the CORE-II simulations analysis for the North Atlantic (Danabasoglu et al., 2014), we cannot find an obvious grouping of the models based on their ocean model lineage or vertical coordinate systems. However, our results confirm the key role of the meridional gradient of the wind stress curl in the equatorial transport (Yu et al., 2000; Kessler et al., 2003). The overall weak Sverdrup transport (approximately a half of the value estimated by the satellite winds) due to the inaccurate CORE-II wind forcing is a major contribution of the weak NECC and SEC in all models. This discrepancy has also been noticed recently in its impact on the ENSO variability so that the NOAA-CIRES $20^{\text {th }}$ century Reanalysis wind field has been attempted to merge into the CORE-II forcing near the equator.

The STCs can be found in all models. In nature, the Southern Hemisphere produces the largest equatorward transport anomaly at $10^{\circ} \mathrm{S}$ where most models show similar mean transport. However, most models show a larger interior STCs transport than the observations due to the overestimated Northern Hemispheric transport. The variation of STCs, mainly forced by the WSC (McCreary and Lu, 1994), is a major driver of Pacific climate variability.

This study provides a detailed evaluation of CORE-II ocean-ice simulations for the mean properties of the North and equatorial Pacific dynamics, a useful guideline for the follow-on study on the interannual and decadal variability of the Pacific dynamics. The presence of high pycnocline variability in the subtropical Pacific is highly related to the Rossby wave activity, which is characterized by a large fraction of energy at decadal time scales (Capotondi and Alexander, 2001; Capotondi et al., 2003). The missing decadal trend of Kuroshio transport in all model results (Fig. 7) also requires further attention at the interannual and decadal scales. Using two configurations $\left(0.25^{\circ}\right.$ and $\left.1^{\circ}\right)$ of GFDL-MOM and ICTP models, Farneti et al. (2014) have shown that the observed variability of 
equatorial SST anomalies can be well simulated and linked with the STC variation over the last 60 years of the CORE-II forcing period. They also confirmed that the subtropical winds drive the decadal to multi-decadal evolution of the STC associated with the equatorial SST change. The Pacific Ocean plays an important, but still not clear, role in tropical-subtropical interaction. More analysis, and comparison of the interannual to decadal variability of the Pacific using CORE-II forcing experiments, will be the subject next.

\section{Acknowledgments}

We thank the constructive and critical comments from Dr. Antonietta Capotondi, Dr. Billy Kessler and four anonymous reviewers, which greatly improved the manuscript. The support and help from the editor Will Perrie are also appreciated. NCAR is sponsored by the U. S. National Science Foundation (NSF). The CESM is supported by the NSF and the U. S. Department of Energy. Y. H. Tseng was partially supported by the NSF Earth System Model (EaSM) Grant 1419292 (EaSM-3: Collaborative Research: Quantifying Predictability Limits, Uncertainties, Mechanisms, and Regional Impacts of Pacific Decadal Climate Variability). The AWI contribution is supported by the German Helmholtz Climate Initiative REKLIM (Regional Climate Change) project. The BERGEN contribution is supported by the Research Council of Norway through the EarthClim (207711/E10) and NOTUR/NorStore projects, as well as the Centre for Climate Dynamics at the Bjerknes Centre for Climate Research. CCLICS contribution is supported by the the National Science Council, Taiwan, under the Consortium for Climate Change Study (CCliCS) project of NSC-100-2119-M-001-029-MY5. The CMCC contribution received funding from the Italian Ministry of Education, University, and Research and the Italian Ministry of Environment, Land, and Sea under the GEMINA project. The GEOMAR integrations were performed at the North-German Supercomputing Alliance (HLRN). L. Patara was financially supported by the Cluster of Excellence 'The Future Ocean' funded within the framework of the Excellence Initiative by the DFG. Finally, we thank both the international CLIVAR and U.S. CLIVAR projects for patiently sponsoring the Ocean Model Development Panel (OMDP; formally Working Groups on Ocean Model Development) over the years as COREs were developed. 
1039 Appendix A: Glossary of Acronyms

\begin{tabular}{|l|l|}
\hline AAIW & Antarctic Intermediate Water \\
\hline CMW & Central Mode Water \\
\hline CORE-II & Coordinated Ocean-ice Reference Experiments \\
\hline ECS & East China Sea \\
\hline ENSO & El Niño Southern Oscillation \\
\hline ESMW & Eastern Subtropical Mode Water \\
\hline EUC & Equatorial Undercurrent \\
\hline KCS & Kuroshio Current System \\
\hline KOE & Kuroshio/Oyashio Extension \\
\hline KT & Kuroshio Transport \\
\hline MLD & Mixed Layer Depth \\
\hline MWR & Mixed Water Region \\
\hline NECC & North Equatorial Counter Current \\
\hline NPIW & North Pacific Intermediate Water \\
\hline PN & Pollution Nagasaki \\
\hline PV & Potential Vorticity \\
\hline RMSD & Root-mean-square difference \\
\hline SEC & South Equatorial Currents \\
\hline SSH & Sea Surface Height \\
\hline SST & Sea Surface Temperature \\
\hline STMW & Subtropical Mode Water \\
\hline WOA09 & World Ocean Atlas 2009 \\
\hline WSC & Wind Stress Curl \\
\hline
\end{tabular}


Appendix B: Description of CCLICS

The CCLICS contribution uses the CESM1.0.4 framework, but the CESM ocean 1045 component has been replaced by the parallel domain-decomposed Taiwan Multi-scale 1046 Community Ocean Model (TIMCOM, Tseng and Chien, 2011; Young et al., 2012). The domain 1047 covers $86^{\circ} \mathrm{S}$ to $90^{\circ} \mathrm{N}$, where a symmetric boundary condition is imposed at North Pole rather 1048 than the commonly used displaced grids. Therefore, the North Pole is treated as an infinitely 1049 small circle which exchanges the northern boundary condition across the Pole symmetrically. 1050 The surface salinity is restored to the Polar Science Center Hydrographic Climatology (PHC) 1051 version 3 (updated from Steele et al., 2001) using an equivalent three-year time scale over $50 \mathrm{~m}$. 1052 The TIMCOM ocean model uses a fourth-order spatial approximation combining Arakawa A1053 and C-grids with fixed resolution along the zonal-direction (1.125 $)$ and variable resolution along 1054 the meridional-direction (approximately $0.3^{\circ}$ near the equator and about $1.0^{\circ}$ at high latitudes). 1055 The vertical resolution is a linear-exponentially stretched grid of 40 levels with a thickness of 1056 roughly $10 \mathrm{~m}$ at the top and $760 \mathrm{~m}$ in the abyssal ocean.

1057 The vertical mixing is based on the K-Profile Parameterization (Large et al., 1994) with a 1058 critical Richardson number of 0.3, as modified by Danabasoglu et al. (2006), with a latitudinally 1059 varying background diffusivity. A constant background vertical diffusivity $\left(1.6 \times 10^{-5} \mathrm{~m}^{2} \mathrm{~s}^{-1}\right)$ is 1060 locally enhanced by the tidal dissipation scheme of Simmons et al. (2004). The horizontal eddy 1061 viscosity/diffusivity is uniformly 200/40 $\mathrm{m}^{2} \mathrm{~s}^{-1}$ with enhanced values at the upper ocean and the 1062 equatorial region. There is no other subgrid scale parameterization or Laplacian operator on the 1063 momentum and tracer equations. The model is integrated using a modified Robert-Asselin1064 Williams filtered leapfrog scheme with a time step of 8 minutes (Williams, 2009; Young et al., 1065 2014). The small time step is required mainly due to the Courant-Friedrichs-Levy condition in 1066 the Arctic. The sea-ice model is the same as the LANL sea-ice model (CICE4; Hunke and 1067 Lipscomb, 2008) used in the CESM. It runs on the same horizontal grid as the ocean with a time 1068 step of 1 hour. 
1074 Deaseasonalization: the observational and model time series are "deseasonalized" prior to 1075 analysis (e.g., calculating the variance). This simply means removing the annual cycle, and $p$ 1076 higher frequency harmonics, by the least squares method. Specifically we express the 1077 observation/model for time $t$ as follows:

$$
x_{t}=\beta_{0}+\sum_{k=1}^{p+1} \beta_{i}^{c} \cos (\omega k t)+\beta_{i}^{s} \sin (\omega k t)+e_{t}
$$

1079 where $\beta$ are regression coefficients to be estimated by the least squares method from the grid 1080 point time series, $\omega$ corresponds to a period of one inverse time year, $p$ is the number of 1081 harmonics of the annual cycle to be removed, and $e$ denotes the deseasonalized version of $x$. The 1082 number of harmonics and the time span of the grid point time series are given in the main body 1083 of the text.

Skewness: This is a nondimensional measure of the asymmetry of a probability density function 1086 (pdf) of a random variable. It is defined by

1088 where $E$ denotes the expectation operator, and $\sigma, \mu$ and $f(x)$ denote the standard deviation, mean, 1089 and pdf of the random variable respectively. A similar formula holds for the sample skewness 1090 calculated from a set of observations: expectation is replaced by an average and $\mu$ and $\sigma$ are 1091 replaced by the sample mean and sample standard deviation. If the pdf (or histogram) has an 1092 extended tail to the right, the skewness will be positive, and vice versa. Thompson and Demirov 1093 (2006) showed that skewness of SSH can be used to identify the mean path of unstable ocean jets 1094 and, like the variance of SSH, is a potentially powerful diagnostic for testing the realism of ocean 1095 circulation models.

1096

1097 Taylor diagrams: Taylor (2001) proposed a useful way of summarizing the performance of 1098 multiple models in a single diagram. Let $\left\{x_{i}, y_{i} \mid i=1, \ldots, n\right\}$ denote a bivariate dataset and denote 
1099 the sample correlation of the two components by $r$, the standard deviation of their differences $1100\left\{x_{i}-y_{i} \mid i=1, \ldots, n\right\}$ by $s_{d}$, and the ratio of their standard deviations by $s_{x} / s_{y}$. In the present 1101 study, we will take $\left\{x_{i} \mid i=1, \ldots, n\right\}$ to be the $n$ grid point values predicted by a model, and $1102\left\{y_{i} \mid i=1, \ldots, n\right\}$ to be the co-located values from an observed climatology (both are normalized by 1103 the observed climatology). In this situation $r$ measures the correlation between the two gridded 1104 fields, $s_{d}$ is the standard deviation of the observation-model values at the $n$ grid points, and $1105 s_{x}^{2} / s_{y}^{2}$ compares the variability of the two fields. A model that fits the observations well would 1106 have $r$ and $s_{x}^{2} / s_{y}^{2}$ close to 1 , and $s_{d}$ close to zero. The important point noted by Taylor is that 1107 these three statistics are not independent $\left(s_{d}^{2}=s_{x}^{2}+s_{y}^{2}-2 s_{y} s_{y} r\right)$ and all three statistics can be 1108 conveniently displayed in a single, two-dimensional plot (the so-called Taylor diagram). The top 1109 left panel of Figure 2 is an example of a Taylor diagram. It compares the mean dynamic 1110 topography of 15 models with an observed topography calculated from altimeter and gravity 1111 observations. Each point corresponds to a particular model. The correlation between the 1112 observed climatology and the model output is given by the angle measured clockwise from the y1113 axis. The standard deviation ratio is given by radial distance from the origin. The RMSD 1114 between the observed and modeled grid point values, normalized by the standard deviation of the 1115 observations, is shown by radial distance from the point $(1,0)$. The closer the point to $(1,0)$ the 1116 closer the fit of the model to the observed mean dynamic topography. Taylor diagrams are used 1117 in this study because they provide a convenient way of comparing the performance of multiple 1118 models, measured by the above three statistics, in a single plot. 


\section{Table 1: Summary of the model configurations}

\begin{tabular}{|c|c|c|c|c|c|}
\hline Group & Ocean model & $\begin{array}{c}\text { Sea-ice } \\
\text { model }\end{array}$ & Vertical & Horiz. res. & $\begin{array}{c}\text { Min. dy in } \\
\text { tropics }\end{array}$ \\
\hline AWI & FESOM 1.4 & FESIM 2 & $z(46)$ & Nominal $1^{\circ}$ & $0.50^{\circ}$ \\
\hline BERGEN & MICOM & CICE 4 & $\rho(53)$ & Nominal $1^{\circ}$ & $0.25^{\circ}$ \\
\hline CCLICS & MUSOC & CICE 4 & $z(40)$ & Nominal 1.25 & $0.35^{\circ}$ \\
\hline CERFACS & NEMO 3.2 & LIM 2 & $z(42)$ & Nominal $1^{\circ}$ & $0.33^{\circ}$ \\
\hline CMCC & NEMO 3.3 & CICE 4 & $z(46)$ & Nominal $1^{\circ}$ & $0.33^{\circ}$ \\
\hline CNRM & NEMO 3.2 & Gelato 5 & $z(42)$ & Nominal $1^{\circ}$ & $0.33^{\circ}$ \\
\hline FSU & HYCOM 2.2 & CICE 5 & hybrid (32) & Nominal $1^{\circ}$ & $0.36^{\circ}$ \\
\hline GFDL-MOM & MOM 4p1 & SIS & $z^{*}(50)$ & Nominal $1^{\circ}$ & $0.33^{\circ}$ \\
\hline GFDL-GOLD & GOLD & SIS & $\rho(63)$ & Nominal $1^{\circ}$ & $0.38^{\circ}$ \\
\hline ICTP & MOM 4p1 & SIS & $z^{*}(30)$ & Nominal $2^{\circ}$ & $1.17^{\circ}$ \\
\hline KIEL-R025 & NEMO 3.4.1 & LIM 2 & $z(46)$ & Nominal 0.25 & $0.25^{\circ}$ \\
\hline KIEL-R050 & NEMO 3.1.1 & LIM 2 & $z(46)$ & Nominal 0.5 & $0.49^{\circ}$ \\
\hline MRI-ASSIM & MOVE/MRI.COM3 & MK89; CICE & $z(50)$ & $1^{\circ}$ (lon.) $\times 0.5^{\circ}($ lat.) & $0.50^{\circ}$ \\
\hline MRI-FREE & MRICOM 3 & MK89; CICE & $z(50)$ & $1^{\circ}$ (lon.) $\times 0.5^{\circ}($ lat.) & $0.50^{\circ}$ \\
\hline NCAR & POP 2 & CICE 4 & $z(60)$ & Nominal $1^{\circ}$ & $0.27^{\circ}$ \\
\hline
\end{tabular}


Table 2: Mean volume transport (in Sv) across selected sections. For PCM-1 and PN, the values in parentheses indicate the transport calculated along extended sections (to $128^{\circ} \mathrm{E}$ and $132^{\circ} \mathrm{E}$ for PCM-1 and PN respectively). For P09, the values in parentheses only take eastward flowing Kuroshio transport into account (Sugimoto et al., 2010). Different averaged periods are used in order to compare with the observation.

\begin{tabular}{cccc}
\hline & PCM-1 (1963-2007) & PN $(1963-2003)$ & P09 (1972-2007) \\
\hline AWI & $26.1(34.6)$ & $7.5(10.6)$ & $24.4(34.1)$ \\
BERGEN & $10.4(16.3)$ & $6.0(11.9)$ & $25.7(29.0)$ \\
\hline CCLICS & $10.2(19.1)$ & $2.2(19.1)$ & $27.8(41.4)$ \\
\hline CERFACS & $12.5(30.7)$ & $5.7(12.7)$ & $22.7(26.3)$ \\
CMCC & $17.7(30.3)$ & $11.8(10.1)$ & $21.1(25.0)$ \\
CNRM & $12.6(30.3)$ & $7.2(13.5)$ & $22.5(25.9)$ \\
\hline FSU & $20.9(29.1)$ & $12.3(15.5)$ & $29.5(59.0)$ \\
\hline GFDL-GOLD & $15.1(29.7)$ & $2.9(15.5)$ & $18.0(31.8)$ \\
\hline GFDL-MOM & $8.3(23.7)$ & $4.8(8.2)$ & $21.0(28.8)$ \\
\hline ICTP & $6.7(21.6)$ & $2.7(0.9)$ & $23.6(27.5)$ \\
KIEL-R025 & $30.9(33.6)$ & $13.9(18.9)$ & $26.8(45.9)$ \\
\hline KIEL-R050 & $25.7(31.8)$ & $7.2(9.4)$ & $29.4(34.6)$ \\
\hline MRI-ASSIM & $24.1(30.8)$ & $12.0(18.3)$ & $26.9(42.1)$ \\
\hline MRI-FREE & $21.7(28.7)$ & $11.0(16.1)$ & $25.3(31.0)$ \\
\hline NCAR & $10.6(24.1)$ & $6.3(11.7)$ & $26.1(30.7)$ \\
\hline Ensemble Mean & $16.4 \pm 7.5(27.4 \pm 5.5)$ & $7.2 \pm 3.7(12.4 \pm 4.7)$ & $24.6 \pm 3.3(33.7 \pm 9.4)$ \\
\hline OBS & $21.2 \pm 2.4$ & $24.1 \pm 3.4$ & $33.0(49.4)$ \\
\hline
\end{tabular}


Table 3: Mean PV along the $26.2 \sigma_{\theta}$ surface and mean March MLD averaged over three regions corresponding to the formation regions of CMW (A: $\left.180^{\circ}-160^{\circ} \mathrm{W}, 37^{\circ}-42^{\circ} \mathrm{N}\right)$, STMW(B: $155^{\circ} \mathrm{E}-$ $\left.180^{\circ}, 29^{\circ}-34^{\circ} \mathrm{N}\right)$ and the gap between them (C: $\left.180^{\circ}-170^{\circ} \mathrm{W}, 32^{\circ}-35^{\circ} \mathrm{N}\right)$.

\begin{tabular}{cccccccc}
\hline Mean PV & $\left(\mathbf{1 0} \mathbf{- 1 0}^{\mathbf{1 0}} \mathbf{~ m}^{\mathbf{- 1}} \mathbf{s}^{\mathbf{- 1}}\right)$ along & $\mathbf{2 6 . 2} \sigma_{\theta}$ & \multicolumn{3}{c}{ Mean March MLD (m) } \\
Region & $\mathbf{A}$ & $\mathbf{B}$ & $\mathbf{C}$ & Region & $\mathbf{A}$ & $\mathbf{B}$ & $\mathbf{C}$ \\
\hline AWI & 1.96 & 3.42 & 2.92 & AWI & 184 & 183 & 127 \\
BERGEN & 4.60 & 3.57 & 3.25 & BERGEN & 218 & 214 & 206 \\
CCLICS & 3.46 & 3.78 & 2.71 & CCLICS & 116 & 215 & 213 \\
CERFACS & 2.03 & 3.28 & 2.50 & CERFACS & 184 & 182 & 158 \\
CMCC & 2.44 & 3.11 & 2.29 & CMCC & 137 & 155 & 122 \\
CNRM & 1.98 & 3.29 & 2.56 & CNRM & 180 & 178 & 149 \\
FSU & 3.83 & 4.38 & 4.47 & FSU & 284 & 251 & 263 \\
GFDL-GOLD & 1.70 & 2.73 & 2.02 & GFDL-GOLD & 233 & 174 & 155 \\
GFDL-MOM & 2.25 & 2.93 & 2.71 & GFDL-MOM & 216 & 174 & 112 \\
ICTP & 2.72 & 3.50 & 3.54 & ICTP & 288 & 234 & 156 \\
KIEL-R025 & 2.08 & 2.81 & 2.58 & KIEL-R025 & 232 & 193 & 145 \\
KIEL-R050 & 1.80 & 2.78 & 2.19 & KIEL-R050 & 179 & 199 & 129 \\
MRI-ASSIM & 2.11 & 2.22 & 1.74 & MRI-ASSIM & 157 & 158 & 130 \\
MRI-FREE & 1.61 & 2.75 & 2.38 & MRI-FREE & 188 & 180 & 115 \\
NCAR & 1.91 & 2.23 & 1.74 & NCAR & 122 & 114 & 103 \\
WOA & 1.97 & 2.08 & 2.23 & WOA & 162 & 117 & 97 \\
\hline
\end{tabular}


Table 4: Maximum mean zonal velocity (in $\mathrm{m} \mathrm{s}^{-1}$ ) and corresponding depth (in $\mathrm{m}$ ) at the equator during 1986-2000.

\begin{tabular}{ccc}
\hline & Velocity & Depth \\
\hline AWI & 94 & 117 \\
BERGEN & 100 & 101 \\
CCLICS & 80 & 106 \\
CERFACS & 100 & 104 \\
CMCC & 104 & 95 \\
\hline CNRM & 104 & 105 \\
FSU & 95 & 115 \\
\hline GFDL-GOLD & 80 & 120 \\
GFDL-MOM & 87 & 119 \\
\hline ICTP & 96 & 110 \\
\hline KIEL-R025 & 109 & 114 \\
KIEL-R050 & 114 & 112 \\
MRI-ASSIM & 75 & 106 \\
MRI-FREE & 79 & 118 \\
\hline NCAR & 109 & 111 \\
Johnson (2002) & 111 & 86 \\
Ensemble Mean & $94 \pm 11$ & $113 \pm 7$ \\
\hline
\end{tabular}

Table 5: The eastward Sverdrup transport (in Sv) of NECC $\left(2^{\circ}-10^{\circ} \mathrm{N}\right)$ estimated using the wind stress on the model grid along $140^{\circ} \mathrm{W}$.

\begin{tabular}{|cc|}
\hline & Transport $\left(2^{\circ}-10^{\circ} \mathrm{N}\right)$ \\
\hline AWI & 4.3 \\
\hline CERGEN & 8.7 \\
\hline CERFACS & 11.2 \\
\hline CMCC & 9.7 \\
\hline CNRM & 8.7 \\
\hline FSU & 9.0 \\
\hline GFDL-GOLD & 7.6 \\
\hline GFDL-MOM & 5.9 \\
\hline ICTP & 4.8 \\
\hline KIEL-R025 & 4.1 \\
\hline KIEL-R050 & 11.6 \\
\hline MRI-ASSIM & 12.2 \\
\hline MRI-FREE & 7.1 \\
\hline NCAR & 7.7 \\
\hline OBS & 11.5 \\
\hline Ensemble Mean & 17.2 \\
\hline
\end{tabular}


Table 6: Mean meridional volume transports (in Sv) across two zonal sections resulting from western boundary (WB), Ekman (EK) and interior STCs. WB is defined from the east coast of Mindanao to $140^{\circ} \mathrm{E}$ for $9^{\circ} \mathrm{N}$ and from the coast of New Guinea to $160^{\circ} \mathrm{E}$ for $9^{\circ} \mathrm{S}$. The interior STCs is from $140^{\circ} \mathrm{E}$ to $80^{\circ} \mathrm{W}$ for $9^{\circ} \mathrm{N}$ and $160^{\circ} \mathrm{E}$ to $80^{\circ} \mathrm{W}$ for $9^{\circ} \mathrm{S}$. The interior STC convergence estimated from McPhaden and Zhang (2004) is $13.4 \pm 1.6$ Sv (07/1992-06/1998) and $24.1 \pm 1.8$ Sv (07/1998-06/2003), respectively.

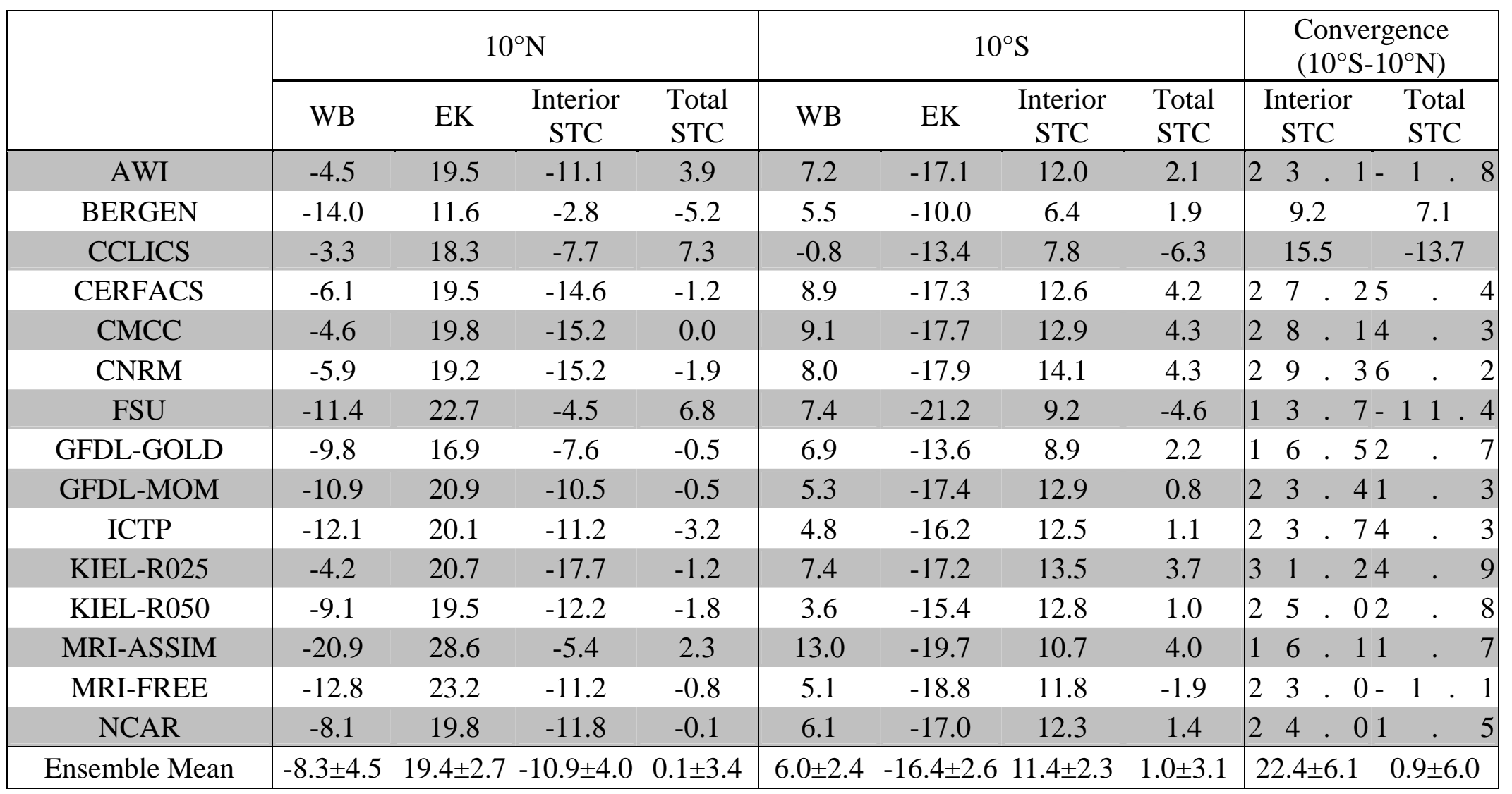


Figure 1: Schematic of the Pacific surface circulation and water mass distribution. Four sections referred to in the text (PCM-1, PN, P09 along $137^{\circ} \mathrm{E}$, and P13 along $\left.167^{\circ} \mathrm{E}\right)$ are shown from west to east. The color shading shows the bathymetry (in $\mathrm{m}$ ).

Figure 2: Comparison of spatial maps of the statistics of model output and observations using Taylor diagrams. The following statistics are compared: (a) mean, (c) standard deviation and (e) skewness of SSH, and (b) mean, (d) standard deviation and (f) skewness of SST. Radial distance of each point is the ratio of the standard deviation of the gridded statistics of one model and the observations. The azimuthal angle gives the corresponding correlation of the statistics of model output and observations Green arcs show the root-mean-square-differences (RMSD) of the gridded statistics of model output and observations.

Figure 3: Standard deviation of monthly sea level from 1993 to 2007 , between $100^{\circ} \mathrm{E}-70^{\circ} \mathrm{W}$ and $15^{\circ} \mathrm{S}-66^{\circ} \mathrm{N}$. The mean seasonal cycles are removed.

Figure 4: Skewness of monthly sea level from 1993 to 2007 , between $100^{\circ} \mathrm{E}-70^{\circ} \mathrm{W}$ and $15^{\circ} \mathrm{S}$ $66^{\circ} \mathrm{N}$. The mean seasonal cycles are removed.

Figure 5: Standard deviation of monthly SST from 1963 to 2007 , between $100^{\circ} \mathrm{E}-70^{\circ} \mathrm{W}$ and $15^{\circ} \mathrm{S}-66^{\circ} \mathrm{N}$. The mean seasonal cycles are removed.

Figure 6: Skewness of monthly SST from 1963 to 2007 , between $100^{\circ} \mathrm{E}-70^{\circ} \mathrm{W}$ and $15^{\circ} \mathrm{S}-66^{\circ} \mathrm{N}$. The mean seasonal cycles are removed.

Figure 7: Seasonal variation of volume transport across the PCM-1 section and the interannual variation of volume transport across the PN and P09 sections.

Figure 8: March-mean mixed layer depth. See text for procedure. The depths calculated from WOA09 are shown in the bottom left panel.

Figure 9: Scatter plots of the March-mean MLD against the corresponding potential temperature, salinity and density biases over the upper $400 \mathrm{~m}$ for regions A (top panel) and B (bottom panel) defined in Table 3. The corresponding linear regression lines along with the correlation coefficients are shown for comparison. The solid circle represents the observed MLD in WOA09.

Figure 10: Vertical cross section of salinity (color) and potential density (contour) along the P09 $\left(137^{\circ} \mathrm{E}\right)$ section. Contour interval is 0.5 . The $26.2 \sigma_{\theta}, 26.8 \sigma_{\theta}, 27.2 \sigma_{\theta}$ levels are shown as thick lines.

Figure 11: Vertical cross section of salinity (color) and potential density (contour) along the P13 $\left(165^{\circ} \mathrm{E}\right)$ section. Contour interval is 0.2. The $26.2 \sigma_{\theta}, 26.8 \sigma_{\theta}, 27.2 \sigma_{\theta}$ levels are shown as thick lines.

Figure 12: Distributions of potential vorticity (color; in $10^{-10} \mathrm{~m}^{-1} \mathrm{~s}^{-1}$ ) and depth (contour) on the $26.2 \sigma_{\theta}$ isopycnal surface.

Figure 13: Distributions of potential temperature (color) and salinity (contour) on the $26.2 \sigma_{\theta}$ isopycnal surface. 
Figure 14: Distributions of potential vorticity (color, in $10^{-10} \mathrm{~m}^{-1} \mathrm{~s}^{-1}$ ) and depth (contour) on the $26.8 \sigma_{\theta}$ isopycnal surface.

Figure 15: Distributions of potential temperature (color) and salinity (contour) on the $26.8 \sigma_{\theta}$ isopycnal surface. The contour interval is every 0.1 .

Figure 16: Distributions of potential vorticity (color, in $10^{-10} \mathrm{~m}^{-1} \mathrm{~s}^{-1}$ ) and depth (contour) on the $27.2 \sigma_{\theta}$ isopycnal surface. The contour interval is every $50 \mathrm{~m}$.

Figure 17: Distributions of potential temperature (color) and salinity (contour) on the $27.2 \sigma_{\theta}$ isopycnal surface. The contour interval is every 0.04 .

Figure 18: Mean zonal velocity (color, in $\mathrm{cm} \mathrm{s}^{-1}$ ) and potential density (black contours) along the equator from 1986 to 2000. The white line denotes the core depth of the EUC (defined as the depth of the maximum eastward velocity).

Figure 19: Mean zonal velocity in the central topical Pacific on a meridional section $\left(140^{\circ} \mathrm{W}\right)$ from 1963 to 2007.

Figure 20: Mean wind stress curl (curl $\tau$ ) in the tropics. The Scatterometer Climatology of Ocean Winds is shown at the bottom for comparison.

Figure 21: Vertically integrated zonal transport/unit width $\left(\mathrm{m}^{2} \mathrm{~s}^{-1}\right)$ from the Sverdrup balance. Red colors indicate eastward transport, blue colors westward.

Figure 22: Longitude-depth sections of time-mean meridional velocity (shading, in $\mathrm{m} \mathrm{s}^{-1}$ ) along $10^{\circ} \mathrm{N}$ with isopycnals (red line, in $\mathrm{kg} \mathrm{m}^{-3}$ ) from 1963 to 2007 . The isopycnals from WOA09 are also shown as dashed lines (22-26 $\left.\sigma_{\theta}\right)$ for comparison.

Figure 23: Same as Fig. 22 but along $10^{\circ} \mathrm{S}$. 


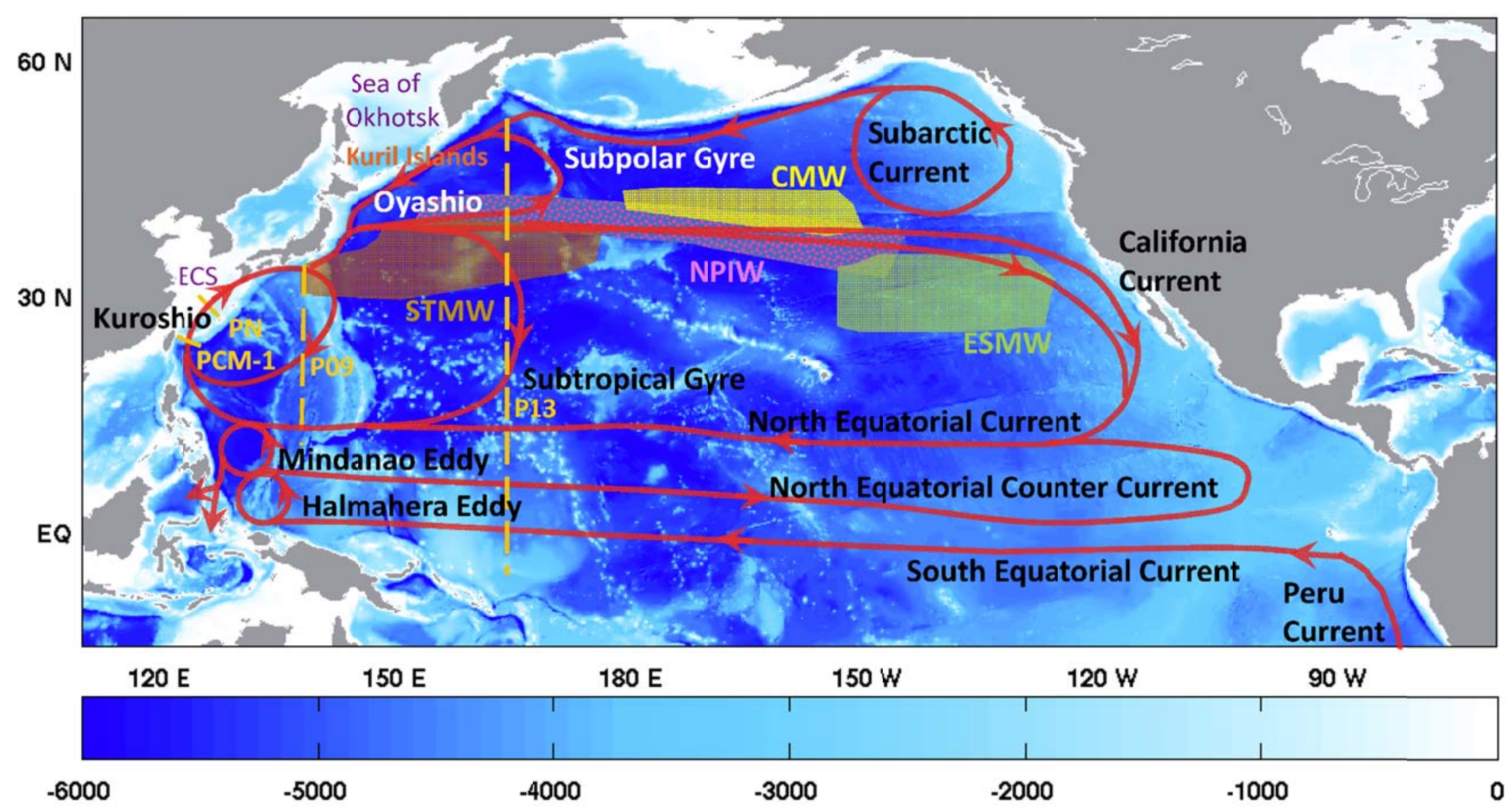

Figure 1: Schematic of the Pacific surface circulation and water mass distribution. Four sections referred to in the text (PCM-1, PN, P09 along $137^{\circ} \mathrm{E}$, and $\mathrm{P} 13$ along $167^{\circ} \mathrm{E}$ ) are shown from west to east. The color shading shows the bathymetry (in m). The Subtropical Counter Current appears east of Taiwan. 

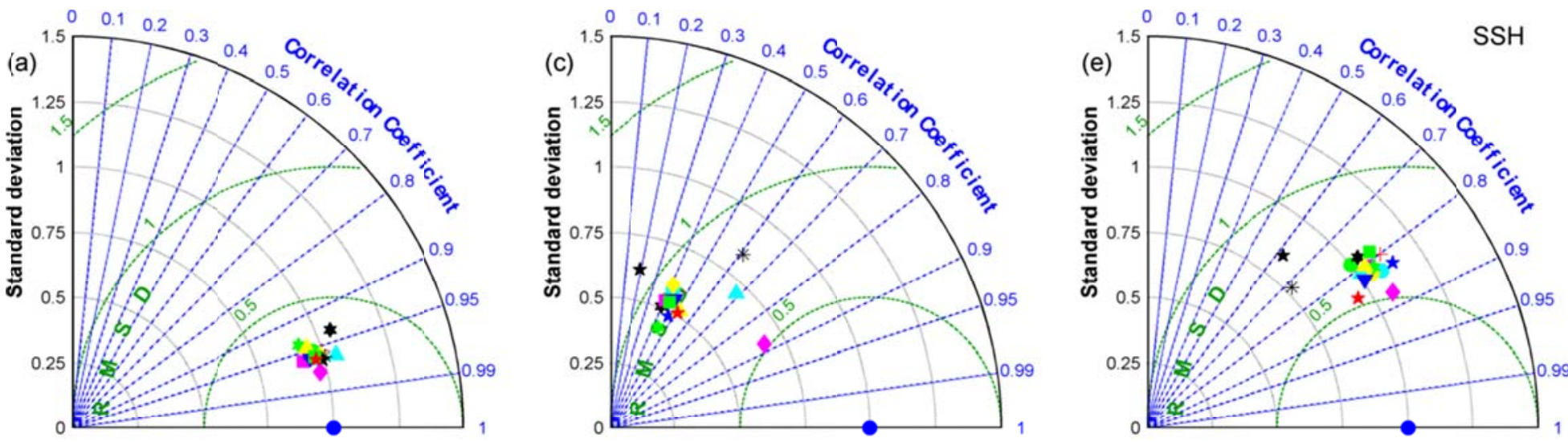

- OBS

$+\quad$ AWI

- BERGEN

* CClics

- CERFACS

- CMCC

CNRM

$\triangle$ FSU

v GFDL-GOLD
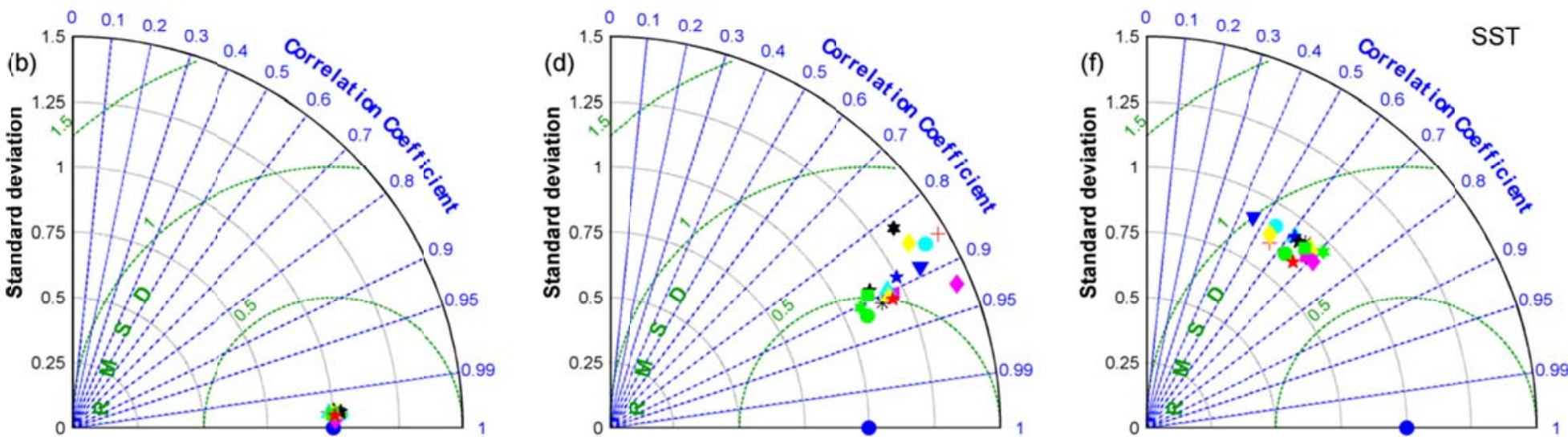

$\star$ GFDL-MOM

* ICTP

* KIEL-R025

^ KIEL-R050

- MRI-ASSIM

MRI-FREE

- NCAR

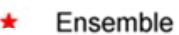

Figure 2: Comparison of spatial maps of the statistics of model output and observations using Taylor diagrams. The following statistics are compared: (a) mean, (c) standard deviation and (e) skewness of SSH, and (b) mean, (d) standard deviation and (f) skewness of SST. Radial distance of each point is the ratio of the standard deviation of the gridded statistics of one model and the observations. The azimuthal angle gives the corresponding correlation of the statistics of model output and observations. Green arcs show the root-meansquare-differences (RMSD) of the gridded statistics of model output and observations. 
AWI
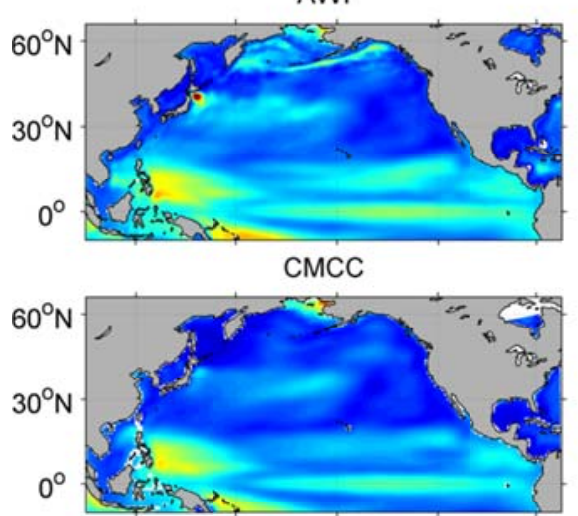

GFDL-MOM
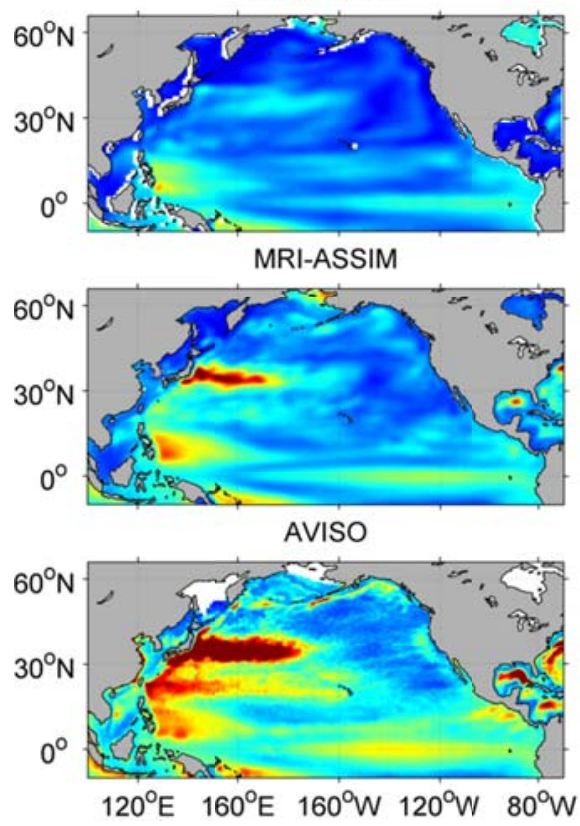

BERGEN

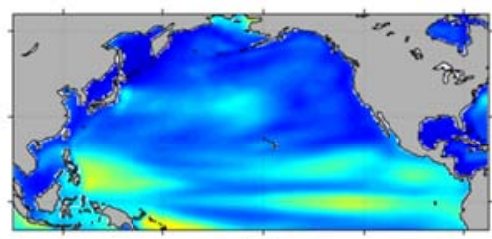

CNRM

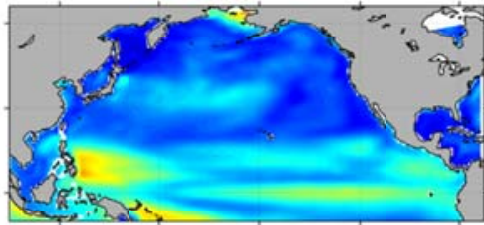

ICTP

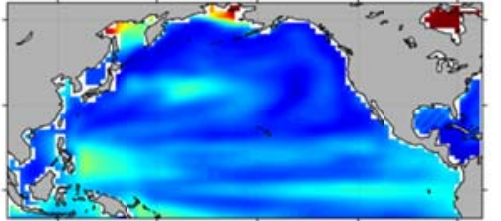

MRI-FREE

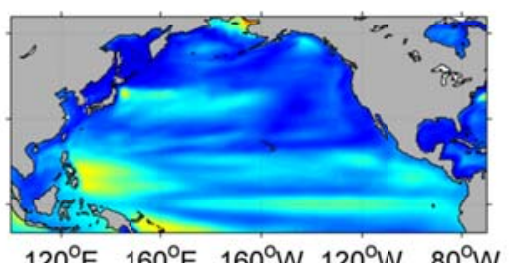

$120^{\circ} \mathrm{E} \quad 160^{\circ} \mathrm{E} \quad 160^{\circ} \mathrm{W} \quad 120^{\circ} \mathrm{W} \quad 80^{\circ} \mathrm{W}$
CCLICS

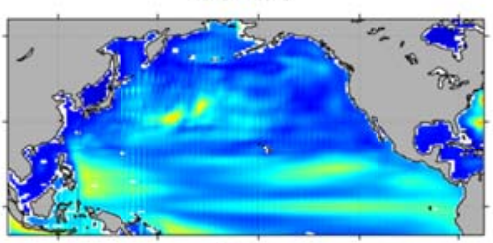

FSU

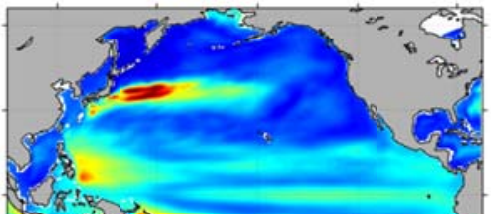

KIEL-R025

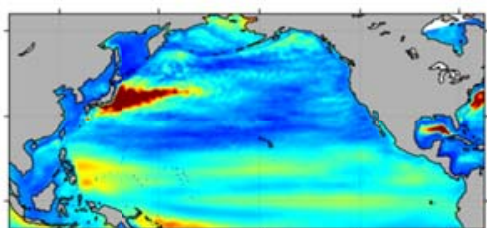

NCAR

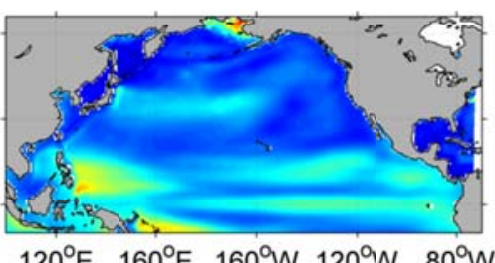

$120^{\circ} \mathrm{E} \quad 160^{\circ} \mathrm{E} \quad 160^{\circ} \mathrm{W} 120^{\circ} \mathrm{W} \quad 80^{\circ} \mathrm{W}$
CERFACS

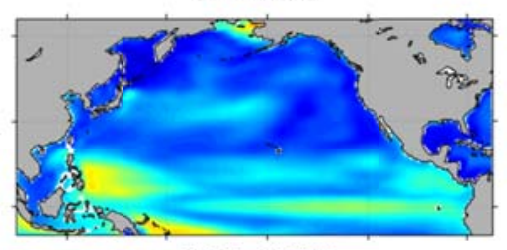

GFDL-GOLD

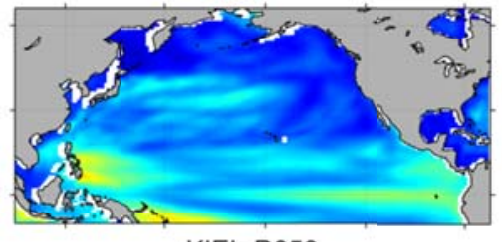

KIEL-R050

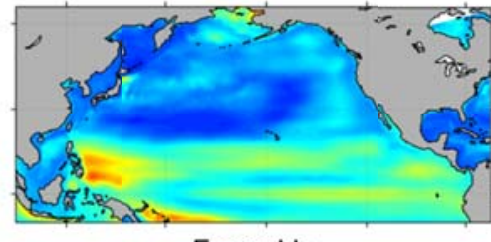

Ensemble

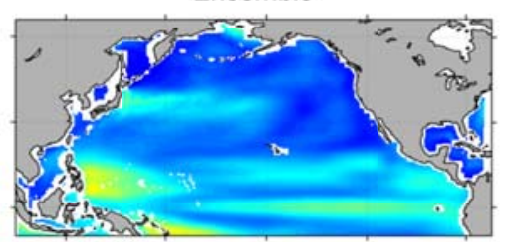

$120^{\circ} \mathrm{E} \quad 160^{\circ} \mathrm{E} \quad 160^{\circ} \mathrm{W} \quad 120^{\circ} \mathrm{W} \quad 80^{\circ} \mathrm{W}$

SSH Standard Deviation (cm)

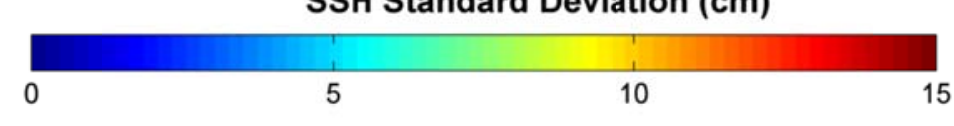

Figure 3: Standard deviation of monthly sea level from 1993 to 2007 , between $100^{\circ} \mathrm{E}-70^{\circ} \mathrm{W}$ and $15^{\circ} \mathrm{S}-66^{\circ} \mathrm{N}$. The mean seasonal cycles are removed. 


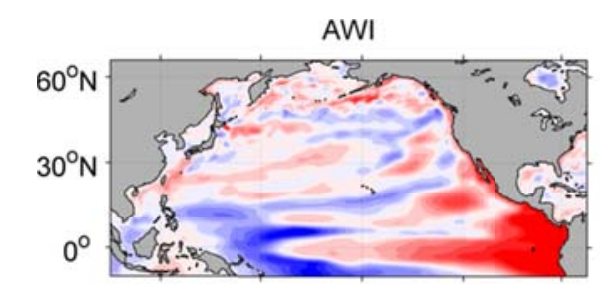

CMCC

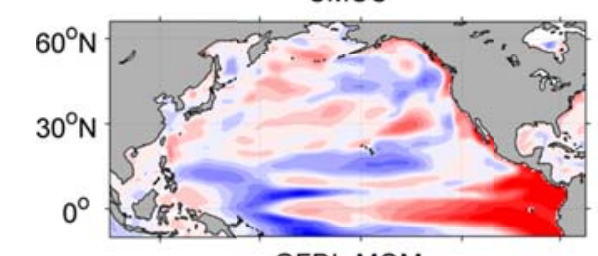

GFDL-MOM

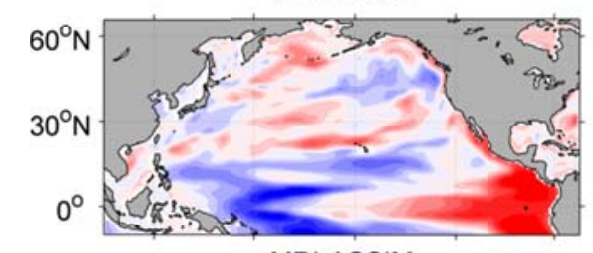

MRI-ASSIM

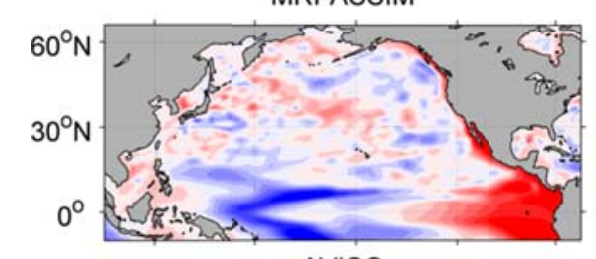

AVISO

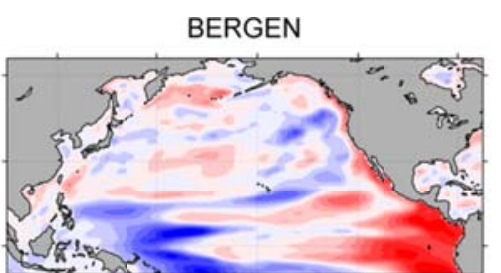

CNRM

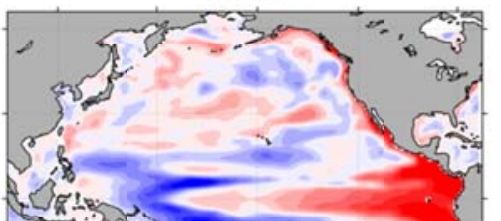

ICTP

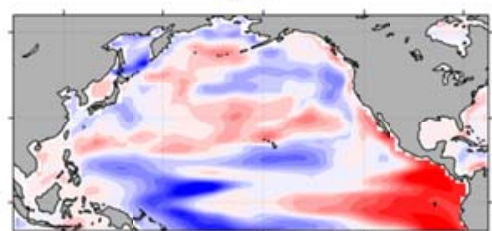

MRI-FREE

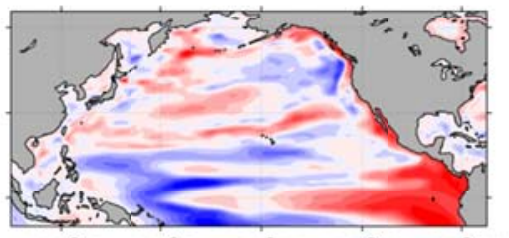

$120^{\circ} \mathrm{E} \quad 160^{\circ} \mathrm{E} \quad 160^{\circ} \mathrm{W} \quad 120^{\circ} \mathrm{W} \quad 80^{\circ} \mathrm{W}$

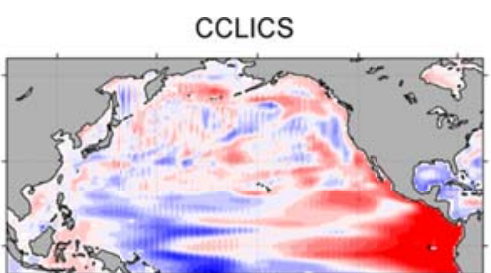

FSU

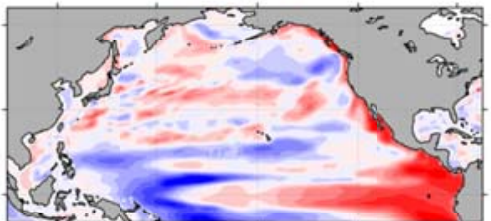

KIEL-R025

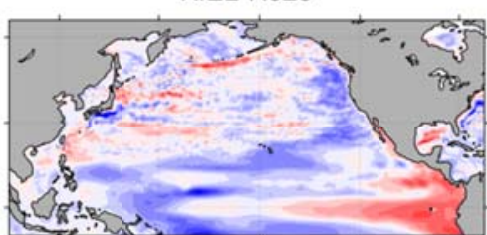

NCAR

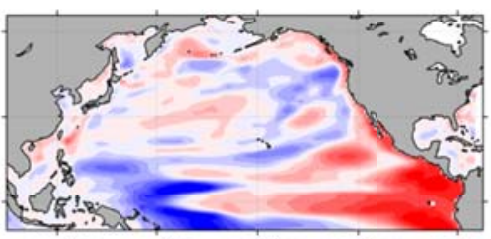

$120^{\circ} \mathrm{E} \quad 160^{\circ} \mathrm{E} \quad 160^{\circ} \mathrm{W} \quad 120^{\circ} \mathrm{W} \quad 80^{\circ} \mathrm{W}$

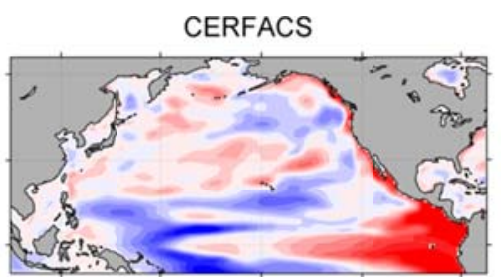

GFDL-GOLD

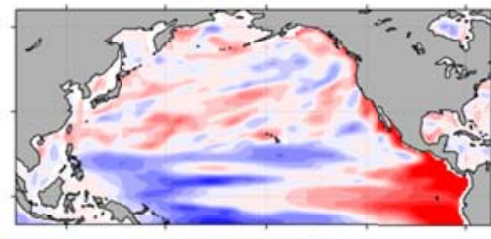

KIEL-R050

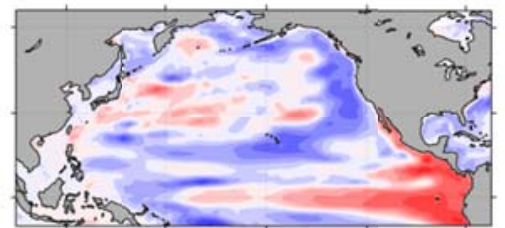

Ensemble

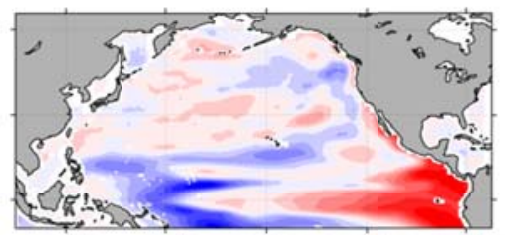

$120^{\circ} \mathrm{E} \quad 160^{\circ} \mathrm{E} \quad 160^{\circ} \mathrm{W} \quad 120^{\circ} \mathrm{W} \quad 80^{\circ} \mathrm{W}$

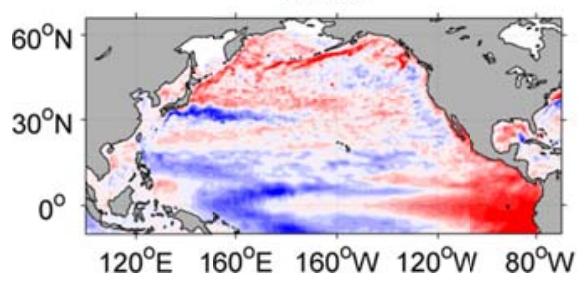

\section{SSH Skewness}

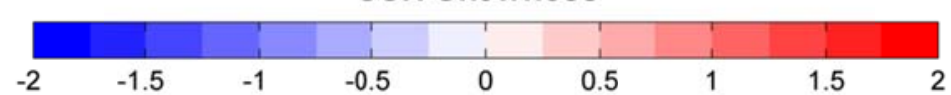

Figure 4: Skewness of monthly sea level from 1993 to 2007 , between $100^{\circ} \mathrm{E}-70^{\circ} \mathrm{W}$ and $15^{\circ} \mathrm{S}-66^{\circ} \mathrm{N}$. The mean seasonal cycles are removed. 
AWI
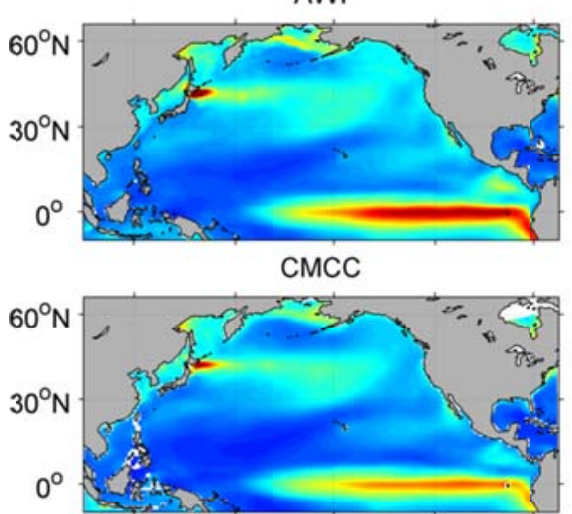

GFDL-MOM

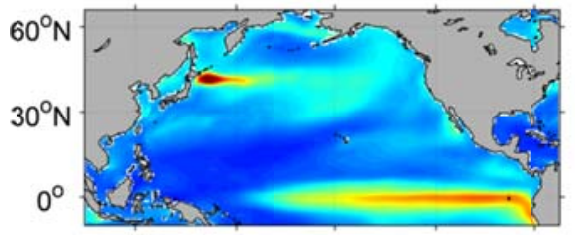

MRI-ASSIM

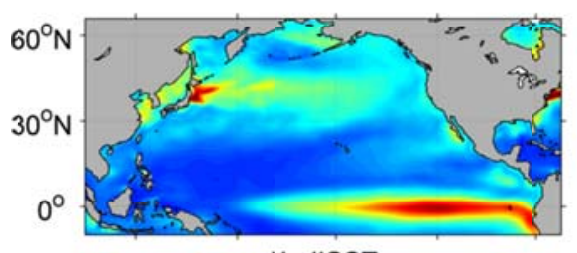

HadISST

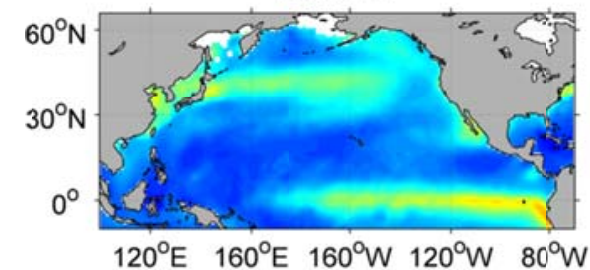

BERGEN

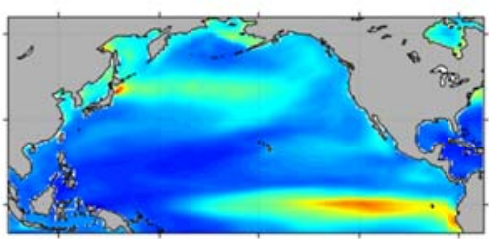

CNRM

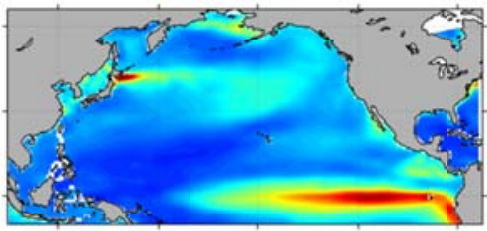

ICTP

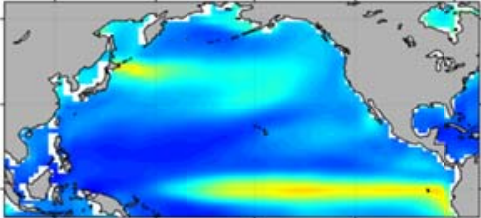

MRI-FREE

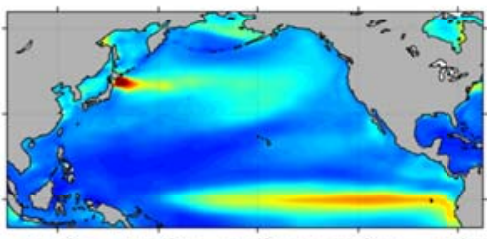

$120^{\circ} \mathrm{E} \quad 160^{\circ} \mathrm{E} \quad 160^{\circ} \mathrm{W} \quad 120^{\circ} \mathrm{W} \quad 80^{\circ} \mathrm{W}$
CCLICS

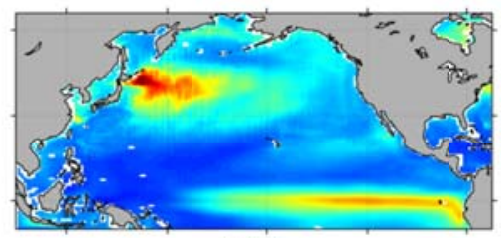

FSU

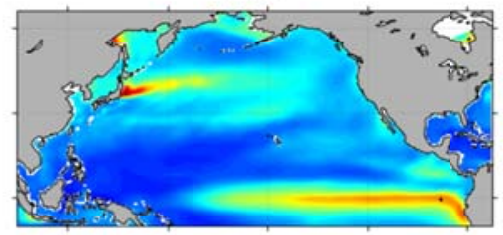

KIEL-R025

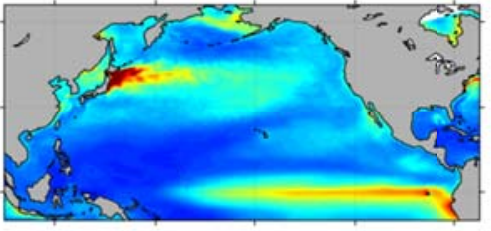

NCAR

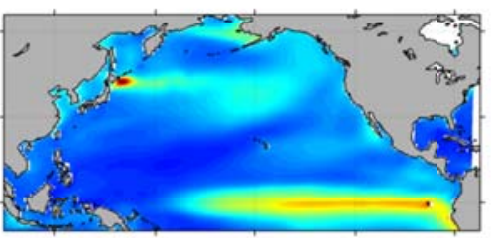

$120^{\circ} \mathrm{E} \quad 160^{\circ} \mathrm{E} \quad 160^{\circ} \mathrm{W} \quad 120^{\circ} \mathrm{W} \quad 80^{\circ} \mathrm{W}$
CERFACS

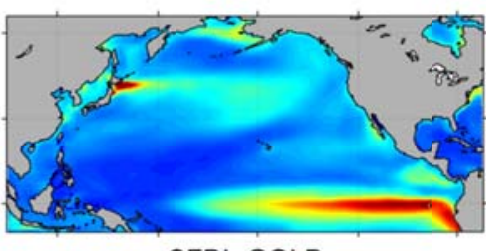

GFDL-GOLD

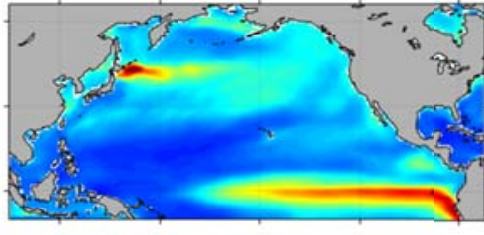

KIEL-R050

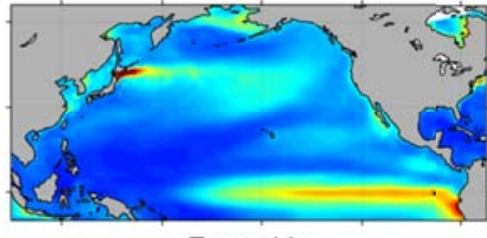

Ensemble

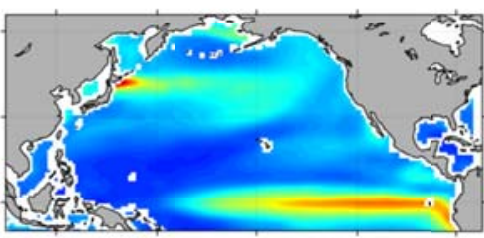

$120^{\circ} \mathrm{E} \quad 160^{\circ} \mathrm{E} \quad 160^{\circ} \mathrm{W} 120^{\circ} \mathrm{W} \quad 80^{\circ} \mathrm{W}$

SST Standard Deviation $\left({ }^{\circ} \mathrm{C}\right)$

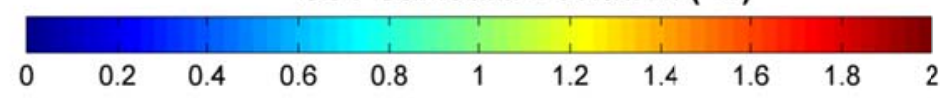

Figure 5: Standard deviation of monthly SST from 1963 to 2007 , between $100^{\circ} \mathrm{E}-70^{\circ} \mathrm{W}$ and $15^{\circ} \mathrm{S}-66^{\circ} \mathrm{N}$. The mean seasonal cycles are removed. 
AWI

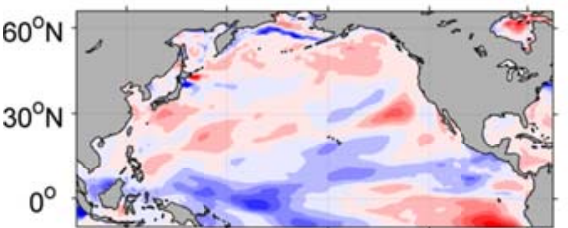

CMCC

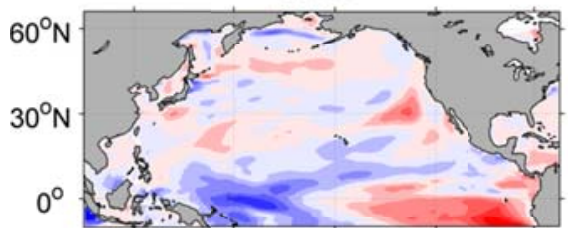

GFDL-MOM

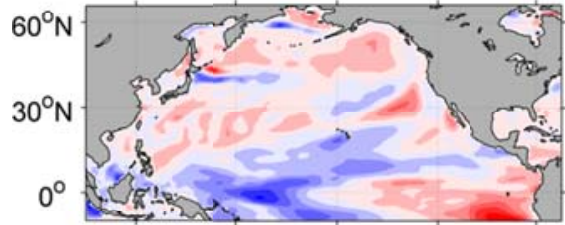

MRI-ASSIM

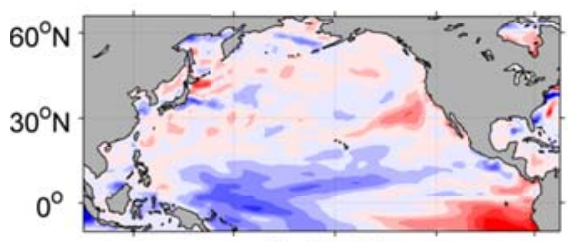

HadISST

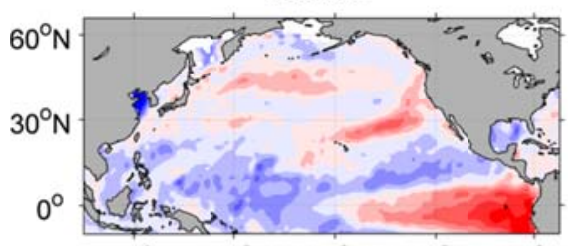

$120^{\circ} \mathrm{E} \quad 160^{\circ} \mathrm{E} \quad 160^{\circ} \mathrm{W} \quad 120^{\circ} \mathrm{W} \quad 80^{\circ} \mathrm{W}$
BERGEN

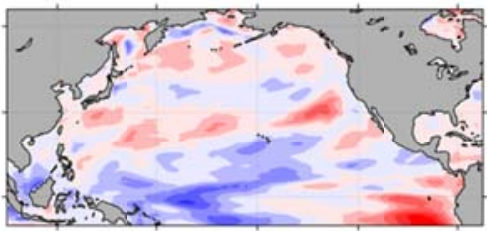

CNRM

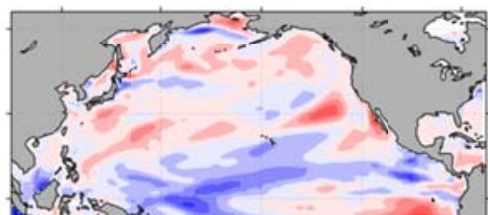

ICTP

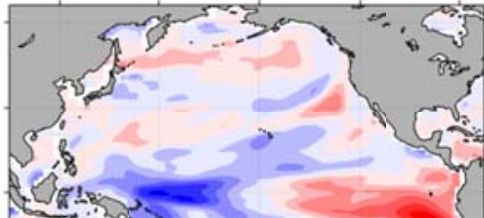

MRI-FREE

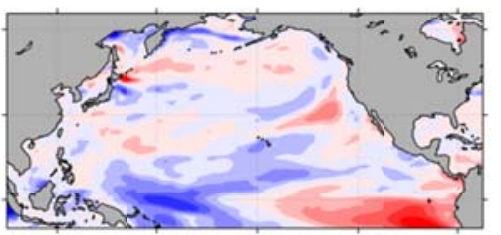

$120^{\circ} \mathrm{E} \quad 160^{\circ} \mathrm{E} \quad 160^{\circ} \mathrm{W} \quad 120^{\circ} \mathrm{W} \quad 80^{\circ} \mathrm{W}$
CCLICS

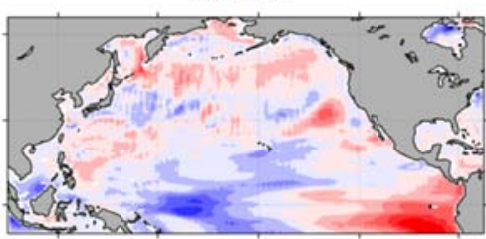

FSU

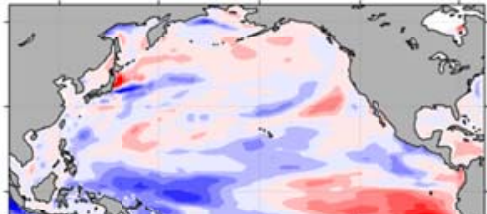

KIEL-R025

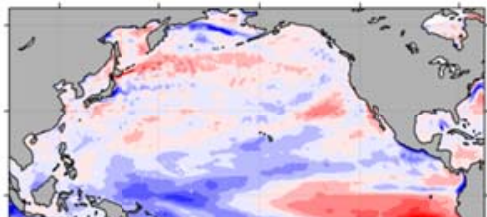

NCAR

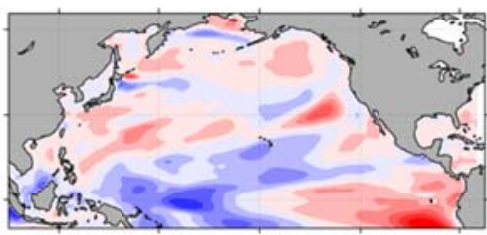

$120^{\circ} \mathrm{E} \quad 160^{\circ} \mathrm{E} \quad 160^{\circ} \mathrm{W} \quad 120^{\circ} \mathrm{W} \quad 80^{\circ} \mathrm{W}$

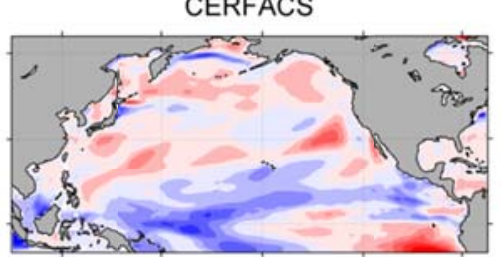

GFDL-GOLD

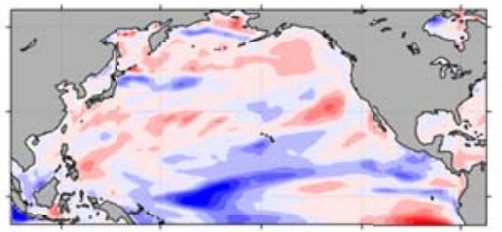

KIEL-R050

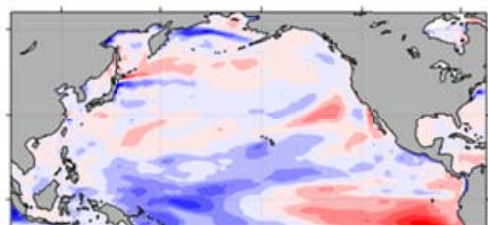

Ensemble

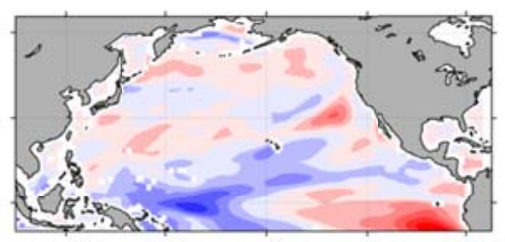

$120^{\circ} \mathrm{E} \quad 160^{\circ} \mathrm{E} \quad 160^{\circ} \mathrm{W} \quad 120^{\circ} \mathrm{W} \quad 80^{\circ} \mathrm{W}$

SST Skewness

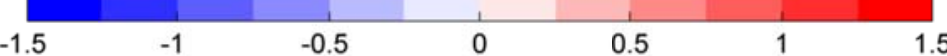

Figure 6: Skewness of monthly SST from 1963 to 2007 , between $100^{\circ} \mathrm{E}-70^{\circ} \mathrm{W}$ and $15^{\circ} \mathrm{S}-66^{\circ} \mathrm{N}$. The mean seasonal cycles are removed. 

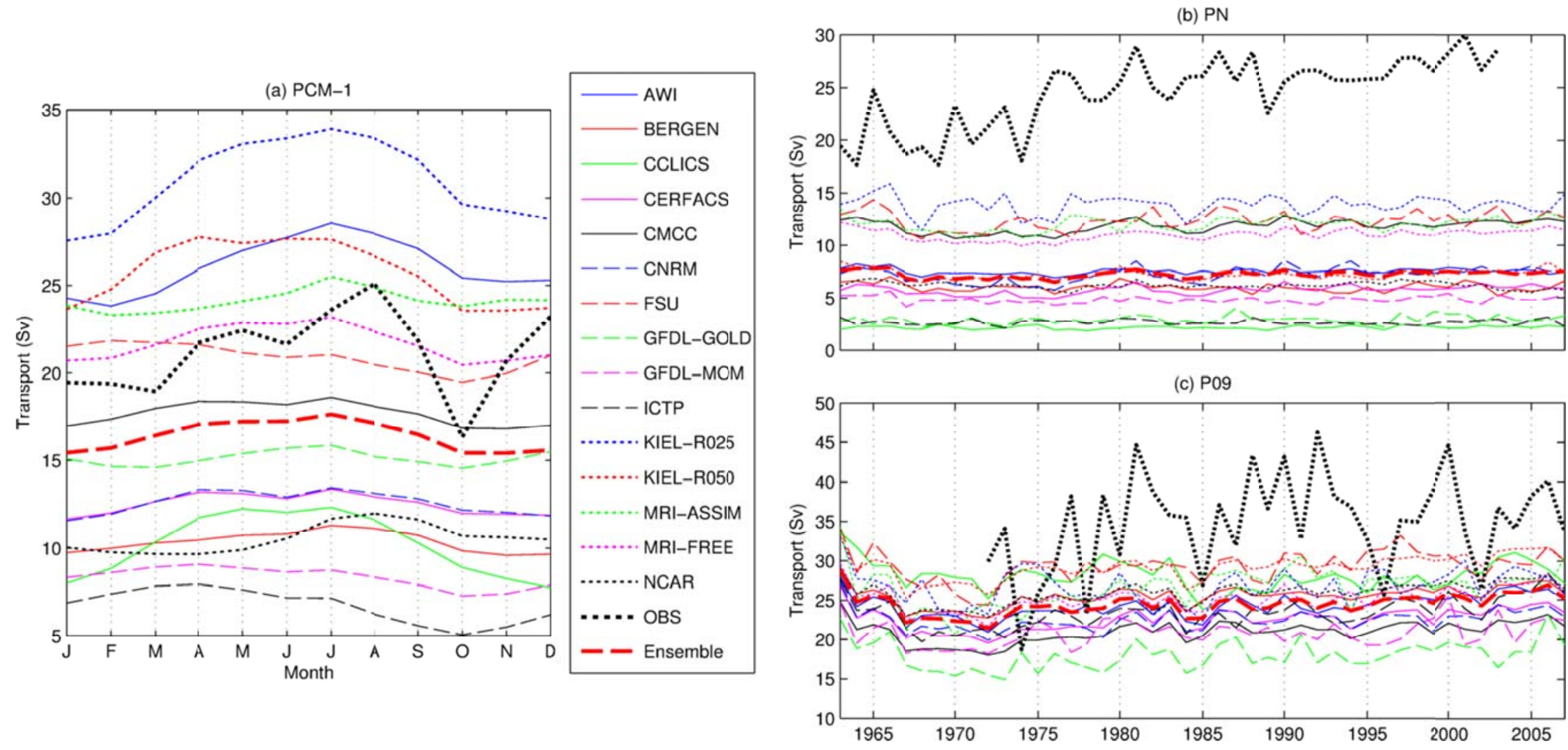

Figure 7: Seasonal variation of volume transport across the PCM-1 section and the interannual variation of volume transport across the PN and P09 sections. 
AWI

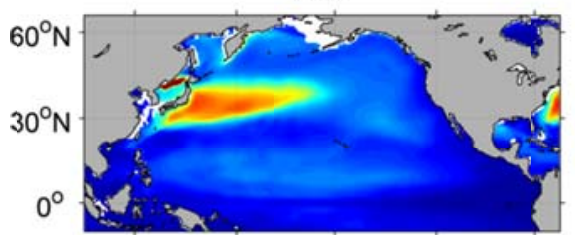

CMCC

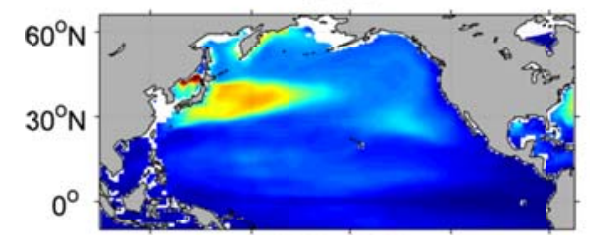

GFDL-MOM

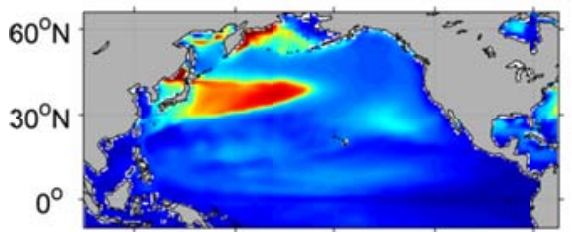

MRI-ASSIM

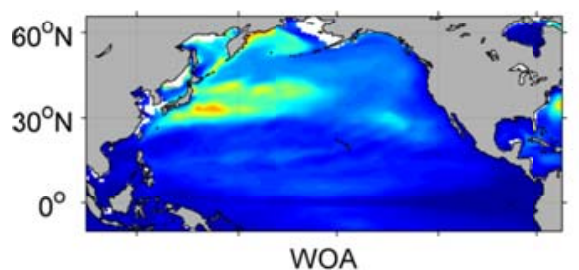

WOA

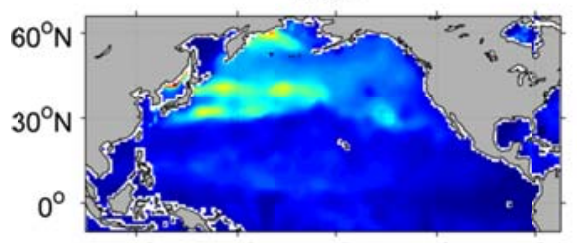

$120^{\circ} \mathrm{E} \quad 160^{\circ} \mathrm{E} \quad 160^{\circ} \mathrm{W} \quad 120^{\circ} \mathrm{W} \quad 80^{\circ} \mathrm{W}$
BERGEN

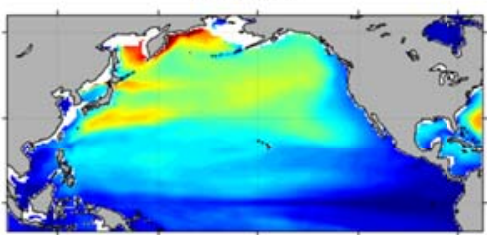

CNRM

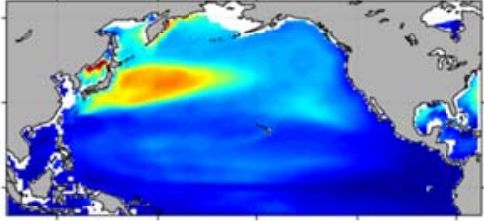

ICTP

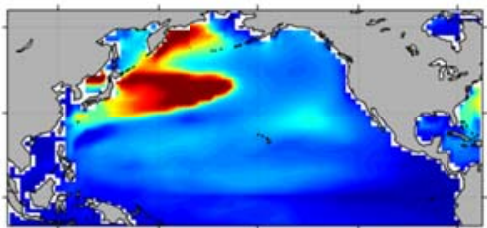

MRI-FREE

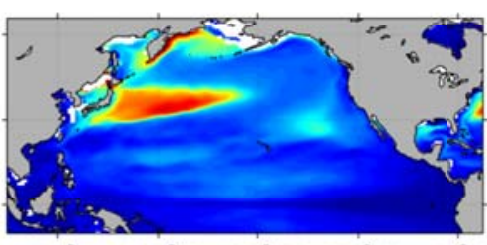

$120^{\circ} \mathrm{E} \quad 160^{\circ} \mathrm{E} \quad 160^{\circ} \mathrm{W} \quad 120^{\circ} \mathrm{W} \quad 80^{\circ} \mathrm{W}$
CCLICS

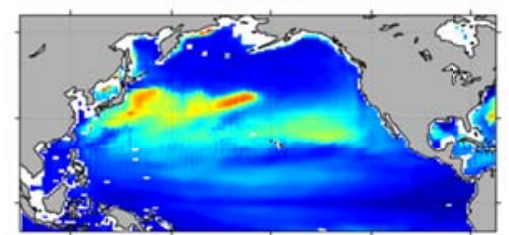

FSU

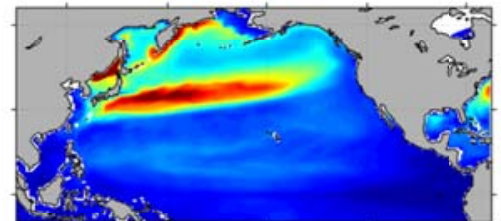

KIEL-R025

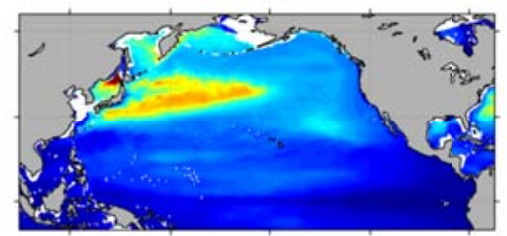

NCAR

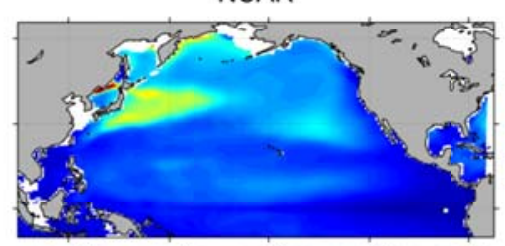

$120^{\circ} \mathrm{E} \quad 160^{\circ} \mathrm{E} \quad 160^{\circ} \mathrm{W} \quad 120^{\circ} \mathrm{W} \quad 80^{\circ} \mathrm{W}$

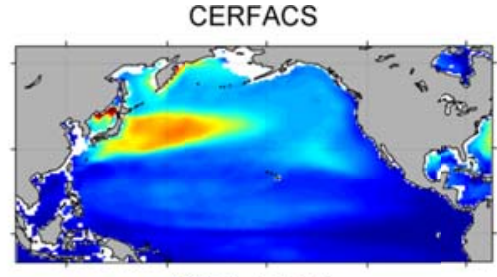

GFDL-GOLD

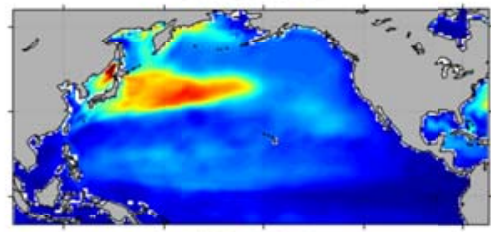

KIEL-R050

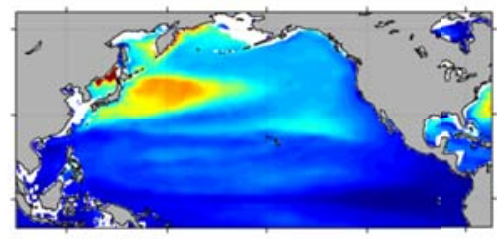

Ensemble

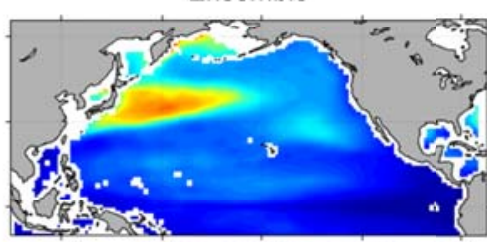

$120^{\circ} \mathrm{E} 160^{\circ} \mathrm{E} \quad 160^{\circ} \mathrm{W} 120^{\circ} \mathrm{W} \quad 80^{\circ} \mathrm{W}$

Figure 8: March-mean mixed layer depth. See text for procedure. The depths calculated from WOA09 are shown in the bottom left panel. 

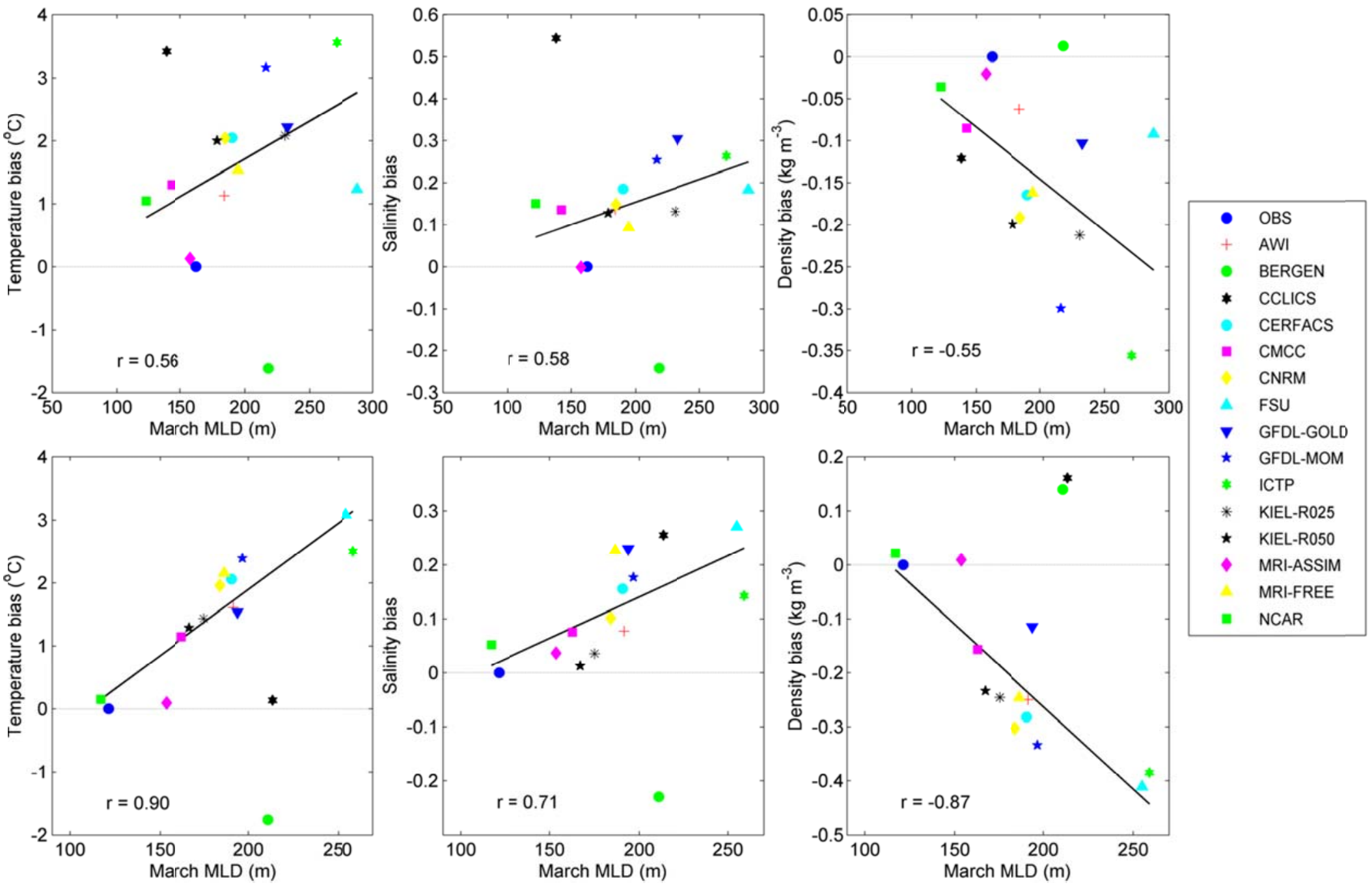

Figure 9: Scatter plots of the March-mean MLD against the corresponding potential temperature, salinity and density biases over the upper $400 \mathrm{~m}$ for regions A (top panel) and B (bottom panel) defined in Table 3. The corresponding linear regression lines along with the correlation coefficients are shown for comparison. The solid circle represents the observed MLD in WOA09. 

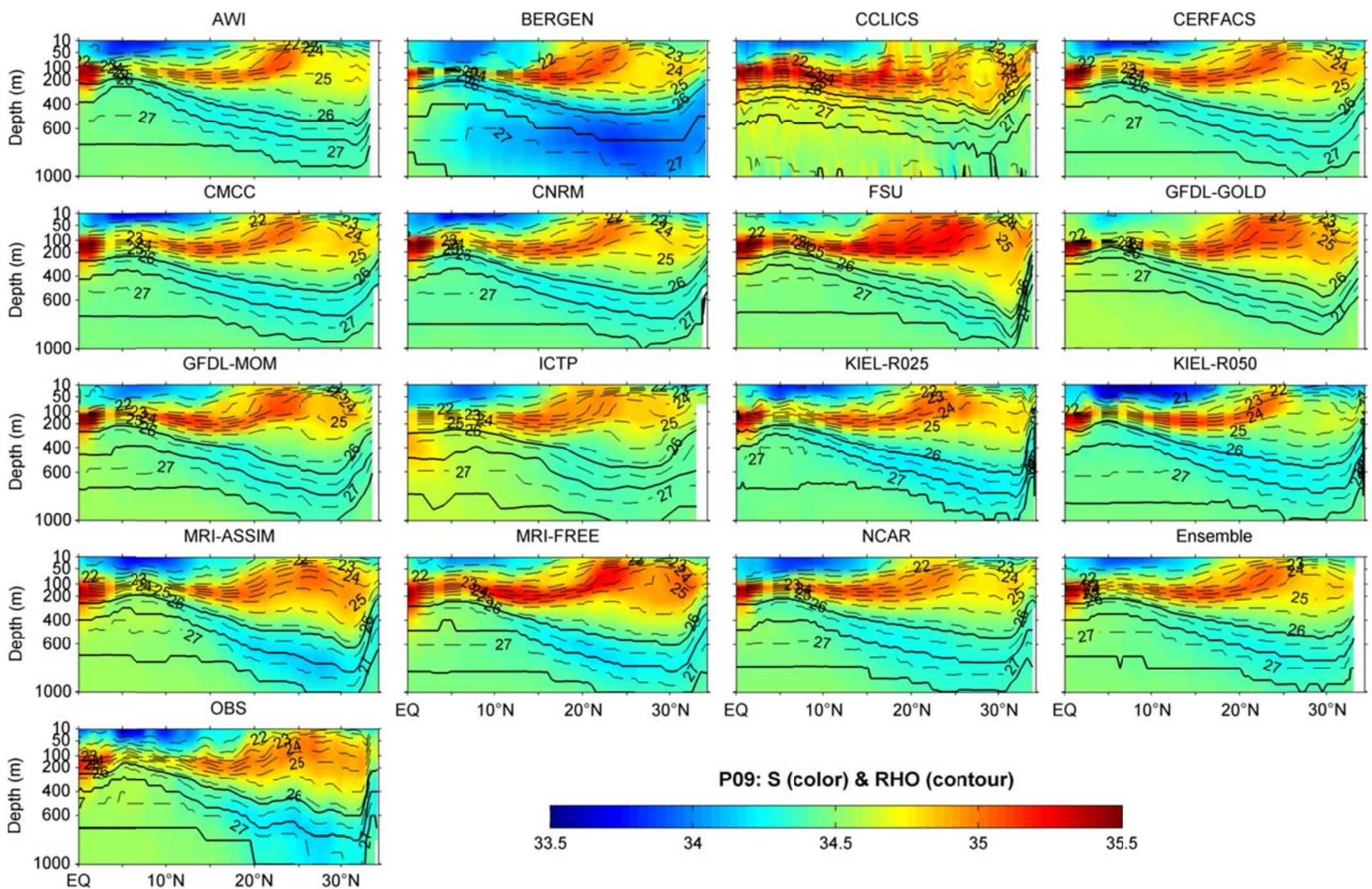

P09: S (color) \& RHO (contour)

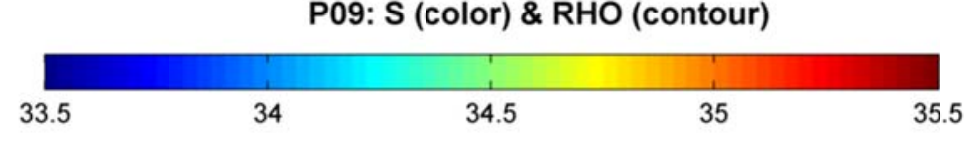

Figure 10: Vertical cross section of salinity (color) and potential density (contour) along the P09 (137 ${ }^{\circ}$ E) section. Contour interval is 0.5. The $26.2 \sigma_{\theta}, 26.8 \sigma_{\theta}, 27.2 \sigma_{\theta}$ levels are shown as thick lines. 

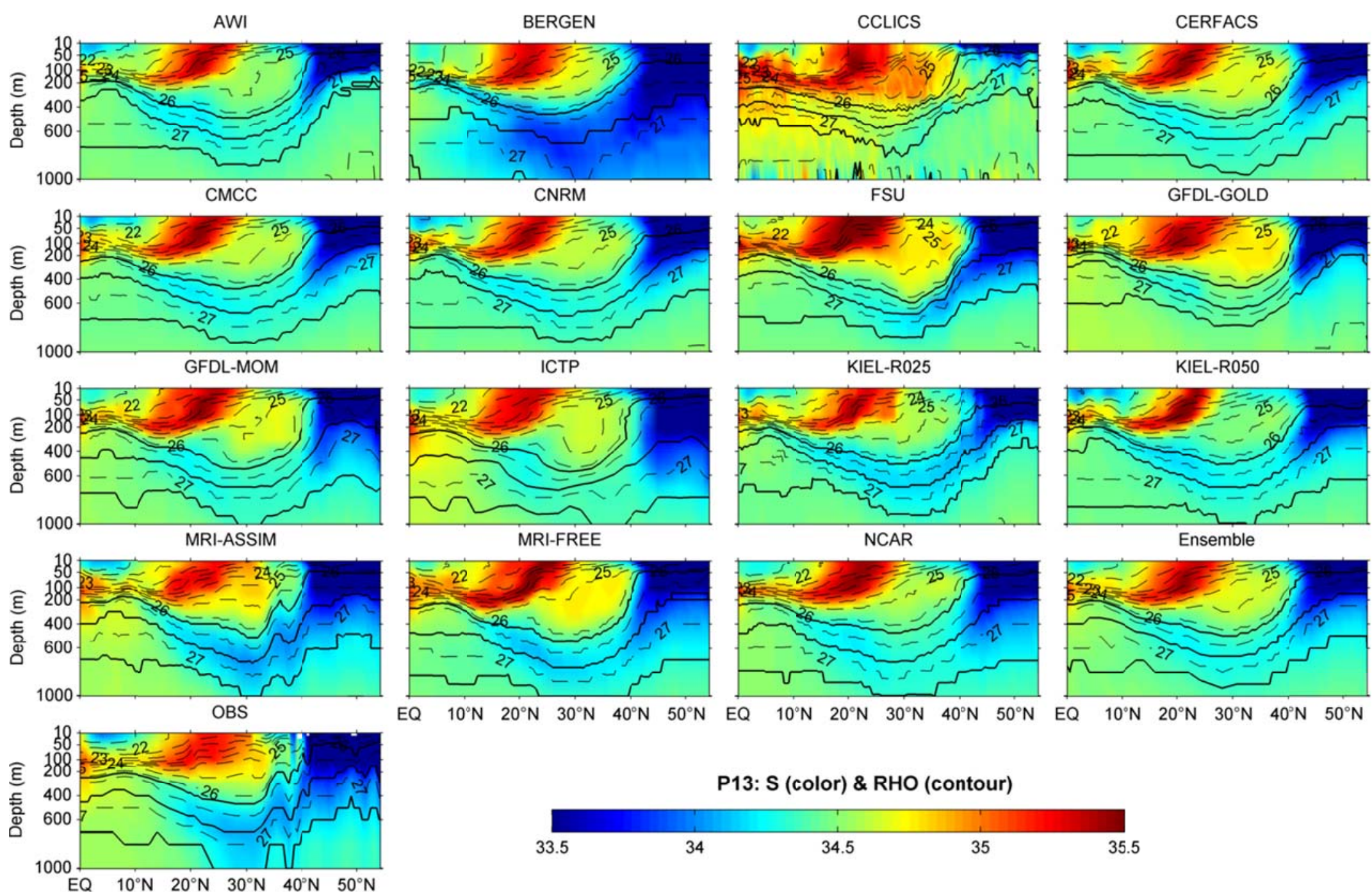

Figure 11: Vertical cross section of salinity (color) and potential density (contour) along the P13 (165ㄹ) section. Contour interval is 0.2. The $26.2 \sigma_{\theta}, 26.8 \sigma_{\theta}, 27.2 \sigma_{\theta}$ levels are shown as thick lines. 
AWI

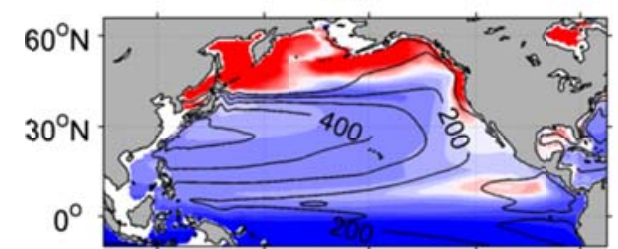

CMCC

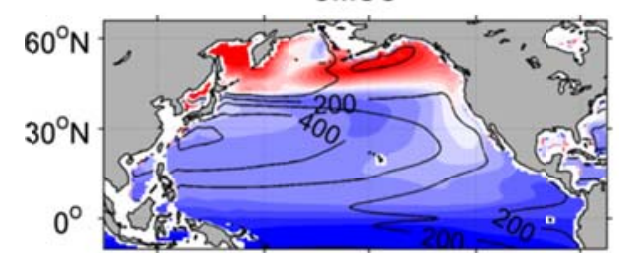

GFDL-MOM

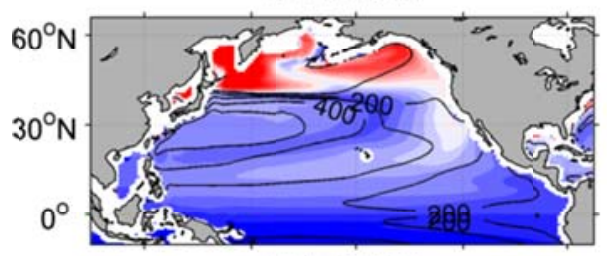

MRI-ASSIM

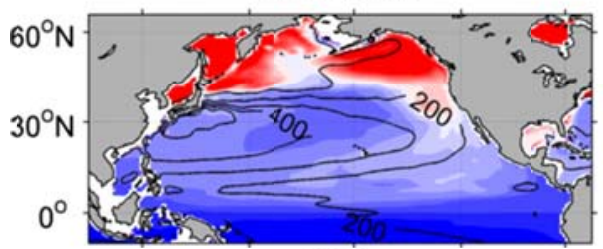

WOA

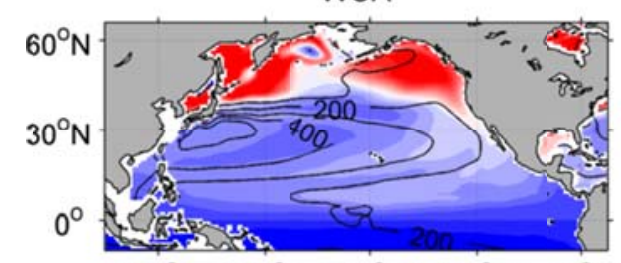

BERGEN

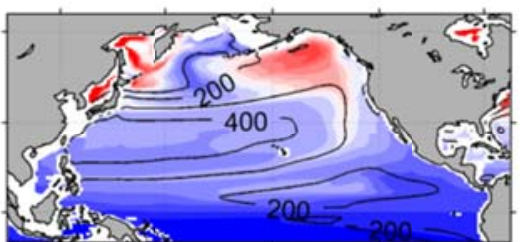

CNRM

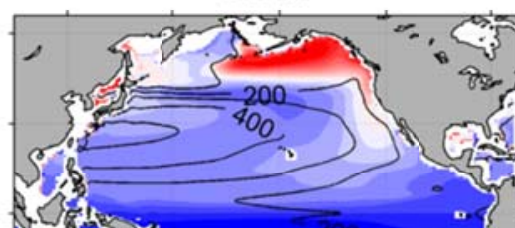

ICTP

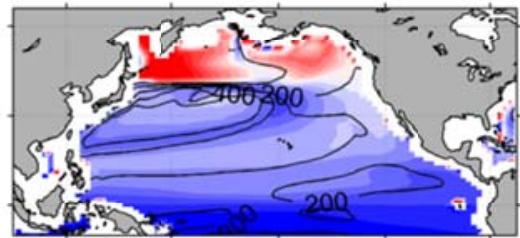

MRI-FREE

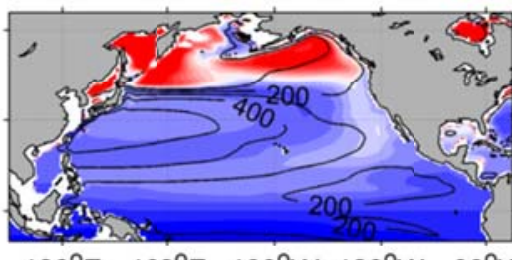

$120^{\circ} \mathrm{E} \quad 160^{\circ} \mathrm{E} \quad 160^{\circ} \mathrm{W} 120^{\circ} \mathrm{W} \quad 80^{\circ} \mathrm{W}$
CCLICS

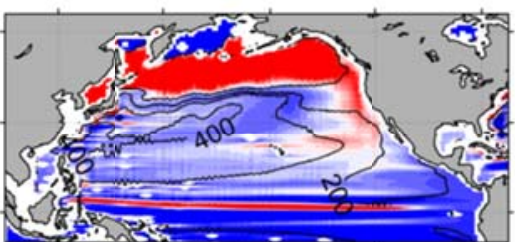

FSU

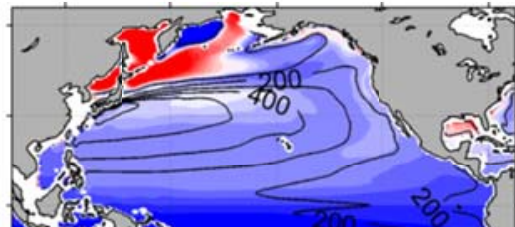

KIEL-R025

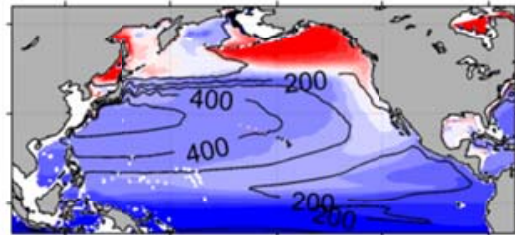

NCAR

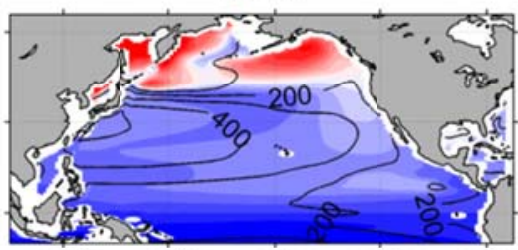

$120^{\circ} \mathrm{E} \quad 160^{\circ} \mathrm{E} \quad 160^{\circ} \mathrm{W} 120^{\circ} \mathrm{W} \quad 80^{\circ} \mathrm{W}$

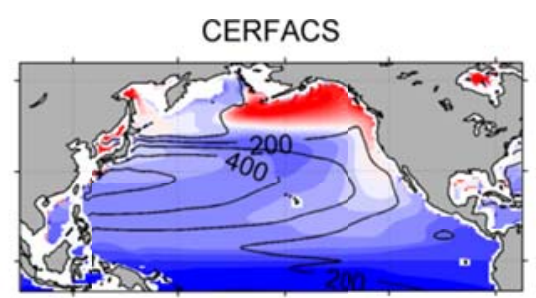

GFDL-GOLD

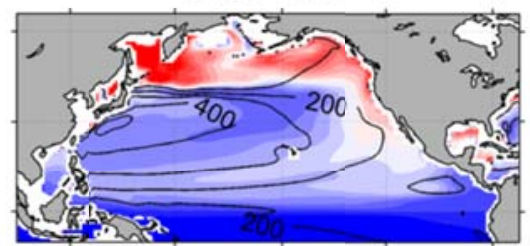

KIEL-R050

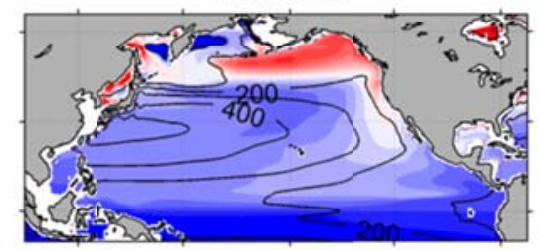

Ensemble

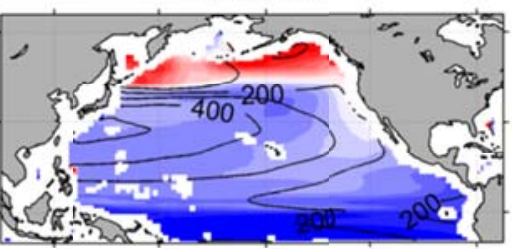

$120^{\circ} \mathrm{E} \quad 160^{\circ} \mathrm{E} \quad 160^{\circ} \mathrm{W} 120^{\circ} \mathrm{W} \quad 80^{\circ} \mathrm{W}$

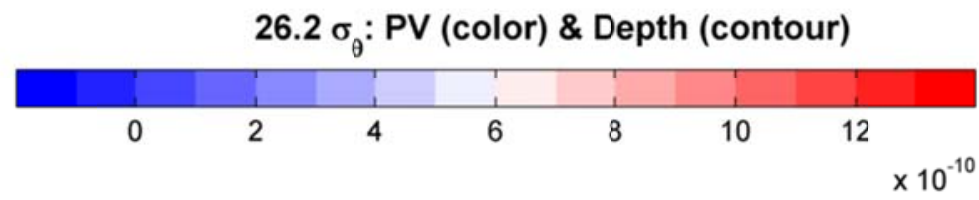

$120^{\circ} \mathrm{E} \quad 160^{\circ} \mathrm{E} \quad 160^{\circ} \mathrm{W} \quad 120^{\circ} \mathrm{W} \quad 80^{\circ} \mathrm{W}$

Figure 12: Distributions of potential vorticity (color; in $10^{-10} \mathrm{~m}^{-1} \mathrm{~s}^{-1}$ ) and depth (contour) on the $26.2 \sigma_{\theta}$ isopycnal surface. The contour interval is every $100 \mathrm{~m}$. 
AWI

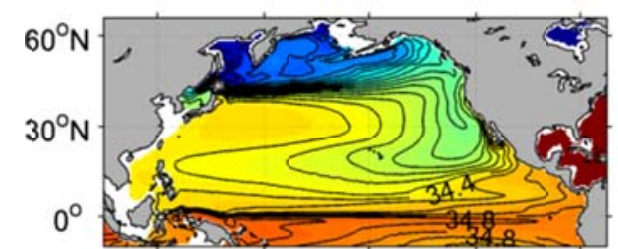

CMCC

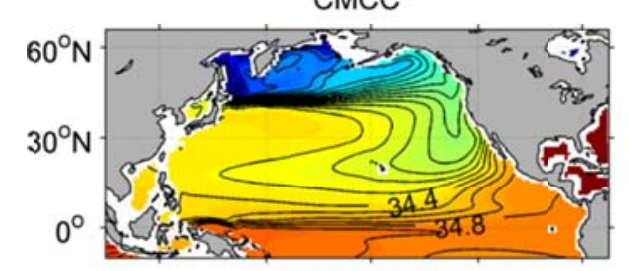

GFDL-MOM
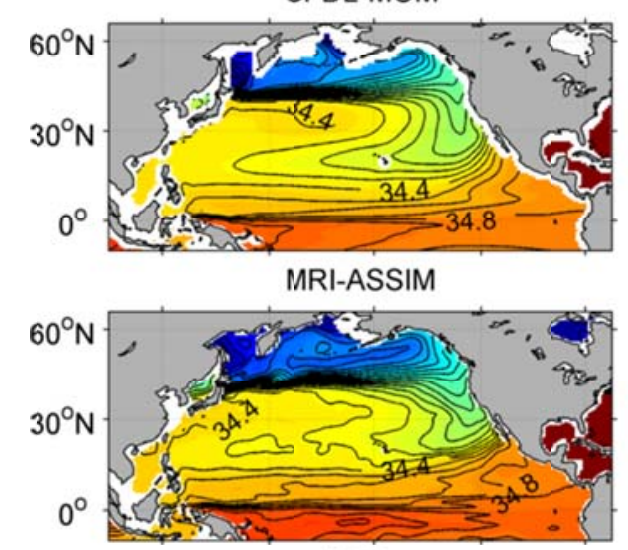

WOA

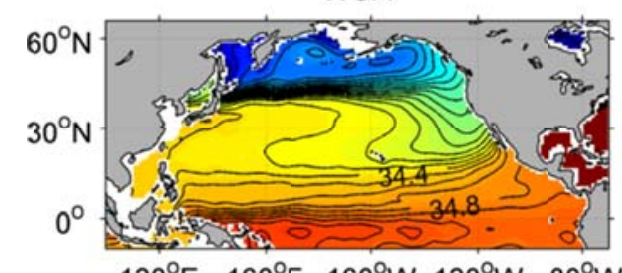

$120^{\circ} \mathrm{E} \quad 160^{\circ} \mathrm{E} \quad 160^{\circ} \mathrm{W} 120^{\circ} \mathrm{W} \quad 80^{\circ} \mathrm{W}$
BERGEN

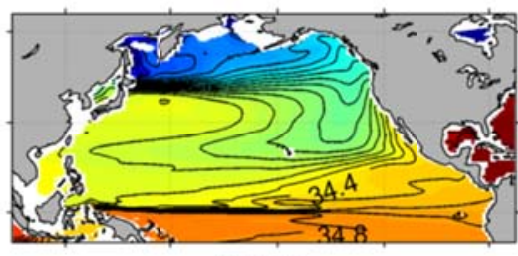

CNRM

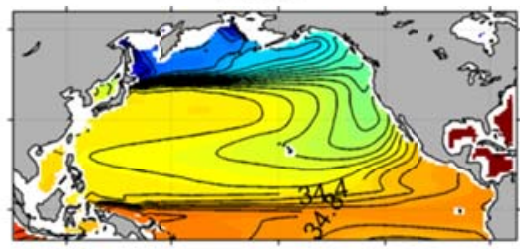

ICTP

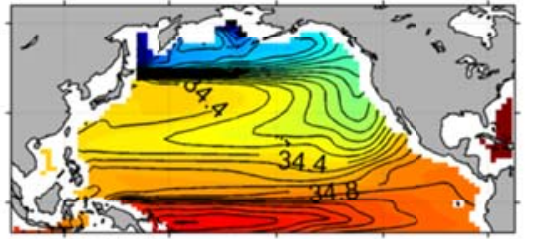

MRI-FREE

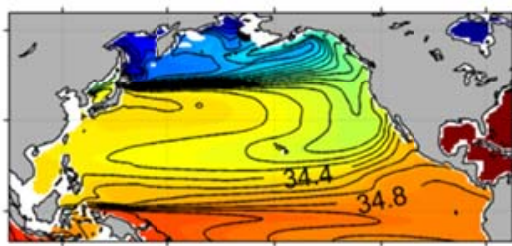

$120^{\circ} \mathrm{E} \quad 160^{\circ} \mathrm{E} \quad 160^{\circ} \mathrm{W} \quad 120^{\circ} \mathrm{W} \quad 80^{\circ} \mathrm{W}$
CCLICS

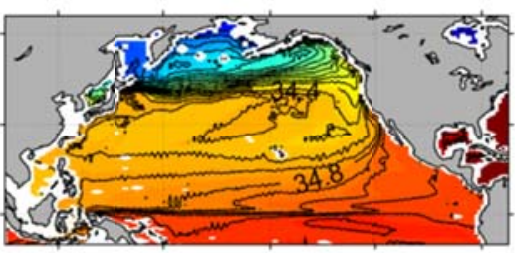

FSU

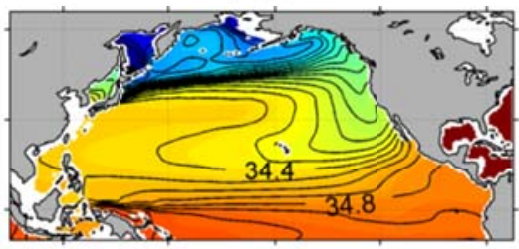

KIEL-R025

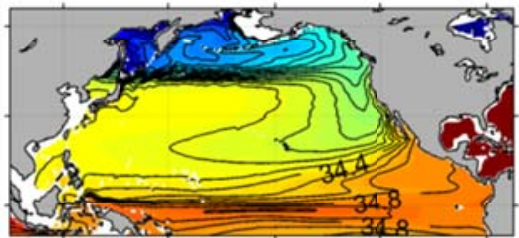

NCAR

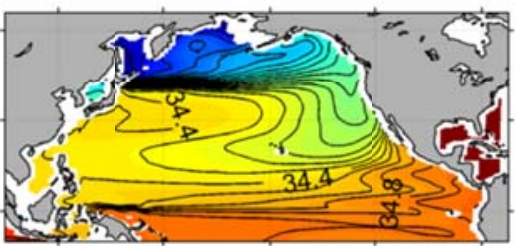

$120^{\circ} \mathrm{E} \quad 160^{\circ} \mathrm{E} \quad 160^{\circ} \mathrm{W} \quad 120^{\circ} \mathrm{W} \quad 80^{\circ} \mathrm{W}$

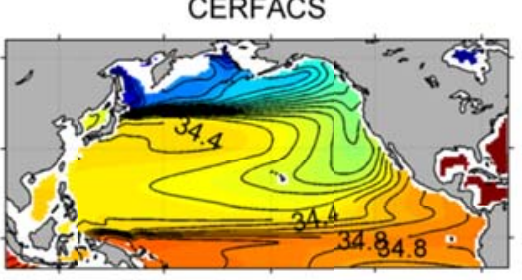

GFDL-GOLD

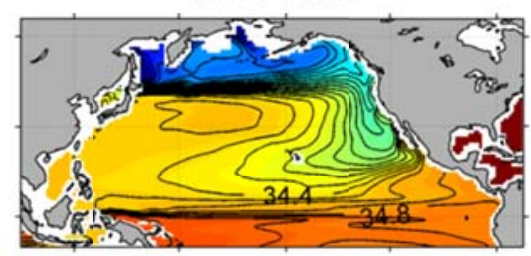

KIEL-R050

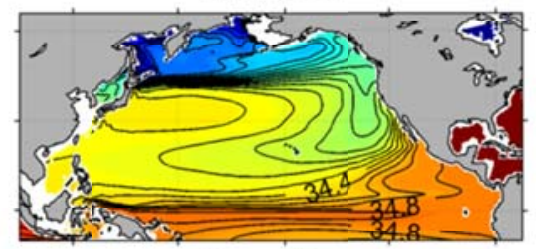

Ensemble

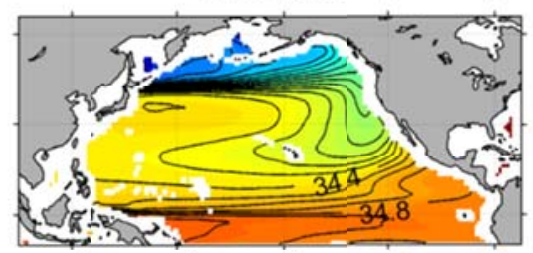

$120^{\circ} \mathrm{E} \quad 160^{\circ} \mathrm{E} \quad 160^{\circ} \mathrm{W} 120^{\circ} \mathrm{W}-80^{\circ} \mathrm{W}$

\section{$26.2 \sigma_{\theta}: \mathrm{T}$ (color) \& $\mathrm{S}$ (contour)}

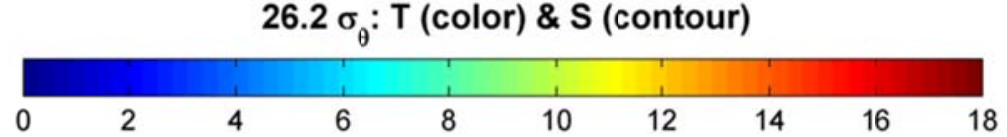

Figure 13: Distributions of potential temperature (color) and salinity (contour) on the $26.2 \sigma_{\theta}$ isopycnal surface. The contour interval is every 0.1 . 
AWI

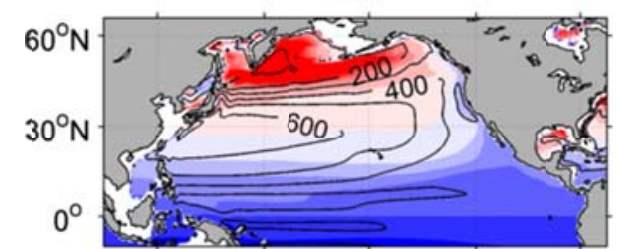

CMCC

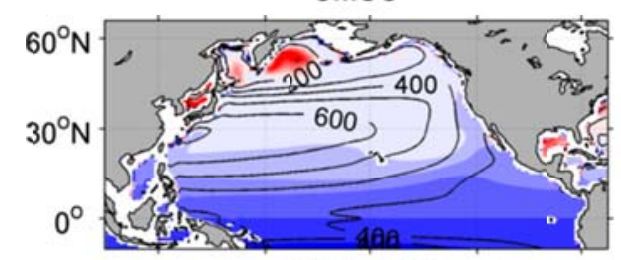

GFDL-MOM

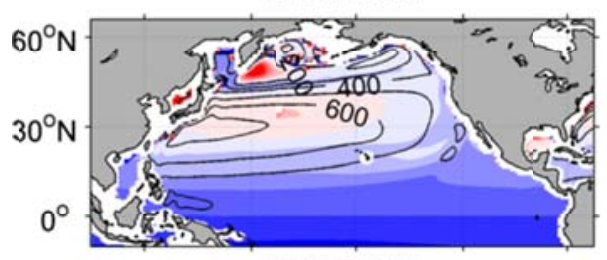

MRI-ASSIM

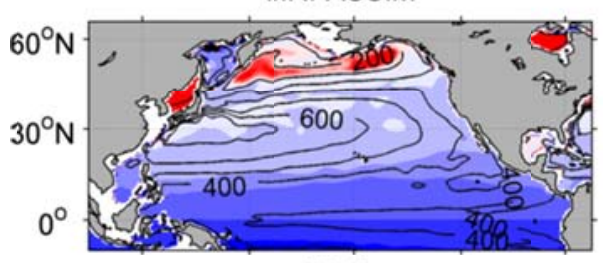

WOA
BERGEN

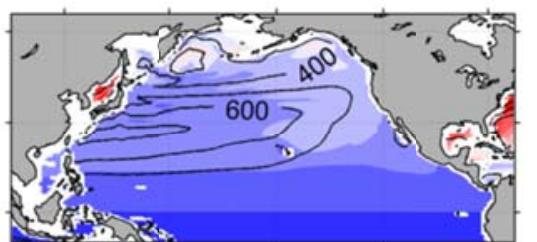

CNRM

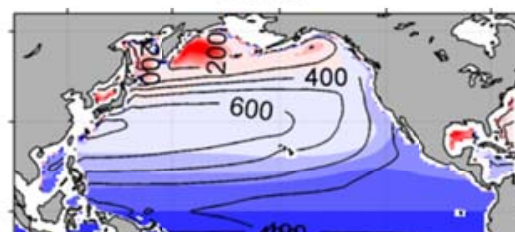

ICTP

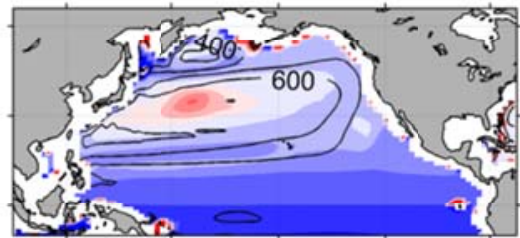

MRI-FREE

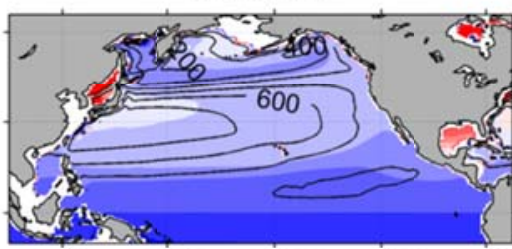

$120^{\circ} \mathrm{E} \quad 160^{\circ} \mathrm{E} \quad 160^{\circ} \mathrm{W} \quad 120^{\circ} \mathrm{W} \quad 80^{\circ} \mathrm{W}$
CCLICS

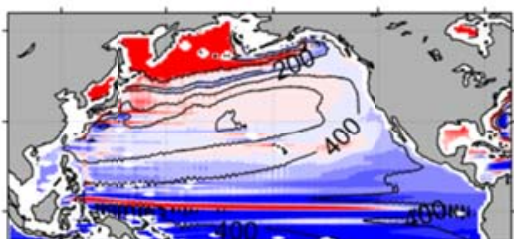

FSU

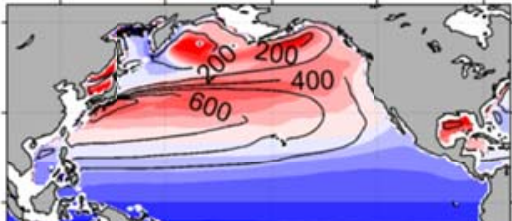

KIEL-R025

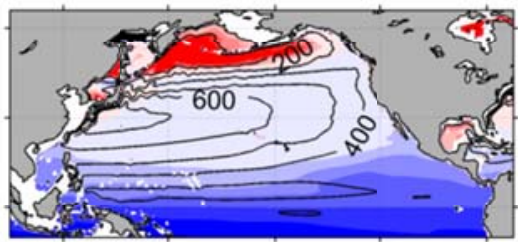

NCAR

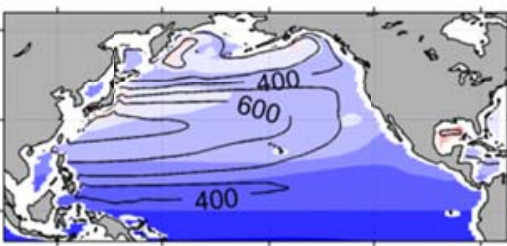

$120^{\circ} \mathrm{E} \quad 160^{\circ} \mathrm{E} \quad 160^{\circ} \mathrm{W} \quad 120^{\circ} \mathrm{W} \quad 80^{\circ} \mathrm{W}$
CERFACS

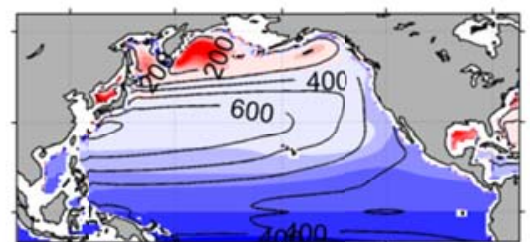

GFDL-GOLD

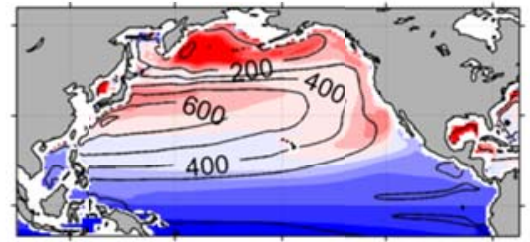

KIEL-R050

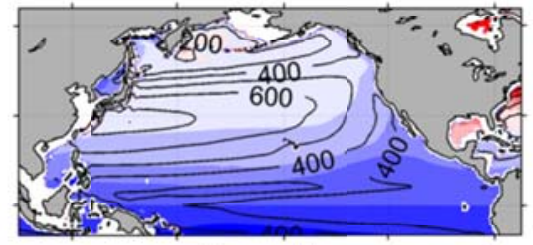

Ensemble

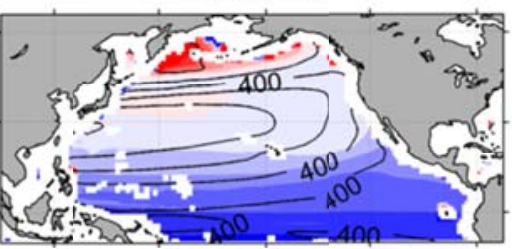

$120^{\circ} \mathrm{E} \quad 160^{\circ} \mathrm{E} \quad 160^{\circ} \mathrm{W} 120^{\circ} \mathrm{W} \quad 80^{\circ} \mathrm{W}$

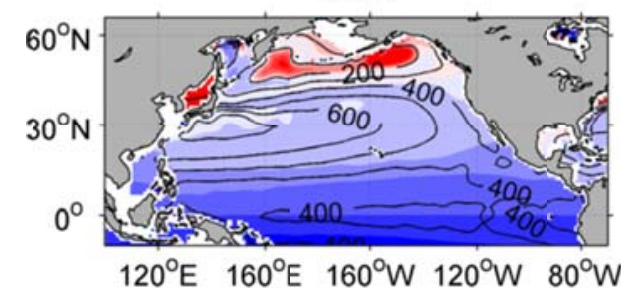

$26.8 \sigma_{\theta}:$ PV (color) \& Depth (contour)

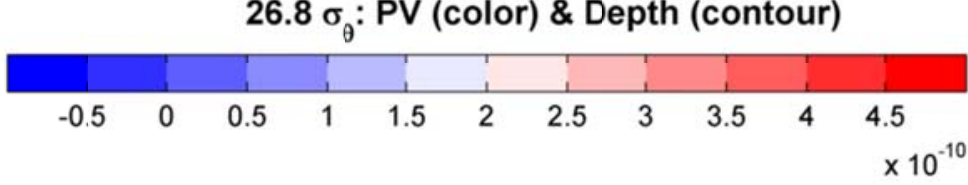

Figure 14: Distributions of potential vorticity (color, in $10^{-10} \mathrm{~m}^{-1} \mathrm{~s}^{-1}$ ) and depth (contour) on the $26.8 \sigma_{\theta}$ isopycnal surface. The contour interval is every $100 \mathrm{~m}$. 
AWI

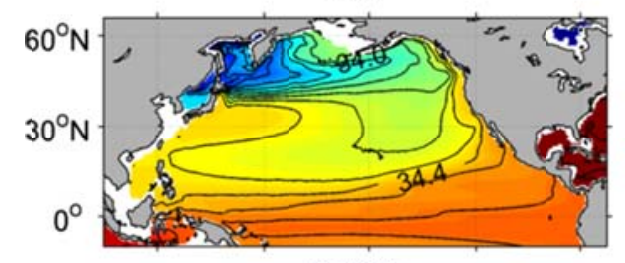

CMCC

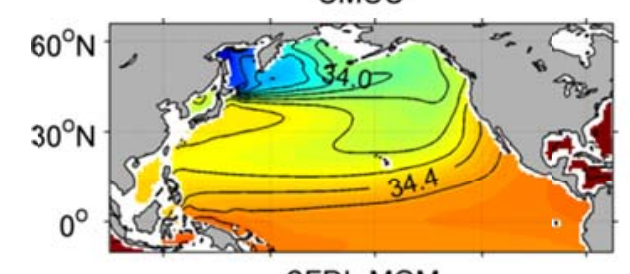

GFDL-MOM
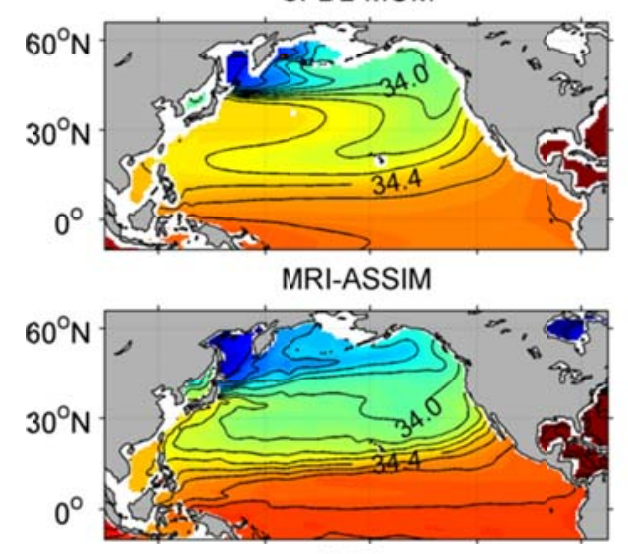

WOA

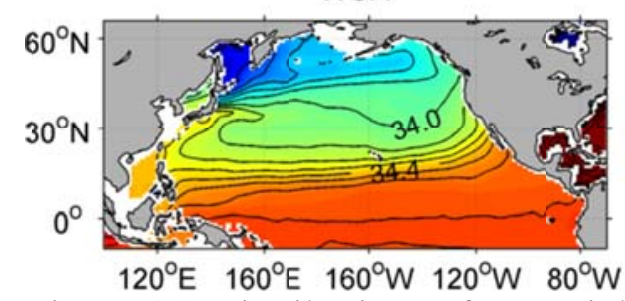

BERGEN

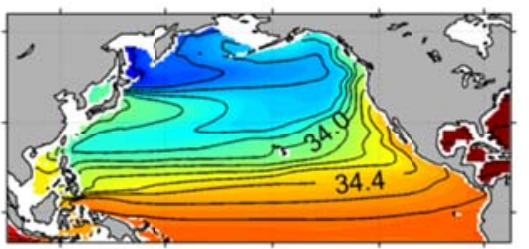

CNRM

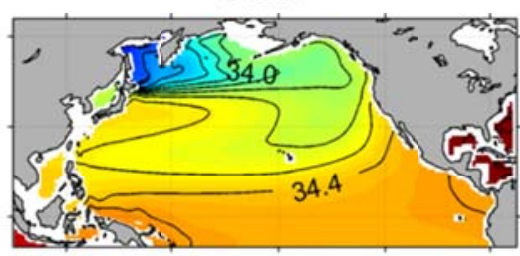

ICTP

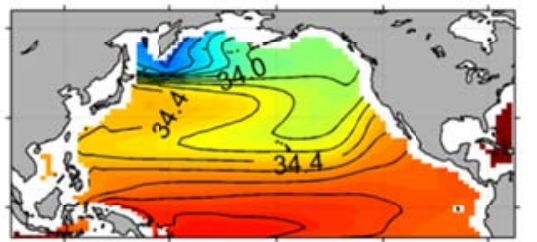

MRI-FREE

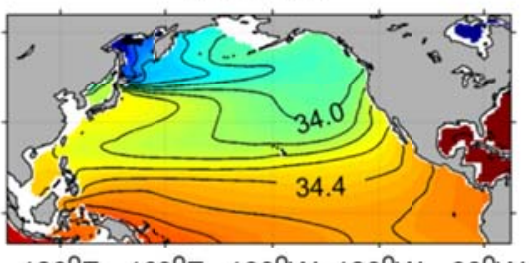

$120^{\circ} \mathrm{E} \quad 160^{\circ} \mathrm{E} \quad 160^{\circ} \mathrm{W} \quad 120^{\circ} \mathrm{W} \quad 80^{\circ} \mathrm{W}$
CCLICS

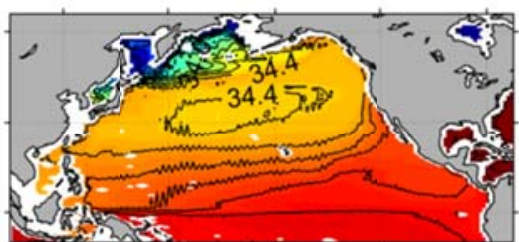

FSU

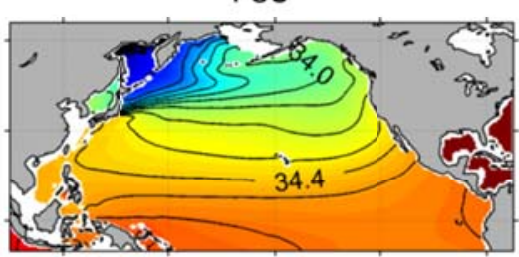

KIEL-R025

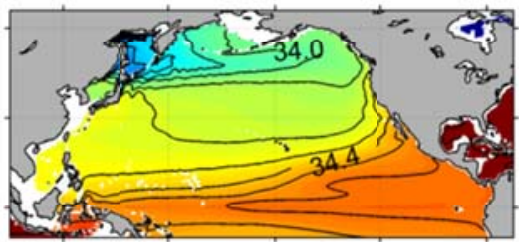

NCAR

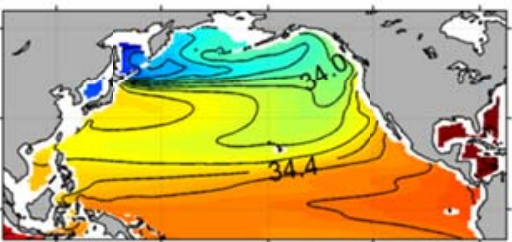

$120^{\circ} \mathrm{E} \quad 160^{\circ} \mathrm{E} \quad 160^{\circ} \mathrm{W} 120^{\circ} \mathrm{W} \quad 80^{\circ} \mathrm{W}$

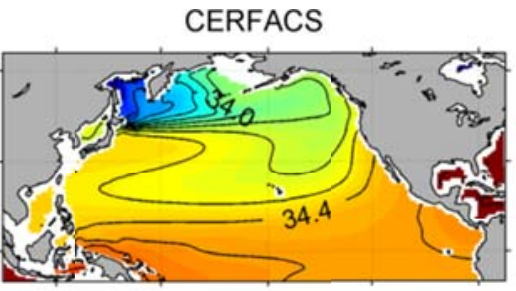

GFDL-GOLD

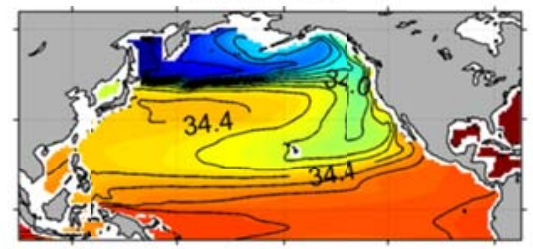

KIEL-R050

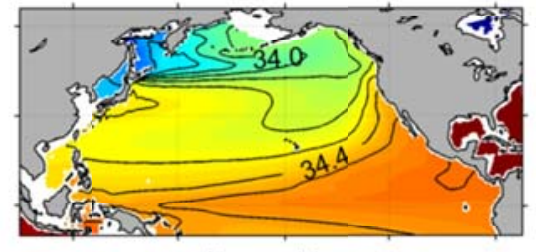

Ensemble

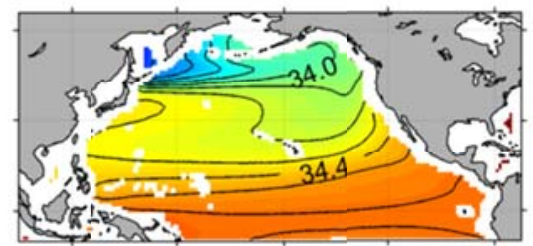

$120^{\circ} \mathrm{E} \quad 160^{\circ} \mathrm{E} \quad 160^{\circ} \mathrm{W} 120^{\circ} \mathrm{W} \quad 80^{\circ} \mathrm{W}$

$26.8 \sigma_{\theta}: \mathrm{T}$ (color) \& $\mathrm{S}$ (contour)

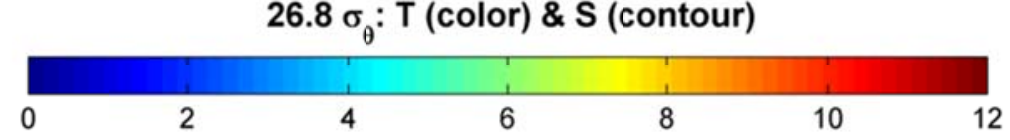

Figure 15: Distributions of potential temperature (color) and salinity (contour) on the $26.8 \sigma_{\theta}$ isopycnal surface. The contour interval is every 0.1 . 
AWI

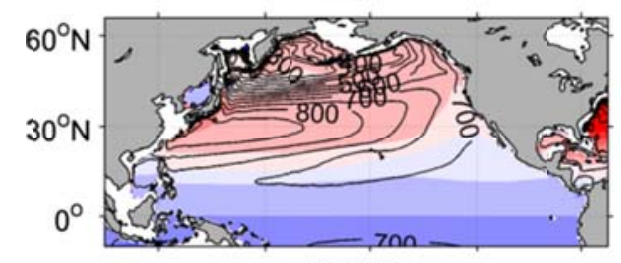

CMCC

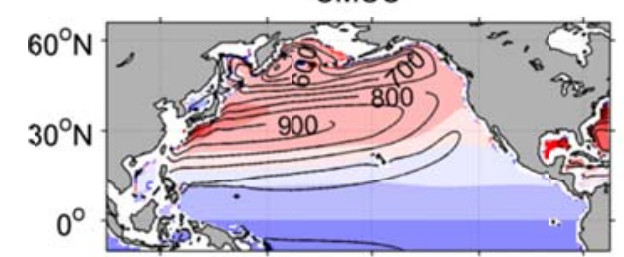

GFDL-MOM

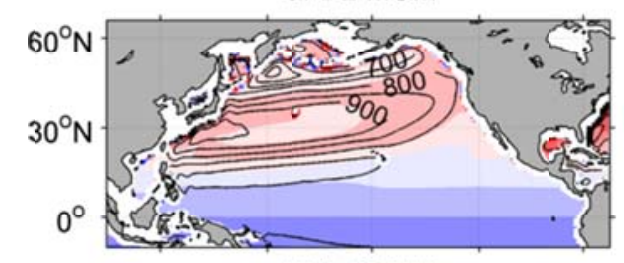

MRI-ASSIM

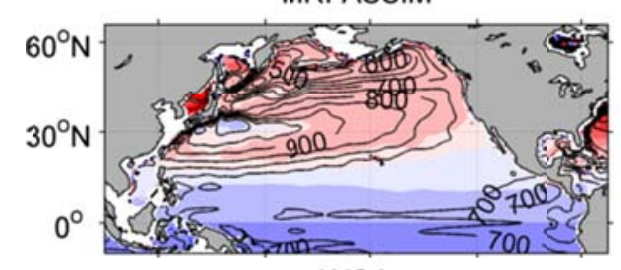

WOA

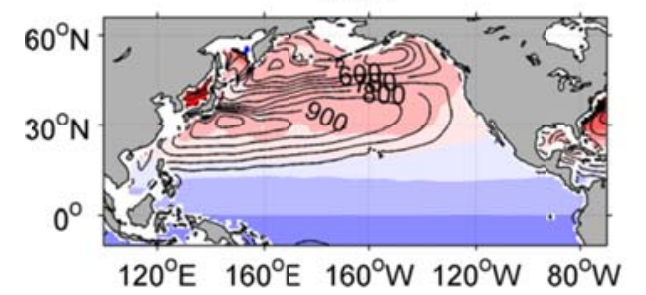

BERGEN

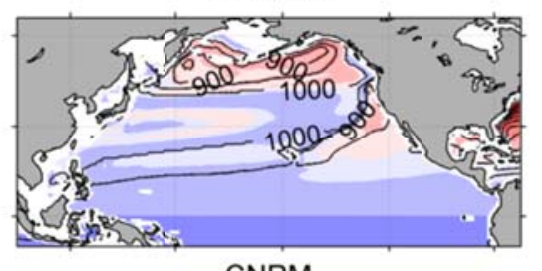

CNRM

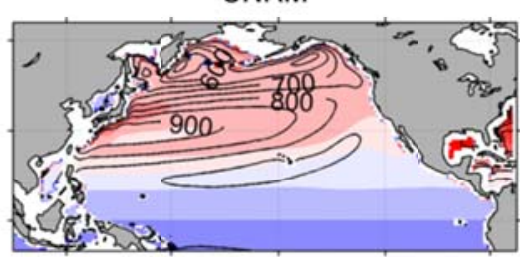

ICTP

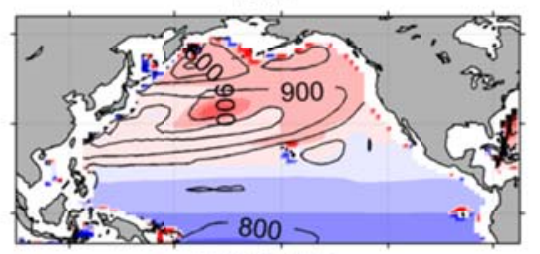

MRI-FREE

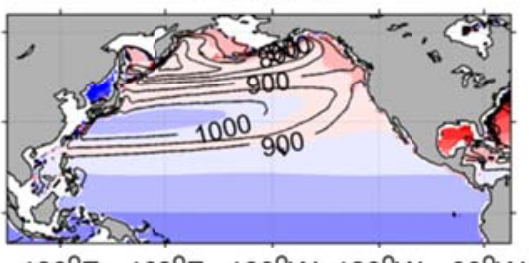

$120^{\circ} \mathrm{E} \quad 160^{\circ} \mathrm{E} \quad 160^{\circ} \mathrm{W} 120^{\circ} \mathrm{W} \quad 80^{\circ} \mathrm{W}$
CCLICS

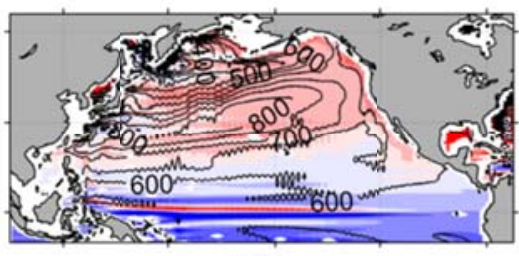

FSU

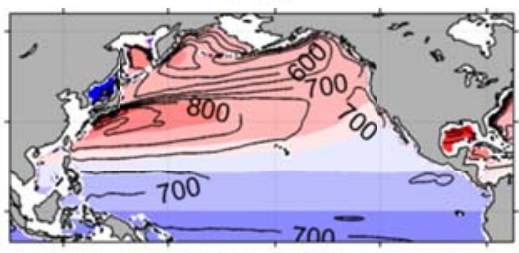

KIEL-R025

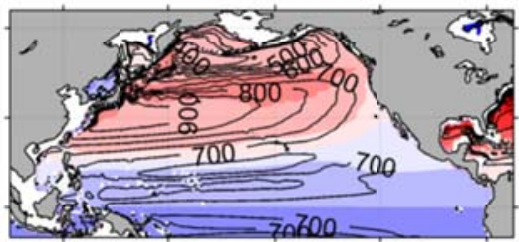

NCAR

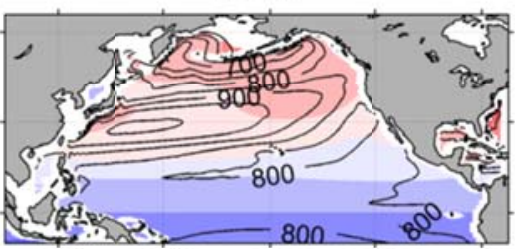

$120^{\circ} \mathrm{E} \quad 160^{\circ} \mathrm{E} \quad 160^{\circ} \mathrm{W} \quad 120^{\circ} \mathrm{W} \quad 80^{\circ} \mathrm{W}$
CERFACS

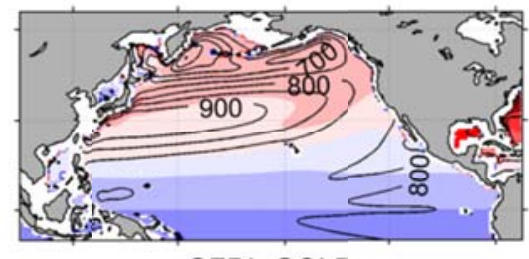

GFDL-GOLD

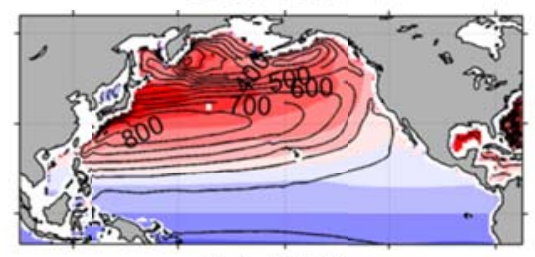

KIEL-R050

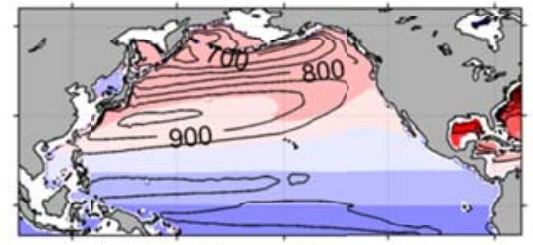

Ensemble

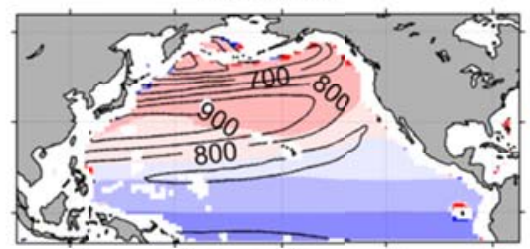

$120^{\circ} \mathrm{E} \quad 160^{\circ} \mathrm{E} \quad 160^{\circ} \mathrm{W} 120^{\circ} \mathrm{W} \quad 80^{\circ} \mathrm{W}$

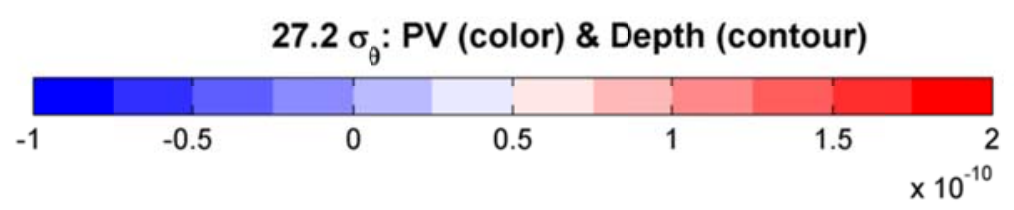

Figure 16: Distributions of potential vorticity (color, in $10^{-10} \mathrm{~m}^{-1} \mathrm{~s}^{-1}$ ) and depth (contour) on the $27.2 \sigma_{\theta}$ isopycnal surface. The contour interval is every $50 \mathrm{~m}$. 

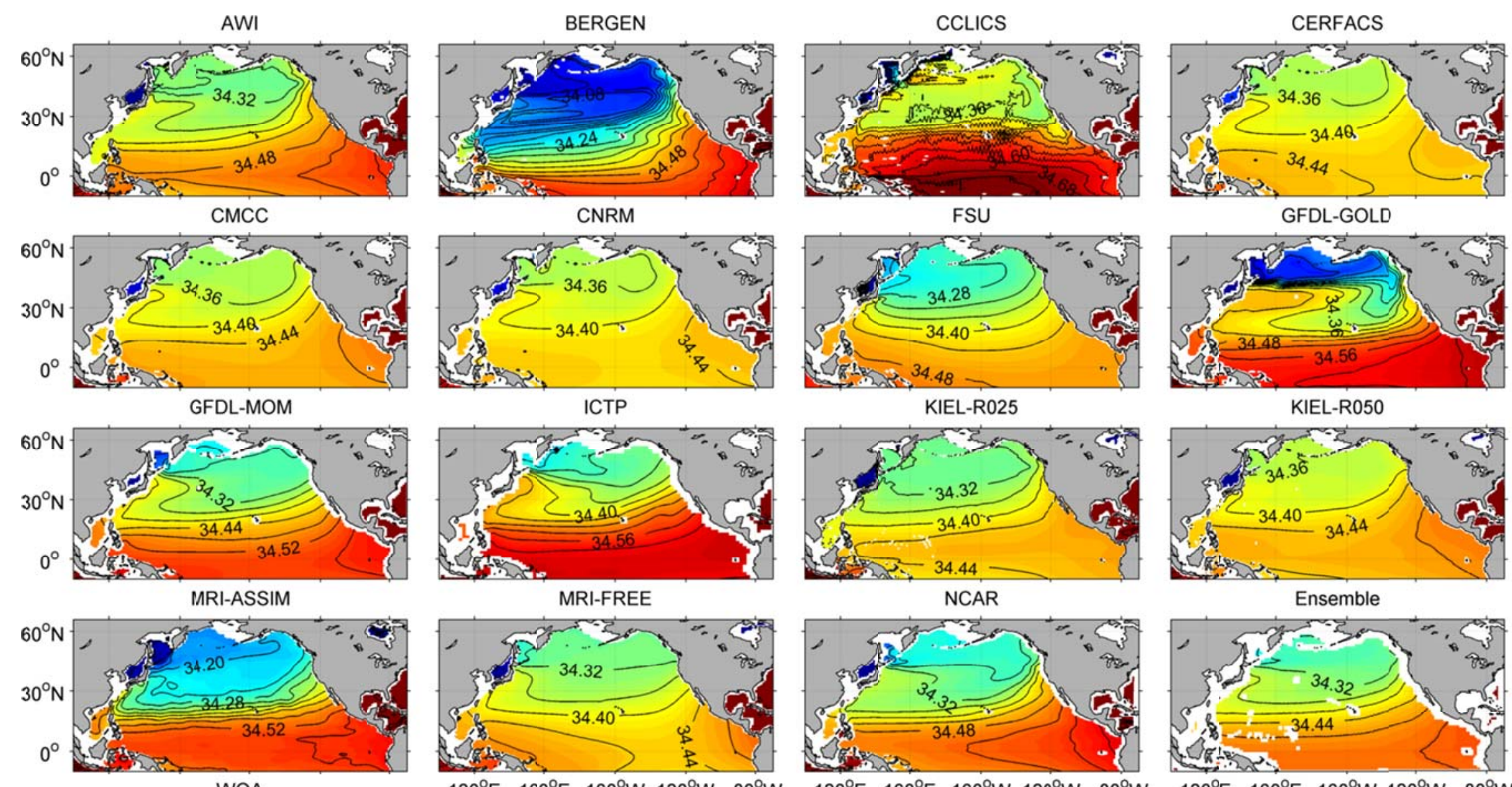

WOA
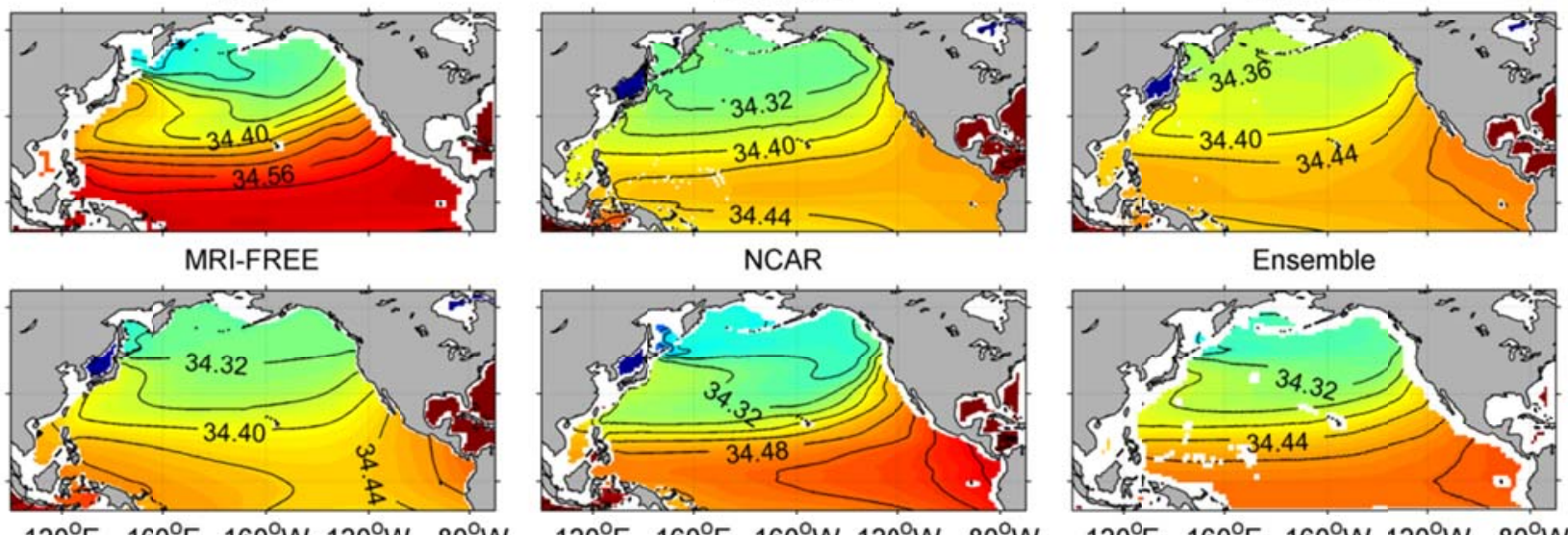

$120^{\circ} \mathrm{E} \quad 160^{\circ} \mathrm{E} 160^{\circ} \mathrm{W} 120^{\circ} \mathrm{W} \quad 80^{\circ} \mathrm{W}$

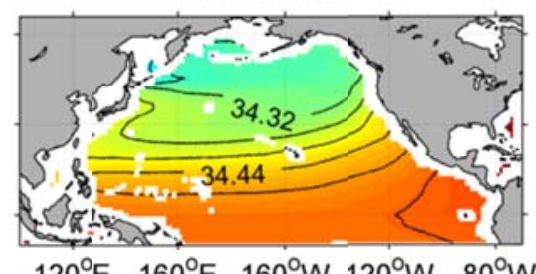

$27.2 \sigma_{\theta}: T$ (color) \& $S$ (contour)
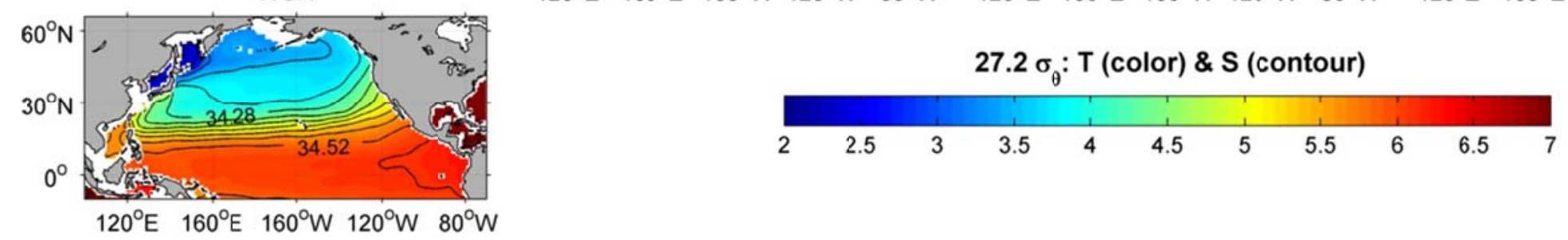

Figure 17: Distributions of potential temperature (color) and salinity (contour) on the $27.2 \sigma_{\theta}$ isopycnal surface. The contour interval is every 0.04 . 

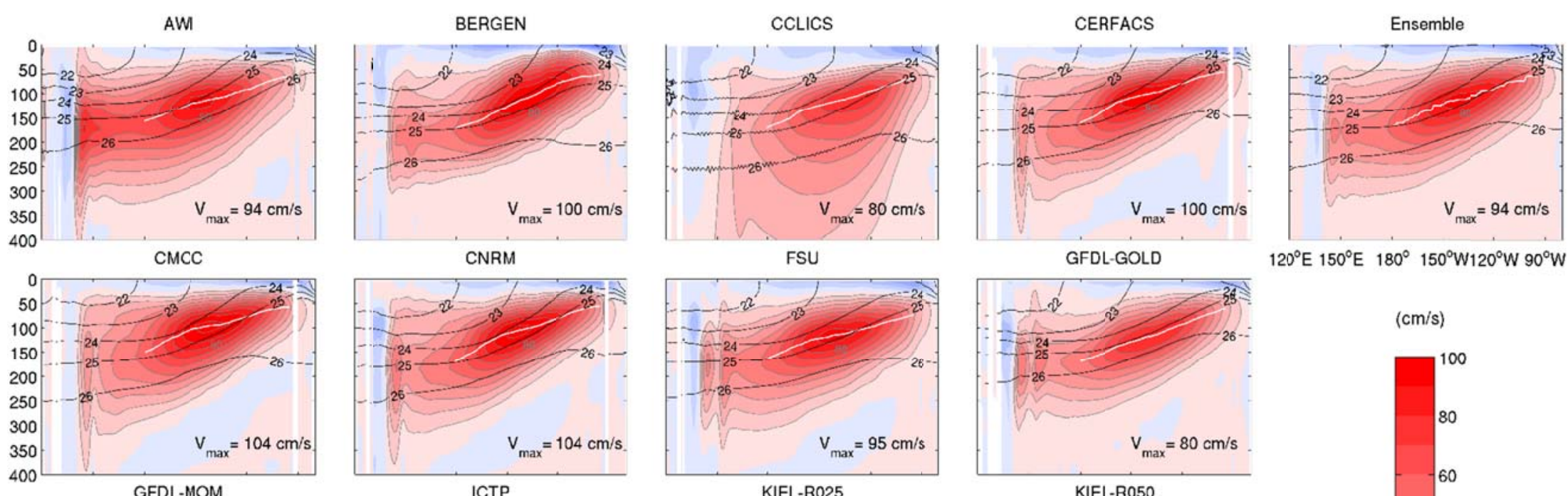

$120^{\circ} \mathrm{E} 150^{\circ} \mathrm{E} 180^{\circ} 150^{\circ} \mathrm{W} 120^{\circ} \mathrm{W} 90^{\circ} \mathrm{W}$
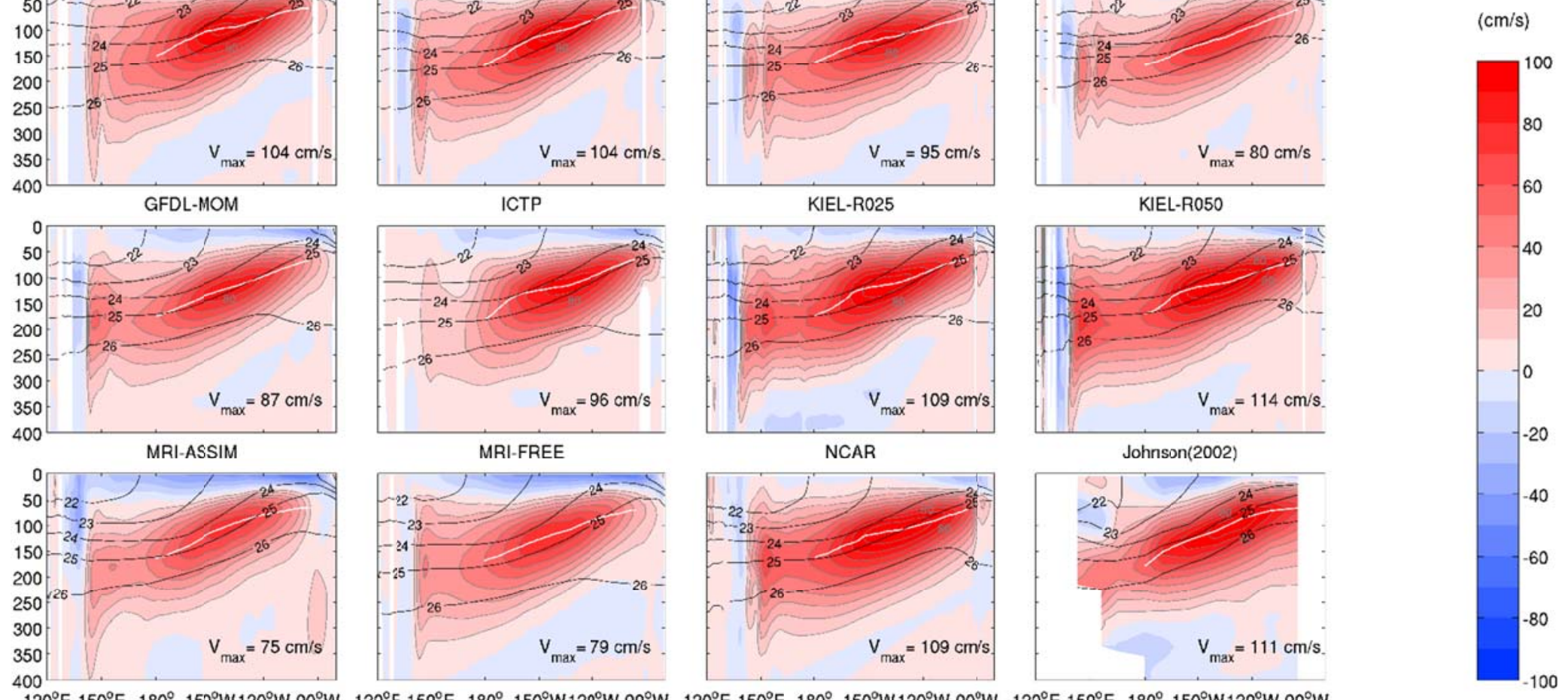

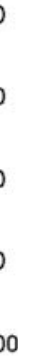

Figure 18: Mean zonal velocity (color, in $\mathrm{cm} \mathrm{s}^{-1}$ ) and potential density (black contours) along the equator from 1986 to 2000 . The white line denotes the core depth of the EUC (defined as the depth of the maximum eastward velocity). 

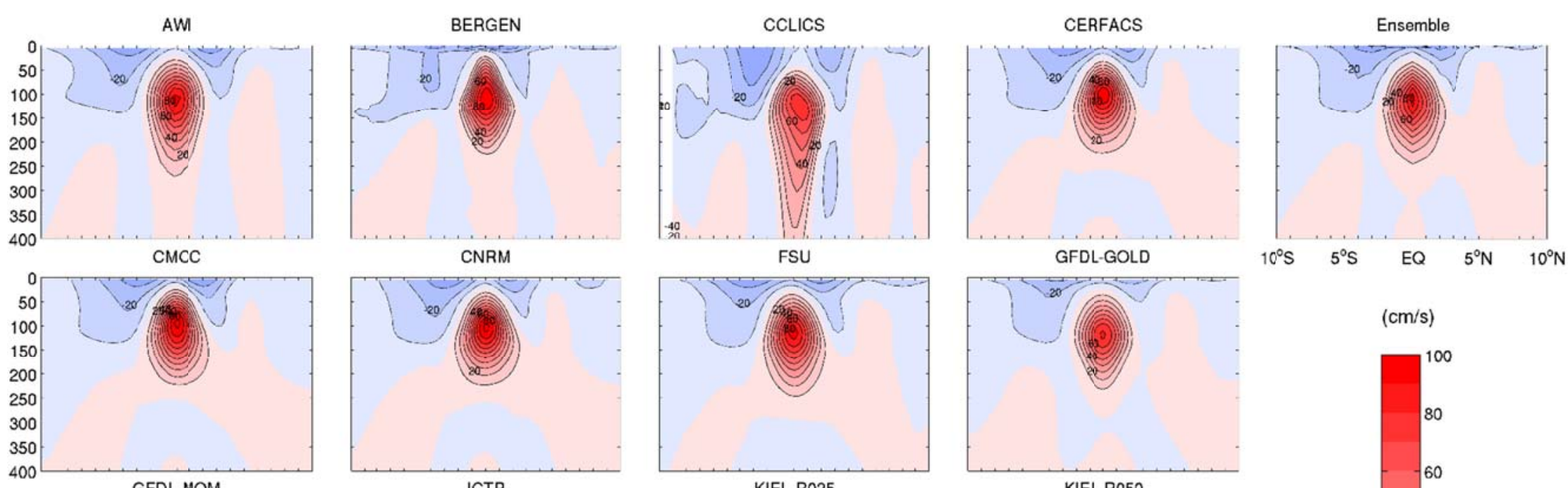

$10^{\circ} \mathrm{S} \quad 5^{\circ} \mathrm{S} \quad$ EQ $\quad 5^{\circ} \mathrm{N} \quad 10^{\circ} \mathrm{N}$
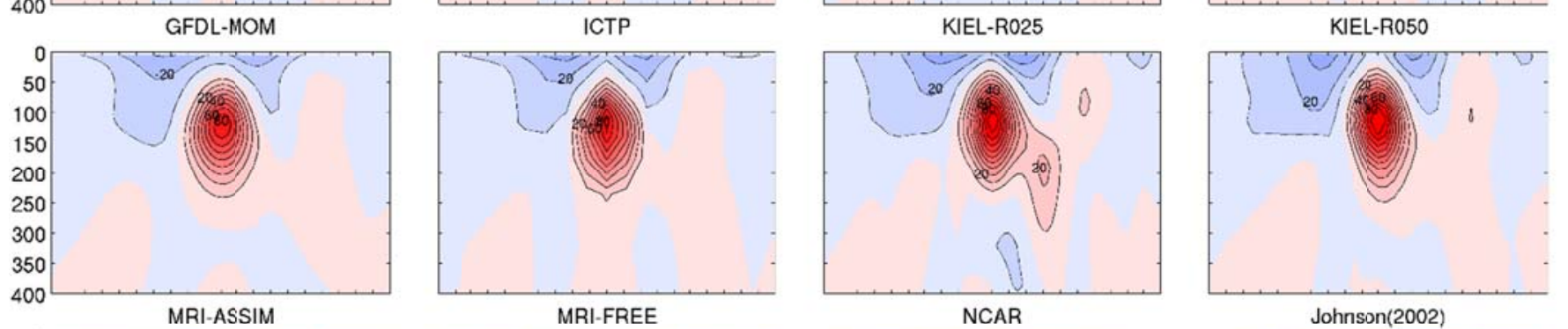

$(\mathrm{cm} / \mathrm{s})$
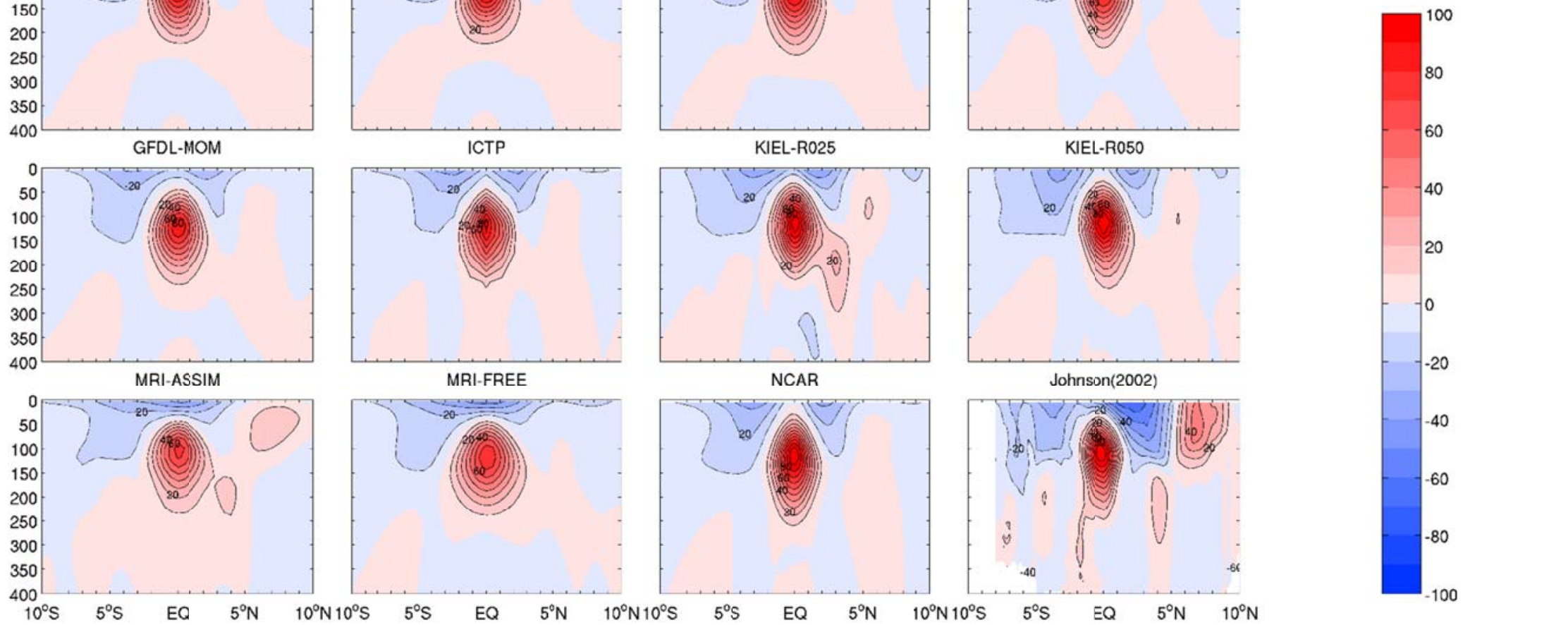

Figure 19: Mean zonal velocity in the central topical Pacific on a meridional section $\left(140^{\circ} \mathrm{W}\right)$ from 1986 to 2000. 

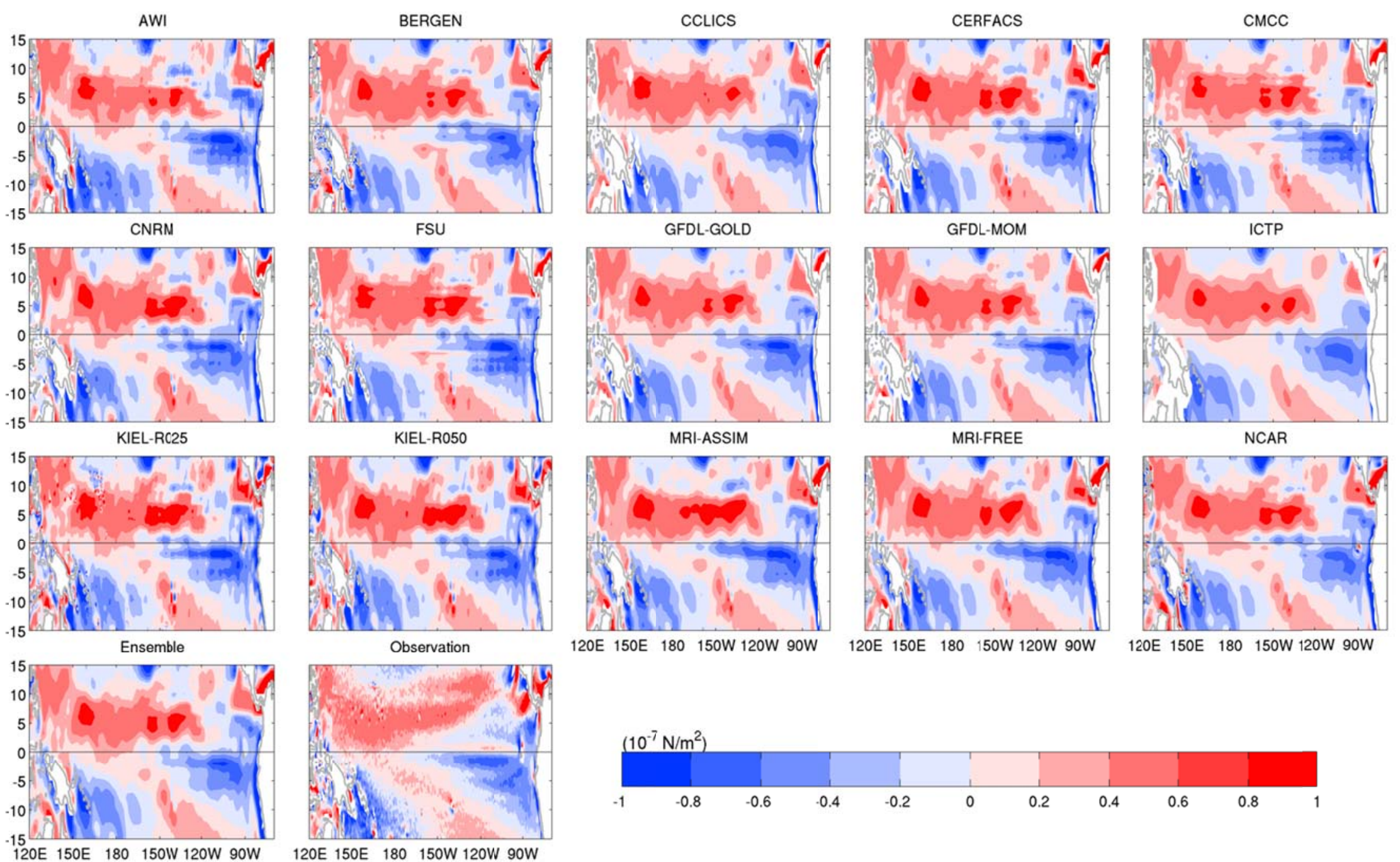

120E 150E 180 150W 120W 90W

120 E 150E 180 150W 120W 90W

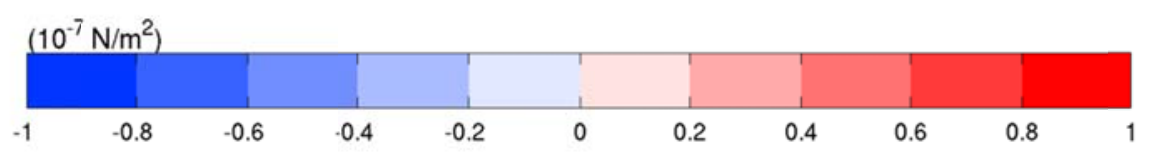

Figure 20: Mean wind stress curl ( $\operatorname{curl} \tau$ ) in the tropics. The Scatterometer Climatology of Ocean Winds is shown at the bottom for comparison. 


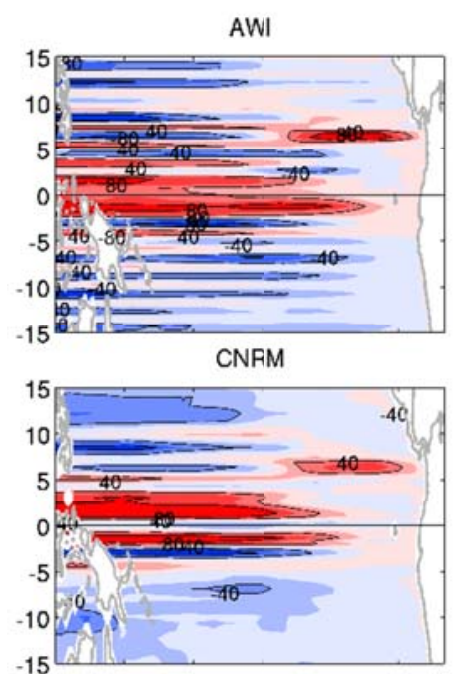

KIEL-R025

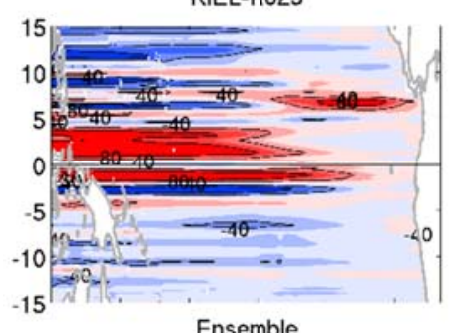

Ensemble

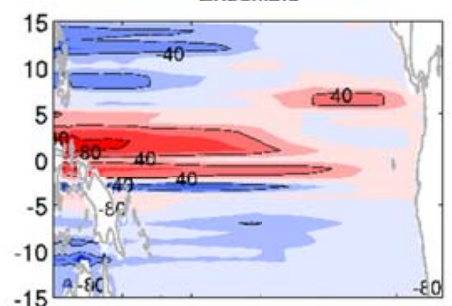

120E 150E 180 150W 120W 90W

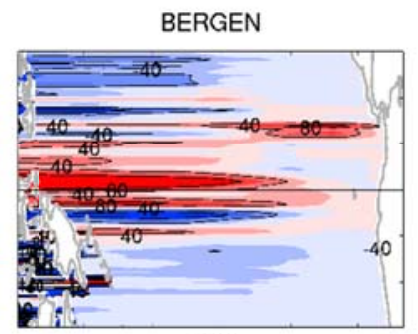

FSU

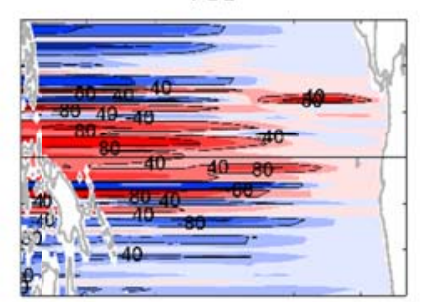

KIEL-R050

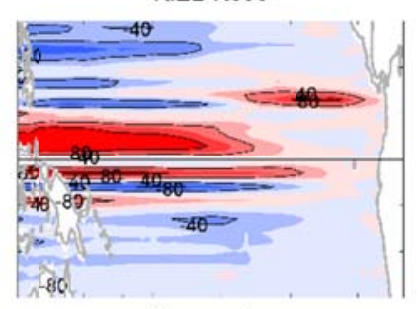

Observation

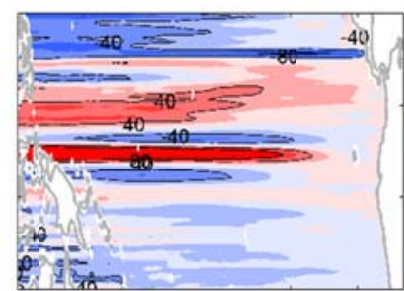

120E 150E 180 150W 120W 90W

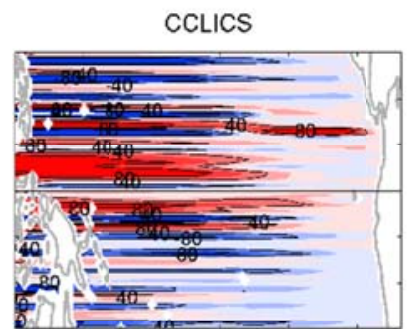

GFDL-GOLD

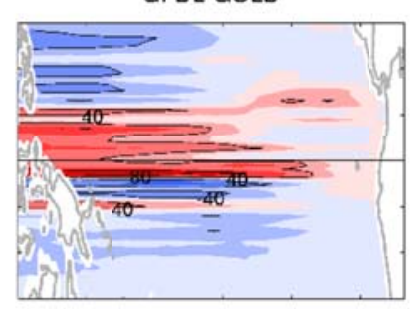

MRI-ASSIM

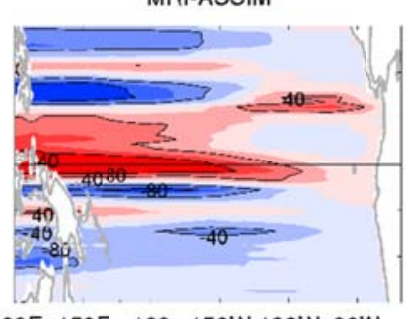

120E 150E 180 150W 120W 90W

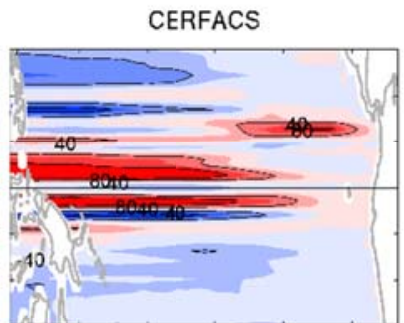

GFDL-MOM

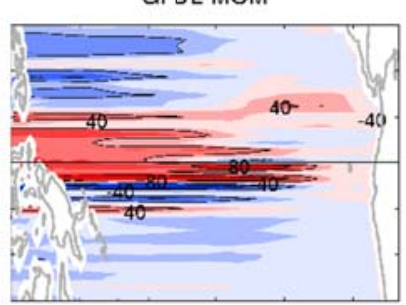

MRI-FREE

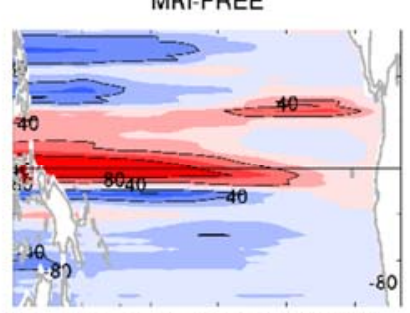

I20E 150E 180 150W 120W 90W

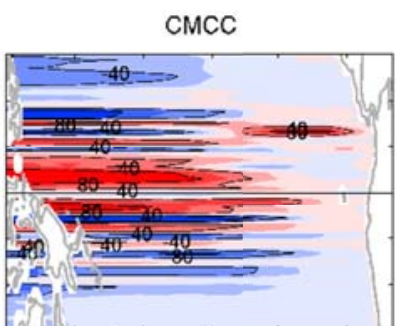

ICTP

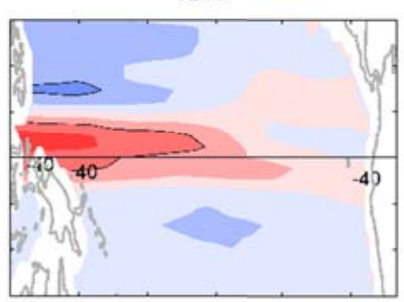

NCAR

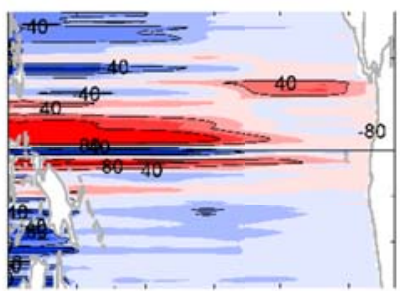

20E 150E 180 150W 120W 90W

Figure 21: Vertically integrated zonal transport/unit width $\left(\mathrm{m}^{2} \mathrm{~s}^{-1}\right)$ from the Sverdrup balance. Red colors indicate eastward transport, blue colors westward.

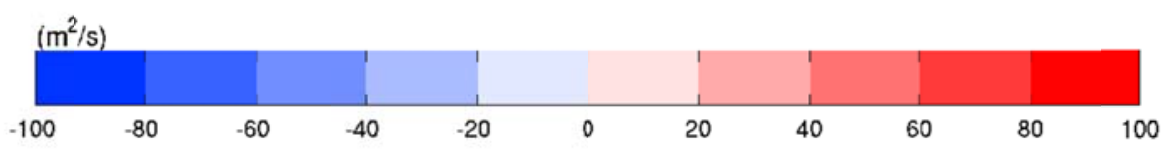



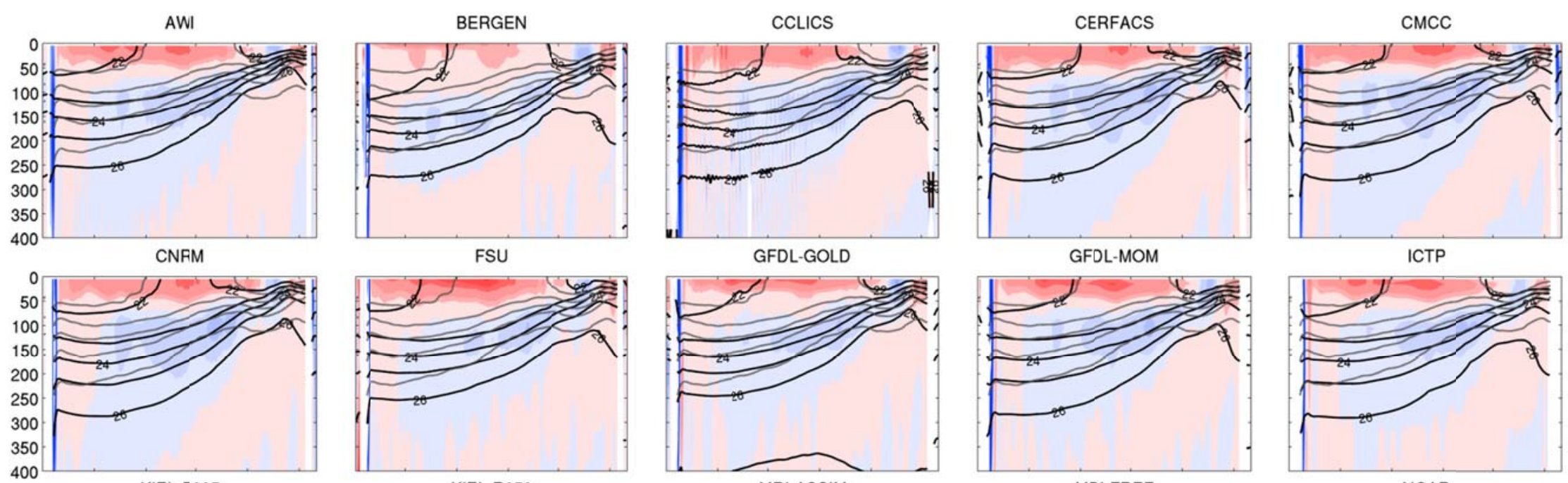

KIEL-R050
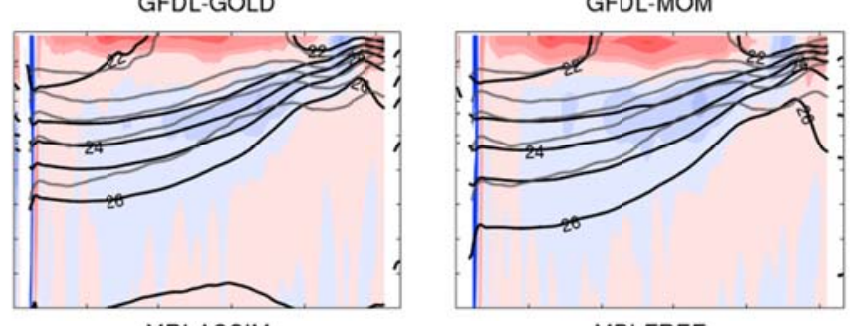

MRI-ASSIM

MRI-FREE
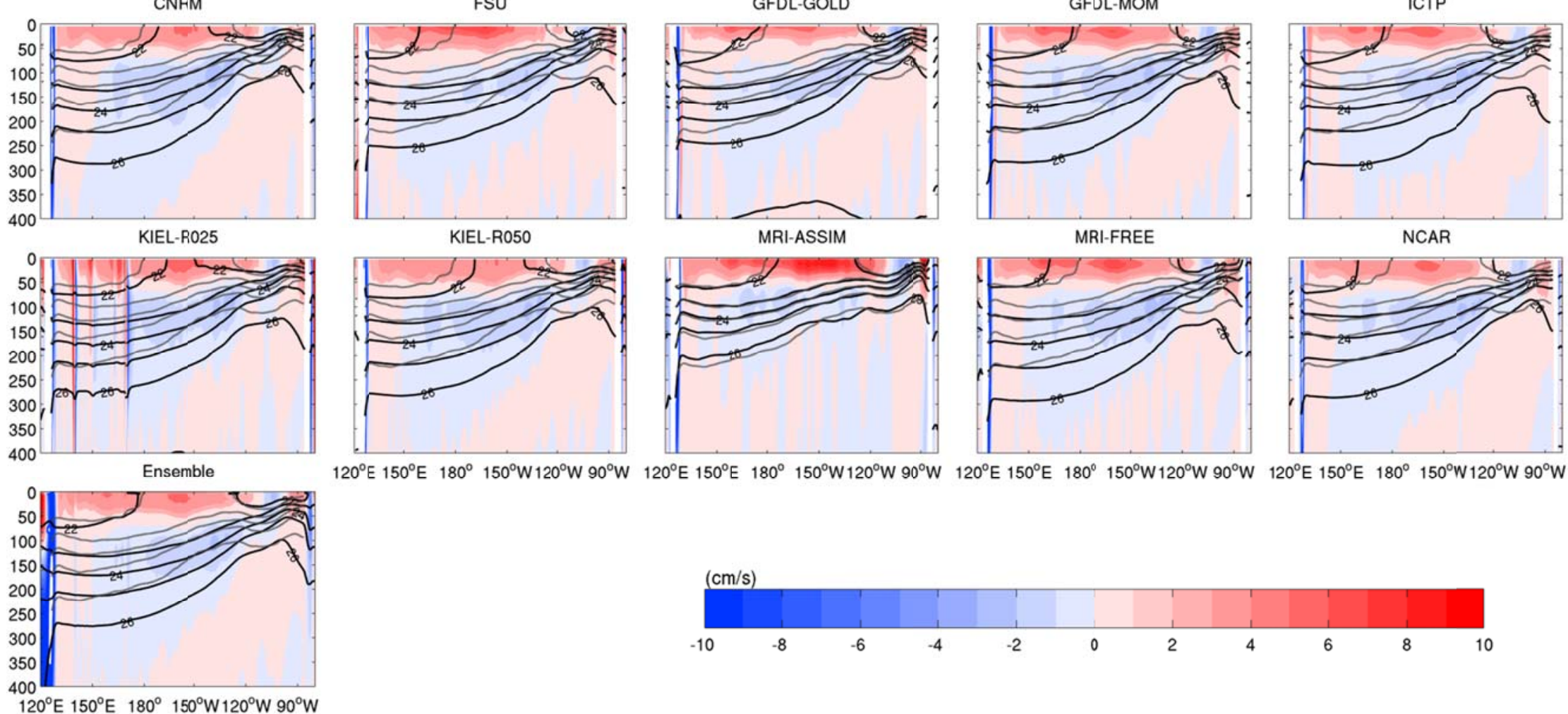

$120^{\circ} \mathrm{E} 150^{\circ} \mathrm{E} \quad 180^{\circ} 150^{\circ} \mathrm{W} 120^{\circ} \mathrm{W} 90^{\circ} \mathrm{W} \quad 120^{\circ} \mathrm{E} 150^{\circ} \mathrm{E} \quad 180^{\circ} 150^{\circ} \mathrm{W} 120^{\circ} \mathrm{W} 90^{\circ} \mathrm{W} \quad 120^{\circ} \mathrm{E} 150^{\circ} \mathrm{E} \quad 180^{\circ} \quad 150^{\circ} \mathrm{W} 120^{\circ} \mathrm{W} 90^{\circ} \mathrm{W} \quad 120^{\circ} \mathrm{E} 150^{\circ} \mathrm{E} \quad 180^{\circ} \quad 150^{\circ} \mathrm{W} 120^{\circ} \mathrm{W} 90^{\circ} \mathrm{W}$

Figure 22: Longitude-depth sections of time-mean meridional velocity (shading, in $\mathrm{m} \mathrm{s}^{-1}$ ) along $10^{\circ} \mathrm{N}$ with isopycnals (solid black line, in $\mathrm{kg} \mathrm{m}^{-3}$ ) from 1963 to 2007. The isopycnals from WOA09 are also shown as dashed black lines (22-26 $\left.\sigma_{\theta}\right)$ for comparison. 

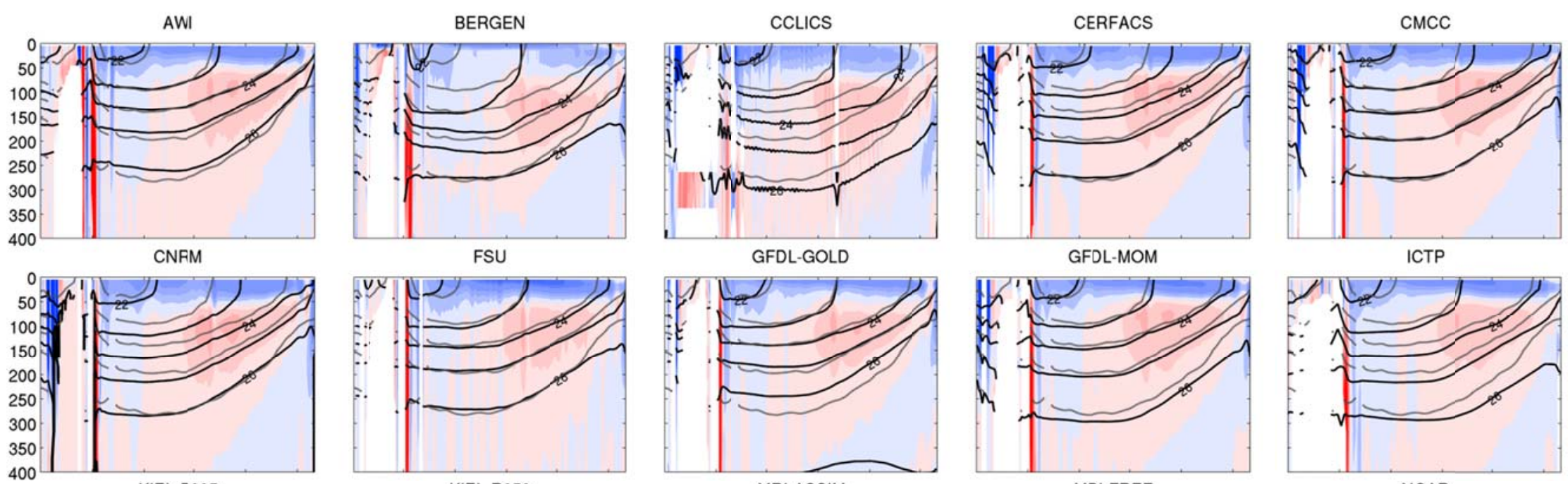

GFDL-MOM
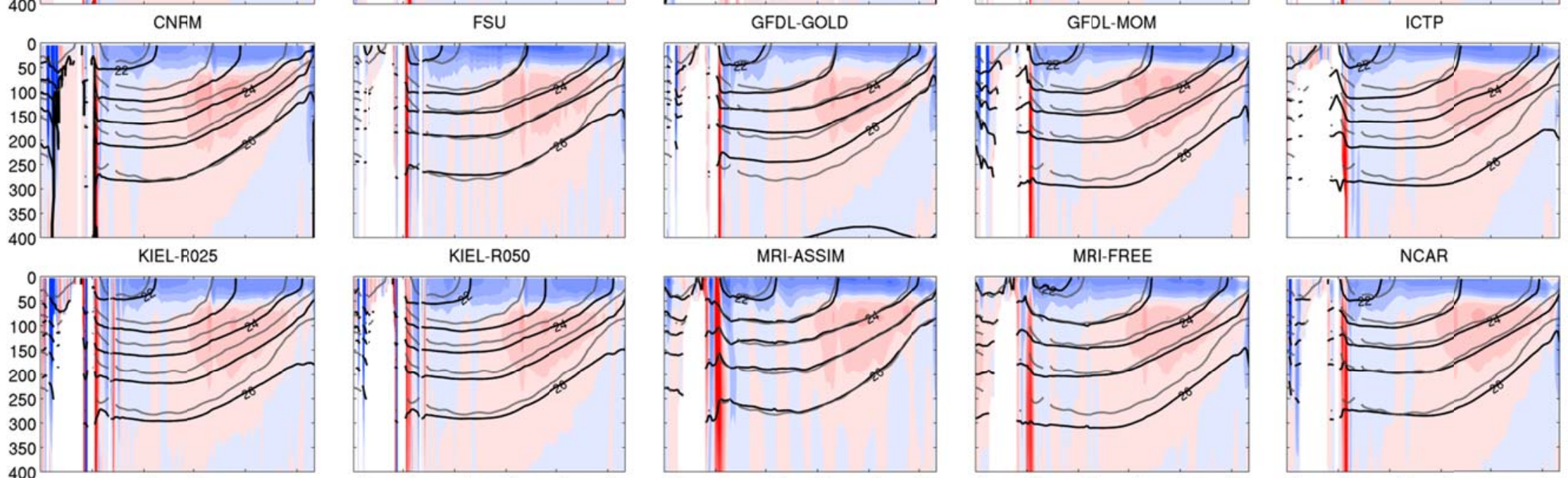

MRI-FREE

NCAR
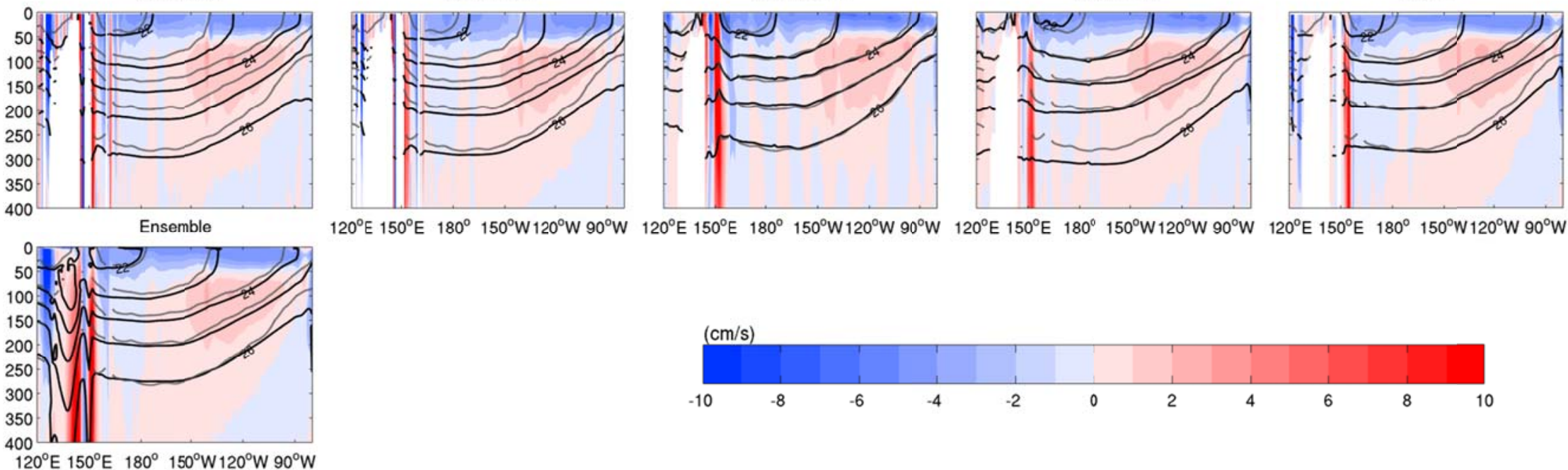

$120^{\circ} \mathrm{E} 150^{\circ} \mathrm{E} \quad 180^{\circ} 150^{\circ} \mathrm{W} 120^{\circ} \mathrm{W} 90^{\circ} \mathrm{W} \quad 120^{\circ} \mathrm{E} 150^{\circ} \mathrm{E} \quad 180^{\circ} \quad 150^{\circ} \mathrm{W} 120^{\circ} \mathrm{W} 90^{\circ} \mathrm{W} \quad 120^{\circ} \mathrm{E} 150^{\circ} \mathrm{E} \quad 180^{\circ} \quad 150^{\circ} \mathrm{W} 120^{\circ} \mathrm{W} 90^{\circ} \mathrm{W} \quad 120^{\circ} \mathrm{E} 150^{\circ} \mathrm{E} \quad 180^{\circ} 150^{\circ} \mathrm{W} 120^{\circ} \mathrm{W} 90^{\circ} \mathrm{W}$

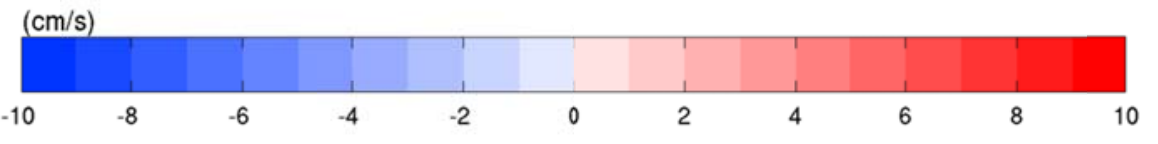

Figure 23: Same as Fig. 22 but for $10^{\circ} \mathrm{S}$. 